\title{
Stacking sequences for Extensionally Isotropic, Fully Isotropic and Quasi-Homogeneous Orthotropic Laminates.
}

\author{
C. B. York ${ }^{*}$ \\ University of Glasgow, Glasgow, Scotland, G12 8QQ
}

\begin{abstract}
Stacking sequence listings are presented for fully uncoupled Extensionally Isotropic (EILs), Fully Isotropic (FILs) and Quasi-Homogeneous Orthotropic (QHOLs) angle-ply Laminates, with up to 21 plies. All are sub-sets of a definitive list of Fully Orthotropic Laminates (FOLs), containing generally non-symmetric stacking sequences that are characterized in terms of angle- and cross-ply sub-sequence symmetries. Dimensionless parameters are given for each stacking sequence, from which the ABD matrix is readily derived. Expressions relating these dimensionless parameters to the well-known lamination parameters are also given, together with graphical representations of the feasible domains for $\pi / 3$ and $\pi / 4$ EILs and angle-ply QHOLs containing two and three ply orientations. The feasible domain for $\pi / 3$ FILs is represented graphically by a single point, whereas the domain for angle-ply QHOLs containing four ply orientations is represented by a single stacking sequence.
\end{abstract}

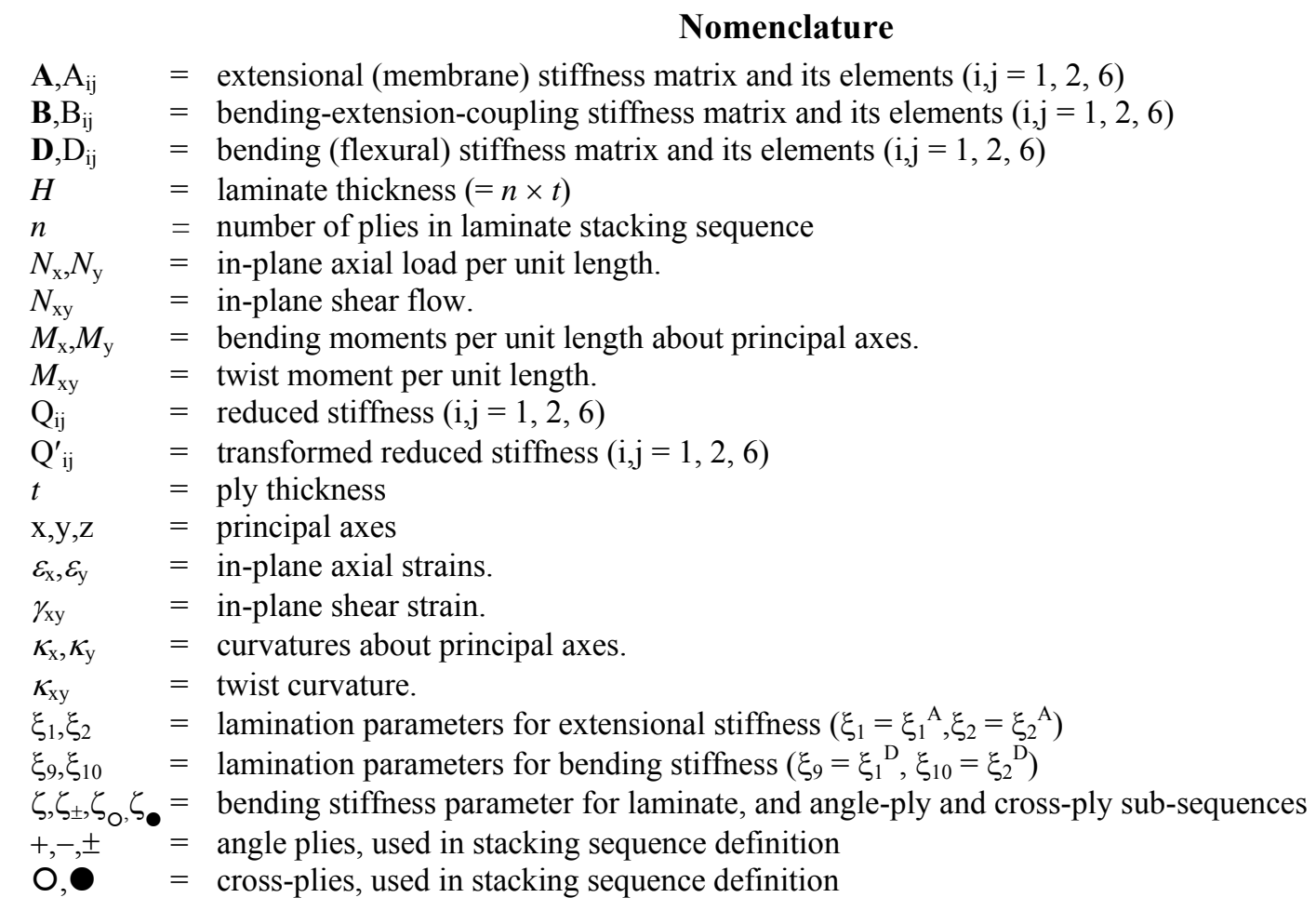

Matrix sub-scripts

$0 \quad=$ All elements zero

$\mathrm{F} \quad=$ All elements finite

I $=$ Isotropic form, see Eqs. (5) - (7)

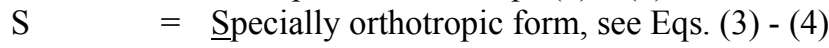

${ }^{*}$ Senior Lecturer, Department of Aerospace Engineering, James Watt Building. 


\section{Keywords}

Stacking Sequences; Fully Uncoupled Laminates; Extensionally (or Membrane or Quasi-) Isotropic Laminates; Fully Isotropic Laminates; Bending Stiffness Parameters; Lamination Parameters; Feasible Domains.

\section{Introduction}

omposite laminate materials are typically characterized in terms of their response to mechanical (and/or thermal) loading, which is generally associated with a description of the coupling behavior, unique to this type of material, i.e. coupling between in-plane (i.e. extension or membrane) and out-of-plane (i.e. bending or flexure) responses when $B_{i j} \neq 0$ in Eq. (1), coupling between in-plane shear and extension when $A_{16}=A_{26} \neq 0$, and coupling between out-of-plane bending and twisting when $D_{16}=D_{26} \neq 0$.

$$
\begin{aligned}
& \left\{\begin{array}{l}
N_{x} \\
N_{y} \\
N_{x y}
\end{array}\right\}=\left[\begin{array}{lll}
\mathrm{A}_{11} & \mathrm{~A}_{12} & \mathrm{~A}_{16} \\
& \mathrm{~A}_{22} & \mathrm{~A}_{26} \\
\text { Sym. } & & \mathrm{A}_{66}
\end{array}\right]\left\{\begin{array}{c}
\varepsilon_{x} \\
\varepsilon_{y} \\
\tau_{x y}
\end{array}\right\}+\left[\begin{array}{ccc}
\mathrm{B}_{11} & \mathrm{~B}_{12} & \mathrm{~B}_{16} \\
& \mathrm{~B}_{22} & \mathrm{~B}_{26} \\
\text { Sym. } & & \mathrm{B}_{66}
\end{array}\right]\left\{\begin{array}{c}
\kappa_{x} \\
\kappa_{y} \\
\kappa_{x y}
\end{array}\right\} \\
& \left\{\begin{array}{l}
M_{x} \\
M_{y} \\
M_{x y}
\end{array}\right\}=\left[\begin{array}{lll}
\mathrm{B}_{11} & \mathrm{~B}_{12} & \mathrm{~B}_{16} \\
& \mathrm{~B}_{22} & \mathrm{~B}_{26} \\
\text { Sym. } & & \mathrm{B}_{66}
\end{array}\right]\left\{\begin{array}{c}
\varepsilon_{x} \\
\varepsilon_{y} \\
\tau_{x y}
\end{array}\right\}+\left[\begin{array}{lll}
\mathrm{D}_{11} & \mathrm{D}_{12} & \mathrm{D}_{16} \\
& \mathrm{D}_{22} & \mathrm{D}_{26} \\
\text { Sym. } & & \mathrm{D}_{66}
\end{array}\right]\left\{\begin{array}{c}
\kappa_{x} \\
\kappa_{y} \\
\kappa_{x y}
\end{array}\right\}
\end{aligned}
$$

Whilst Eq. (1) describes the well-known ABD relation from classical laminate plate theory, it is more often expressed using compact notation:

$$
\left\{\begin{array}{l}
\mathbf{N} \\
\mathbf{M}
\end{array}\right\}=\left[\begin{array}{ll}
\mathbf{A} & \mathbf{B} \\
\mathbf{B} & \mathbf{D}
\end{array}\right]\left\{\begin{array}{l}
\boldsymbol{\varepsilon} \\
\mathbf{\kappa}
\end{array}\right\}
$$

The coupling behavior, which is dependent on the form of the elements in each of the extensional (A), coupling (B) and bending (D) stiffness matrices is now described by an extended subscript notation, defined previously by the Engineering Sciences Data Unit, or ESDU ${ }^{1}$ and subsequently augmented for the purposes of this article. Hence, balanced and symmetric stacking sequences, which generally possess bending anisotropy, give rise to coupling between out-of-plane bending and twisting and are referred to by the designation $\mathbf{A}_{\mathrm{S}} \mathbf{B}_{0} \mathbf{D}_{\mathrm{F}}$, signifying that the elements of the extensional stiffness matrix (A) are specially orthotropic in nature, i.e. uncoupled, since

$$
\mathrm{A}_{16}=\mathrm{A}_{26}=0 \text {, }
$$

the bending-extension coupling matrix $(\mathbf{B})$ is null, whilst all elements of the bending stiffness matrix (D) are finite, i.e. $\mathrm{D}_{\mathrm{ij}} \neq 0$.

Laminates possessing extensional anisotropy give rise to coupling between in-plane shear and extension only and, by the same rationale, are referred to by the designation $\mathbf{A}_{\mathrm{F}} \mathbf{B}_{0} \mathbf{D}_{\mathrm{S}}$, signifying that all elements of the extensional stiffness matrix (A) are finite, i.e. $\mathrm{A}_{\mathrm{ij}} \neq 0$, the bending-extension coupling matrix $(\mathbf{B})$ is null, and the elements of the bending stiffness matrix (D) are specially orthotropic in nature, i.e. uncoupled, since

$$
\mathrm{D}_{16}=\mathrm{D}_{26}=0
$$

The $\mathbf{A}_{\mathrm{F}} \mathbf{B}_{0} \mathbf{D}_{\mathrm{S}}$ designation is not listed as part of the ten laminate classifications described in the ESDU data item ${ }^{1}$, but is however the subject of a recent article ${ }^{2}$, identifying the definite list of $\mathbf{A}_{\mathrm{F}} \mathbf{B}_{0} \mathbf{D}_{\mathrm{S}}$ stacking sequences with up to 21 plies, thus complementing a new definitive list $t^{3}$ of Fully Orthotropic Laminates or FOLs. Note that the term for FOLs is synonymous with specially orthotropic laminates, which possess none of the coupling characteristics described above and are represented by the designation $\mathbf{A}_{\mathrm{S}} \mathbf{B}_{0} \mathbf{D}_{\mathrm{S}}$. 
This article presents the characterization of uncoupled Extensionally Isotropic Laminates or EILs, with the designation $\mathbf{A}_{\mathrm{I}} \mathbf{B}_{0} \mathbf{D}_{\mathrm{S}}$ and Fully Isotropic Laminates or FILs, with the designation $\mathbf{A}_{\mathrm{I}} \mathbf{B}_{0} \mathbf{D}_{\mathrm{I}}$. These laminates represent sub-sets of FOLs and are therefore contained within the definitive list ${ }^{3}$, since in addition to the specially orthotropic form of each matrix, see Eq. (3), elements simplify further in EILs and the designation $\mathbf{A}_{\mathrm{S}}$ is replaced with $\mathbf{A}_{\mathrm{I}}$ to indicate that:

$$
\mathrm{A}_{11}=\mathrm{A}_{22}
$$

and

$$
\mathrm{A}_{66}=\left(\mathrm{A}_{11}-\mathrm{A}_{12}\right) / 2
$$

and further still in FILs, in which the designation $\mathbf{D}_{\mathrm{S}}$ is replaced with $\mathbf{D}_{\mathrm{I}}$ to indicate that:

$$
\mathrm{D}_{\mathrm{ij}}=\mathrm{A}_{\mathrm{ij}} H^{2} / 12 \text {, }
$$

where $H$ is the laminate thickness, corresponding to the total number of plies, $n$, of thickness $t$.

Quasi-Homogeneous Orthotropic Laminates, or QHOLs, similar to the Quasi-Homogeneous Anisotropic Laminates, or QHALs, described and patented by Wu and Avery ${ }^{5}$, satisfy Eq. (7) but not Eqs. (5) and/or (6). QHOLs (QHALs) offer matching orthotropy (anisotropy) in both extensional and bending stiffness. Note that QHOLs are developed herein for general ply angle $\pm \theta$, but the same stacking sequences produce QHALs when $+\theta$ $\neq-\theta$.

Fully orthotropic laminates, from which all stacking sequences presented in this article are derived, minimize distortion during manufacturing and maximize compression buckling strength ${ }^{6}$, particularly in comparison to balanced and symmetric laminates, which are commonly adopted in aircraft and spacecraft construction, despite the fact that such laminates generally possess bending anisotropy. Valot and Vannucci provide recent examples of laminate stacking sequences for FOLs with anti-symmetric sequences ${ }^{7}$, following a previous article ${ }^{8}$ on FILs. These two articles are part of, and provide reference to, a growing number of related articles by a community of coworkers addressing the development of laminate stacking sequences exhibiting a range of physical characteristics, all of which refer back to an original article by Caprino and Crivelli-Visconti ${ }^{9}$, identifying the specially orthotropic angle-ply laminate with eight plies. Much of this related work has been focused on laminate stacking sequences for Quasi-Isotropic or Extensionally Isotropic Laminates (EILs), Fully Isotropic Laminates (FILs), and laminates with material homogeneity. However, with the exception of FILs, these material characterizations generally provide little or no distinction between laminates with or laminates without coupling behavior. For instance, the quasihomogenous laminate, which is defined as possessing the same elastic propertied in both flexural and membrane actions, but with no coupling between these two actions, may be designated as either $\mathbf{A}_{\mathrm{F}} \mathbf{B}_{0} \mathbf{D}_{\mathrm{F}}$ or $\mathbf{A}_{\mathrm{S}} \mathbf{B}_{0} \mathbf{D}_{\mathrm{S}}$, and extensionally isotropic laminate may be designated as either $\mathbf{A}_{\mathrm{I}} \mathbf{B}_{0} \mathbf{D}_{\mathrm{F}}$ or $\mathbf{A}_{\mathrm{I}} \mathbf{B}_{0} \mathbf{D}_{\mathrm{S}}$. Such sequences have been obtained through an inverse polar (or Mohr's circle) representation method developed by Verchery and co-workers, which is acknowledged ${ }^{10}$ to be similar to the method presented previously by Tsai and Pagano ${ }^{11}$.

By contrast, original work by Bartholomew ${ }^{12,13}$, which forms the basis of the Engineering Sciences Data Unit (ESDU) publication ${ }^{14}$ for the so called definitive list of fully orthotropic angle-ply laminates with designation $\mathbf{A}_{S} \mathbf{B}_{0} \mathbf{D}_{\mathrm{S}}$, precedes the findings of Caprino and Crivelli-Visconti ${ }^{9}$, but appears to have been completely overlooked in the literature described above. This published list of stacking sequences contains 75 symmetric sequences for laminates with up to 21 plies, 653 anti-symmetric sequences for laminates with up to 20 plies and 49 additional nonsymmetric (asymmetric) sequences, which were derived by combining the symmetric and anti-symmetric sequences. Further inspection reveals that there are no angle-ply laminates possessing specially orthotropic properties with fewer than 7 plies. Indeed, there is only one generic 7-layer angle-ply anti-symmetric stacking sequence. This number increases to 233 generic anti-symmetric sequences with 20 ply layers. There are no symmetric stacking sequences with less than 12 layers, and only 25 combinations with 20 layers. These twenty-five generic stacking sequences possess balanced and symmetric combinations of angle plies, together with cross plies, which may be 0 and/or $90^{\circ}$, symmetrically disposed about the laminate mid-plane; all possess angle-ply layers on the outer surfaces of the laminate. The term 'generic' is used here to describe the form of the stacking sequences adopted, defined by three parameters:,+- and $*$, relating to positive and negative angle plies with general orientation, $\theta$, and cross ply, respectively. The derivation ${ }^{12,13}$ adopted in the ESDU data item ${ }^{14}$, made the explicit assumption that cross plies, as well as angle plies, are symmetrically disposed about the laminate mid-plane, i.e. the mixing of 0 and $90^{\circ}$ plies is 
permitted only in one half of the laminate, which is then reflected symmetrically about the laminate mid-plane. This rule applies to both symmetric and anti-symmetric angle-ply stacking sequences. For this reason, cross plies are legitimately represented by the single parameter $*$.

The relatively small number of fully orthotropic sequences for thin laminates clearly leaves limited scope for composite tailoring, particularly where ply terminations are necessary and fully orthotropic characteristics are a design requirement. This was the key motivation leading to the redevelopment of the definitive list $^{3}$ for specially orthotropic angle-ply laminates with up to 21 plies, which is presented in a related article in abridged form ${ }^{4}$.

In the derivation of this list for (but not restricted to) standard angle-ply configurations, i.e. $\pm 45,0$ and $90^{\circ}$, the general rule of symmetry is relaxed. Cross-plies, as well as angle-plies, are therefore no longer constrained to be symmetric about the laminate mid-plane, leading to an increase in the number of possible solutions. For 16-ply laminates, there are approximately one million possible stacking sequence combinations, of which 368 comply with the requirements of special orthotropy, increasing to approximately 1 billion combinations for 21 plies, giving rise to a hundred-fold increase in the number of fully orthotropic laminates.

Because of the substantial number of sequences identified in the definitive list, it is beneficial, for design purposes, to express the stiffness properties in terms of lamination parameters, which can be conveniently presented in graphical form, as originally conceived by Fukunaga and Vanderplaats ${ }^{15}$ for the purposes of optimum design: the flexural stiffness terms are now fully defined by two linear design variables. Optimized lamination parameters may then be matched against a corresponding set of stacking sequences for a given laminate thickness $H(=n \times t)$. These graphical representations of feasible domains are readily extended to other laminate classifications: EILs with $\pi / 3$ ply separation are reduced to a single line representation, whilst $\pi / 3$ FILs are represented by a single point.

\section{Stacking sequence derivation}

In the derivation of the stacking sequences that follow, the general rule of symmetry is relaxed. Cross plies, as well as angle plies, are therefore no longer constrained to be symmetric about the laminate mid-plane. Consequently, the mixing of 0 and $90^{\circ}$ plies needs special attention to avoid violation of the rules for special orthotropy, see Eqs. (3) - (4). There are many non-symmetric forms contained in the definitive list of fully orthotropic laminates for standard angle-ply configurations, e.g. $\pm 45,0$ and $90^{\circ}$, being both extra-ordinary in appearance and seemingly infeasible in terms of the uncoupled behavior that the laminates possess. The great majority of sequences are non-symmetric and many of these are without any sub-sequence patterns, which is contrary to the assumptions on which many previous studies have been based.

\section{Arrangement and form of stacking sequence data}

For compatibility with the previously published data, similar symbols have been adopted for defining all stacking sequences that follow. Additional symbols and parameters are necessarily included to differentiate between cross plies $\left(0^{\circ}\right.$ and $\left.90^{\circ}\right)$, given that symmetry about the laminate mid-plane is no longer assumed.

The resulting sequences are characterized by sub-sequence symmetries using a double prefix notation, the first character of which relates to the form of the angle-ply sub-sequence and the second character to the cross-ply subsequence. The double prefix contains combinations of the following characters: $A$ to indicate Anti-symmetric form; $N$ for Non-symmetric; and $S$ for Symmetric. Additionally, for cross-ply sub-sequence only, $C$ is used to indicate Cross-symmetric form.

To avoid the trivial solution of a stacking sequence with cross plies only, all sequences have an angle-ply $(+)$ on one outer surface of the laminate. As a result, the other outer surface may have an angle-ply of equal (+) or opposite $(-)$ orientation or a cross ply (O), which may be either 0 or $90^{\circ}$. A subscript notation, using these three symbols, is employed to deferential between similar forms of sequence.

The form (and number) of FOL stacking sequences contained in the definitive list ${ }^{3}$ for up to 21 plies can be summarized as: $A C(210), A N(14,532), A S(21,906), S C(12), S N(192), S S(1,029),{ }_{+} N S_{+}(220),{ }_{+} N S_{-}(296),{ }_{+} N N_{+}$ $(5,498),{ }_{+} N N_{-}(15,188)$ and ${ }_{+} N N_{\circ}={ }_{+} N N_{\bullet}(10,041)$. From these sequence listings, the form (and number) of the subset for fully uncoupled EIL stacking sequences with $\pi / 3$ isotropy can be summarized as: AS (173), SS (10), ${ }_{N} N N_{+}$ (106), ${ }_{+} N N_{-}$(208) and ${ }_{+} N N_{\circ}={ }_{+} N N_{\bullet}$ (238), whilst the form (and number) of EIL stacking sequences with $\pi / 4$ isotropy can be summarized as: $A C(12), A S(72), S C$ (2), SS (6) and ${ }_{+} N N_{\circ}={ }_{+} N N_{\bullet}$ (6). Angle-ply QHOLs containing a single cross-ply orientation, i.e.,+- and $\mathrm{O}$ only, can be summarized as: $A S(28), S S(4),{ }_{+} N S_{+}(4),{ }_{+} N N_{+}$ (8), ${ }_{,} N N_{-}$(4) and ${ }_{+} N N_{\circ}={ }_{+} N N_{\bullet}(16)$. 


\section{Development of parameters}

As adopted in the published ESDU listings ${ }^{14}$, the new sequences are ordered in terms of ascending numbers of plies, $n$, or $\zeta\left(=n^{3}\right)$, which are in turn ordered by ascending value of the bending stiffness parameter for the angle plies $\left(\zeta_{ \pm}\right)$and finally by one of the two cross-ply sub-sequences $\left(\zeta_{O}\right)$ within the laminate. Hence, the numbering of sequences for each sub-symmetric form, described in the previous section, may be readily extended for higher numbers of plies. All sequences presented in the current article retain their original FOL reference number.

The calculation of the bending stiffness parameter, $\zeta_{ \pm}$, is readily demonstrated for the 9-ply fully uncoupled $\pi / 3$ EIL, designated $A 382$ in the ESDU listings ${ }^{14}$ and $A S 7$ in the definitive list ${ }^{3}$, with stacking sequence $[ \pm / O /-/ O /+/ O / \pm]_{\mathrm{T}}$, where the bending stiffness terms,

$$
\mathrm{D}_{\mathrm{ij}}=\sum_{k=1}^{n} \mathrm{Q}_{\mathrm{ij}}^{\prime}\left(\mathrm{z}_{k}{ }^{3}-\mathrm{z}_{k-1}{ }^{3}\right) / 3
$$

may be written in sequence order for the 9 individual plies, where $z$, representing the distance from the laminate mid-plane, is expressed here in terms of the uniform ply thickness $t$ :

$$
\begin{aligned}
& D_{i j}=\left\{Q^{\prime}{ }_{i j+}\left((-7 t / 2)^{3}-(-9 t / 2)^{3}\right)+Q^{\prime}{ }_{i j-}\left((-5 t / 2)^{3}-(-7 t / 2)^{3}\right)+Q^{\prime}{ }_{i j o}\left((-3 t / 2)^{3}-(-5 t / 2)^{3}\right)+\right. \\
& \mathrm{Q}_{\mathrm{ij}-}^{\prime}\left((-t / 2)^{3}-(-3 t / 2)^{3}\right)+\mathrm{Q}^{\prime}{ }_{\mathrm{ij}}\left((t / 2)^{3}-(-t / 2)^{3}\right)+\mathrm{Q}_{\mathrm{ij}+}^{\prime}\left((3 t / 2)^{3}-(t / 2)^{3}\right)+ \\
& \left.\mathrm{Q}^{\prime}{ }_{\mathrm{ij} \mathrm{o}}\left((5 t / 2)^{3}-(3 t / 2)^{3}\right)+\mathrm{Q}_{\mathrm{ij}+}^{\prime}\left((7 t / 2)^{3}-(5 t / 2)^{3}\right)+\mathrm{Q}_{\mathrm{ij}-}{ }^{\prime}\left((9 t / 2)^{3}-(7 t / 2)^{3}\right)\right\} / 3
\end{aligned}
$$

where subscripts $i, j=1,2,6$.

The bending stiffness contribution from the angle plies is therefore:

$$
\mathrm{D}_{\mathrm{ij} \pm}=157.5 t^{3} / 3 \times \mathrm{Q}_{\mathrm{ij} \pm}^{\prime}
$$

and for cross-plies:

$$
\mathrm{D}_{\mathrm{ijO}}=24.75 t^{3} / 3 \times \mathrm{Q}_{\mathrm{ij} \mathrm{O}}^{\prime}
$$

These bending stiffness terms are written in alternative form in Ref. 14 as:

$$
\mathrm{D}_{\mathrm{ij} \pm}=\zeta_{ \pm} t^{3} / 12 \times \mathrm{Q}_{\mathrm{ij} \pm}^{\prime}
$$

and

$$
\mathrm{D}_{\mathrm{ijo}}=\zeta_{\mathrm{O}} t^{3} / 12 \times \mathrm{Q}_{\mathrm{ijo}}^{\prime}
$$

respectively, since the number of plies $(n=9)$ is now related directly to the bending stiffness terms by the expression:

$$
\zeta_{ \pm}+\zeta_{O}=\zeta=n^{3}
$$

where $\zeta_{ \pm}=630$ and $\zeta=n^{3}=729$, hence $\zeta_{0}=99$.

The stiffness parameters are hereby extended to incorporate both cross-plies $\left(\zeta_{0}\right.$ and $\left.\zeta_{\bullet}\right)$, including percentage values to indicate the relative proportion $\left(n_{ \pm} / n, n_{0} / n\right.$ and $\left.n_{\bullet} / n\right)$ and relative contribution to bending stiffness $\left(\zeta_{ \pm} / \zeta\right.$, $\zeta_{\mathrm{o}} / \zeta$ and $\zeta_{\bullet} / \zeta$ ) of each ply sub-sequences within the laminate, i.e. a sub-sequence containing either \pm , $\mathrm{O}$ or $\bullet$ plies. These relationships also help to identify other laminate properties, which are sub-sets of FOLs. For instance, a Quasi-Homogeneous Orthotropic Laminate, or QHOL, has $n_{ \pm} / n=\zeta_{ \pm} / \zeta, n_{\circ} / n=\zeta_{0} / \zeta$ and $n_{\bullet} / n=\zeta_{\bullet} / \zeta$; a $\pi / 3(\pi / 4)$ 
Extensionally Isotropic Laminate, or EIL, has $n_{ \pm} / n=2 n_{\mathrm{o}} / n$ (or $=n_{\mathrm{o}} / n=n_{\bullet} / n$ ) and; a $\pi / 3$ Fully Isotropic Laminate, or FIL, has $n_{ \pm} / n=2 n_{\mathrm{O}} / n=\zeta_{ \pm} / \zeta=2 \zeta_{\mathrm{O}} / \zeta$. The set of FOLs with up to 21 plies contains no $\pi / 4$ FILs.

\section{Validation}

The definitive list of FOL stacking sequences, from which the sub-sets of EILs FILs and QHOLs are derived, have been validated against the published ESDU listing ${ }^{14}$, containing symmetric (SS) and anti-symmetric (AS) laminates, together with a limited number of non-symmetric sequences.

The laminates detailed in Refs 7, 8, 10 and 16, which have been algorithmically filtered to provide mathematically and mechanically unique stacking sequences, provide further validation. Applying this filtering to the 18 FILs, with $\pi / 3$ isotropy, identified as a sub-set of FOLs, which are of the form (and number) ${ }_{+} N N_{+}(2),{ }_{+} N N_{-}$ (8) and ${ }_{+} N N_{\odot}$ (8), reveals that: only 1 of the $2{ }_{+} N N_{+}$sequences is unique when the order is reversed, see Fig. 1; only 4 from the $8+N N_{-}$sequences are unique when the order is reversed and + and - plies are inter-changed, see Fig. 2 and; ${ }_{+} N N_{\circ}$ sequences are identical to ${ }_{+} N N_{-}$sequences with - and $\bigcirc$ plies inter-changed, see Fig. 3 , leaving the 5 mathematically and mechanically unique sequences identified by Vannucci and Verchery ${ }^{8}$, i.e.:

$$
\begin{gathered}
{\left[ \pm /-/ \mathrm{O}_{3} /+_{2} / \mathrm{O} / \mp / \pm /-{ }_{2} / \mathrm{O}_{2} /+\right]_{\mathrm{T}}} \\
{\left[+/ \mathrm{O} /-_{2} / \mathrm{O} /+/ \mathrm{O} / \mp / \pm / O / \mp / \mathrm{O}_{2} / \pm\right]_{\mathrm{T}}} \\
{\left[+/ \mathrm{O} /-/ \mathrm{O} / \mp_{2} / \mathrm{O} /-/ \mathrm{O} /+/ \pm / \mathrm{O}_{2} / \pm\right]_{\mathrm{T}}} \\
{\left[+/ \mathrm{O}_{2} /-{ }_{2} / \pm / \mp /+/ \mathrm{O}_{3} / \pm / \mathrm{O} / \pm\right]_{\mathrm{T}}} \\
{\left[+/ \mathrm{O} /-/ \mathrm{O} / \mp_{2} / \mathrm{O} / \mp / \mathrm{O}_{2} / \mp /+/ \mathrm{O} /-\right]_{\mathrm{T}}}
\end{gathered}
$$

in which $+/-/ O$ are presented as $+60 /-60 / 0^{\circ}$, respectively, in the feasible domains of lamination parameters that follow, but may indeed be any combination of ply angles with $\pi / 3$ separation; the designations in parentheses correspond to the FOL sequences of Ref. 3. However, the notion of mathematically and mechanically unique stacking sequences is believed to be of limited practical significance, particularly in view of the identical stress distributions of sequences \#1 and \#4 of Ref. 8, illustrated in Figs 3(g) and 3(e), respectively. This situation arises because the cross-ply subsequences are identical in these two laminates and, for the particular load combination used, the stress distribution is insensitive to the angle-ply subsequence. Similarly, laminates NN 1073, 1075, 1081 and 1082, of Figs 2(a), 2(c), 3(c) and 3(a) respectively, have identical stress distributions for the same load combination when the material axis is rotated through $-60^{\circ}$, i.e. $+/-/ O$ now represent $0 / 60 /-60^{\circ}$, because the crossply subsequences are identical in all four laminates.

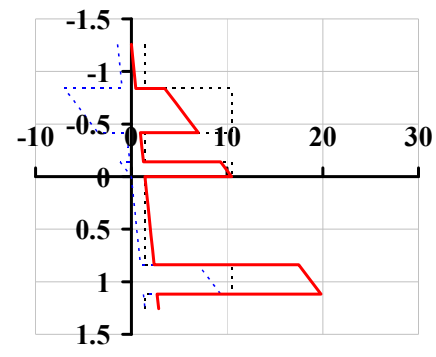

(a) $N N$ 1071:

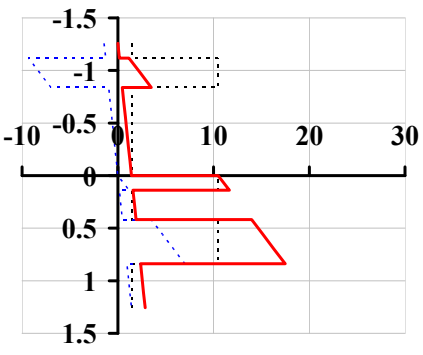

(b) $N N 1071 \rightarrow N N 1072 \rightarrow \# 5:$ $\left[+/ \mathrm{O}_{2} /-{ }_{2} / \mp / \pm / \mathrm{O} /+_{2} / \mathrm{O}_{3} /-/ \mp\right]_{\mathrm{T}}$

Figure 1 - Through the thickness stress distribution for fully isotropic, unrestrained laminate (a) $N N$ 1071, and (b) NN 1072 when stacking sequence is reversed, giving rise to sequence \#5 of Ref. 8. 


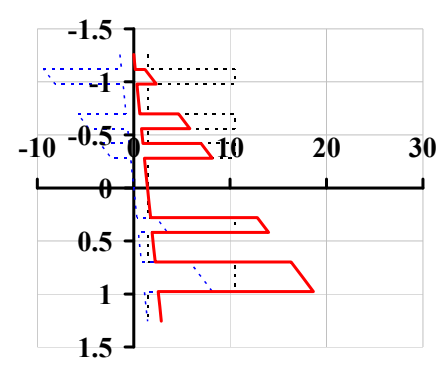

(a) $N N$ 1073:

$\left[+/ \mathrm{O} /{ }_{2} / \mathrm{O} /+/ \mathrm{O} / \mp / \pm / O / \mp / \mathrm{O}_{2} / \pm\right]_{\mathrm{T}}$

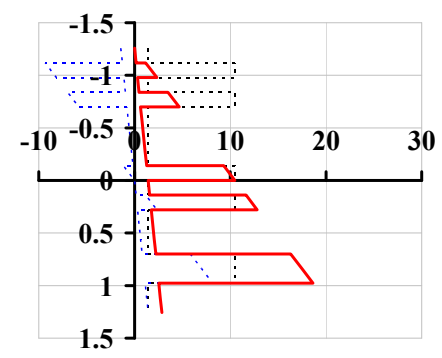

(b) $N N 1074$ :

$\left[+/ \mathrm{O} /-/ \mathrm{O} / \mp_{2} / \mathrm{O} /-/ \mathrm{O} /+/ \pm / \mathrm{O}_{2} / \pm\right]_{\mathrm{T}}$

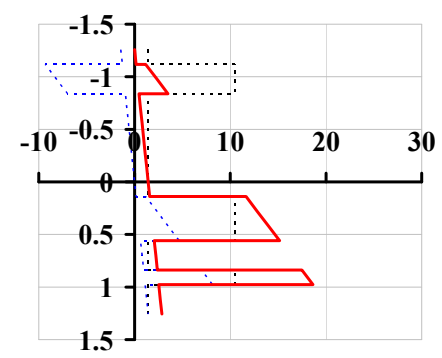

(c) NN 1075:

$\left[+/ \mathrm{O}_{2} /-{ }_{2} / \pm / \mp /+/ \mathrm{O}_{3} / \pm / \mathrm{O} / \pm\right]_{\mathrm{T}}$

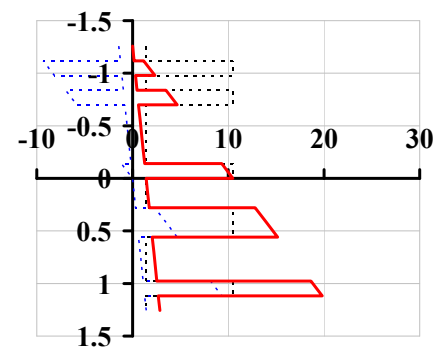

(d) NN 1077:

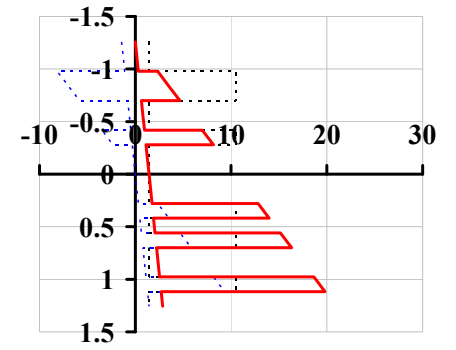

(e) $N N 1073 \rightarrow N N 1076$

$\left[+/ \mathrm{O} /{ }_{2} / \mathrm{O} /+/ \mathrm{O} / \mp / \pm / \mathrm{O} / \mp / \mathrm{O}_{2} / \pm\right]_{\mathrm{T}}$

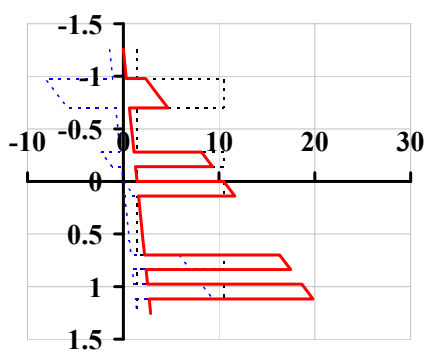

(f) $N N 1074 \rightarrow$ NN 1078:

$\left[ \pm / \mathrm{O}_{2} / \pm /-/ \mathrm{O} /+/ \mathrm{O} / \bar{\mp}_{2} / \mathrm{O} /+/ \mathrm{O} /-\right]_{\mathrm{T}}$

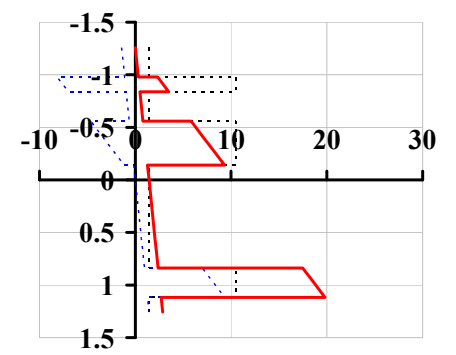

(g) NN $1075 \rightarrow$ NN 1080:

$\left[ \pm / O / \pm / O_{3} /-{ }_{2} /+_{2} / \mp /+/ O_{2} /-\right]_{\mathrm{T}}$

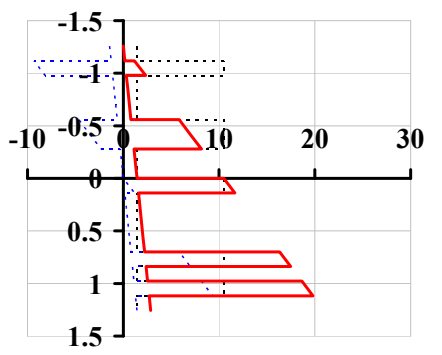

(h) $N N 1077 \rightarrow N N 1079 \rightarrow$ \#2:

$\left[+/ \mathrm{O} /-/ \bar{\mp} / \mathrm{O}_{2} / \mp / \mathrm{O} / \mp_{2} / \mathrm{O} /+/ \mathrm{O} /-\right]_{\mathrm{T}}$

Figure 2 - Through the thickness stress distribution for fully isotropic, unrestrained laminates (a) - (d) $N N 1071$ - NN 1075 and $N N$ 1077, subject to combined in-plane load $\mathrm{N}_{\mathrm{x}}$ and bending moment $\mathrm{M}_{\mathrm{x}}$, and (e) - (h) $N N 1076, N N$ 1078 - NN 1080 when stacking sequence is reversed and + and - plies inter-changed; (h) NN 1079 represents sequence \#2 of Ref. 8. 


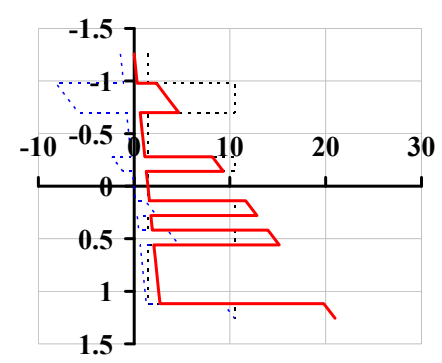

(a) $N N 1073 \rightarrow N N$ 1082:

$\left[ \pm / \mathrm{O}_{2} /-/ \pm / O /+_{2} / \mathrm{O} /-/ \mathrm{O} / \pm / \mp / O\right]_{\mathrm{T}}$

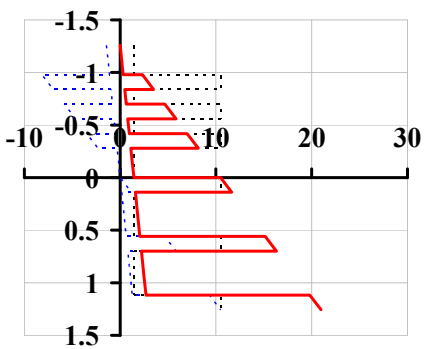

(b) $N N 1074 \rightarrow N N$ 1083:

$[ \pm / O /-/ O /+/ O / \pm / O / \mp /+/ O /-/ \mp / O]_{\mathrm{T}}$

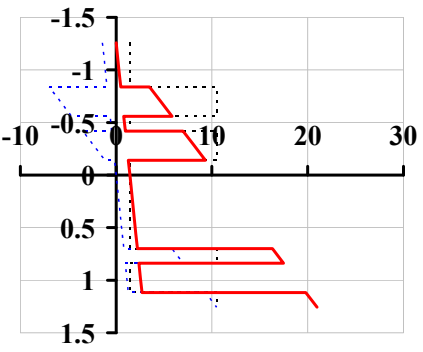

(c) $N N 1075 \rightarrow N N$ 1081: $\left[ \pm /-/ \mathrm{O}_{2} /+/ \mathrm{O}_{2} /+_{2} /-_{3} /+/ \mathrm{O} / \mp / \mathrm{O}\right]_{\mathrm{T}}$

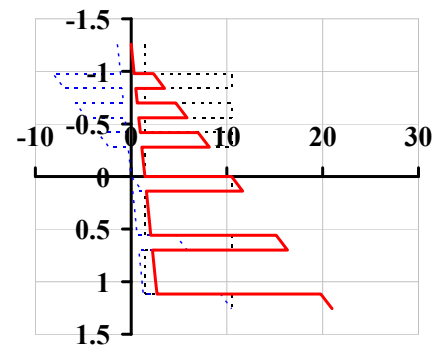

(d) $N N 1077 \rightarrow N N$ 1084:

$[ \pm / O /-/ O /+/ O / \pm / O / \pm /-/ O /+/ \pm / O]_{\mathrm{T}}$

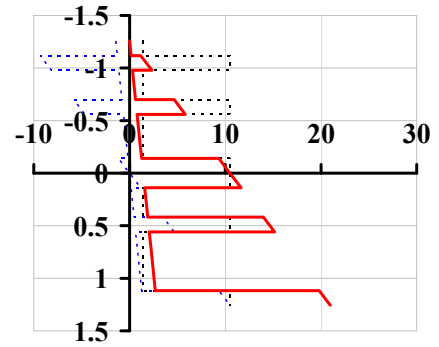

(e) NN $1076 \rightarrow$ NN $1085 \rightarrow$ \#4 $\left[ \pm / \mathrm{O}_{2} / \mp / \mathrm{O} / \pm / \mp / \mathrm{O} /-/ \mathrm{O} /+_{2} / \mathrm{O} /-\right]_{\mathrm{T}}$

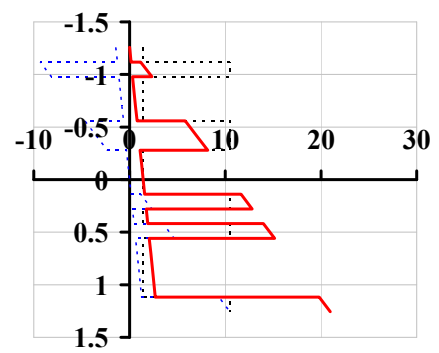

(f) $N N 1078 \rightarrow$ NN $1087 \rightarrow$ \#3: $\left[+/ \mathrm{O} /-/ \mp / \mathrm{O}_{2} / \mp /-/ \mathrm{O} /+/ \mathrm{O} / \pm_{2} / \mathrm{O}\right]_{\mathrm{T}}$

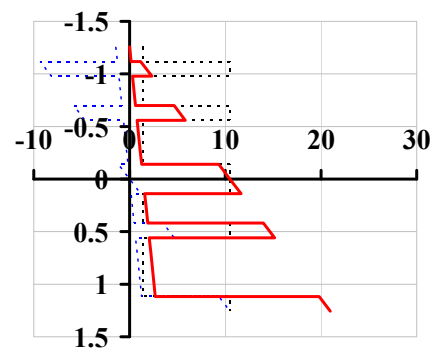

(g) NN $1080 \rightarrow$ NN $1088 \rightarrow$ \#1: $\left[+/ \mathrm{O} / \mp / \mathrm{O} /-_{3} / \mathrm{O}_{2} /+_{2} / \mathrm{O} /+_{2} /-_{2} / \mathrm{O}\right]_{\mathrm{T}}$

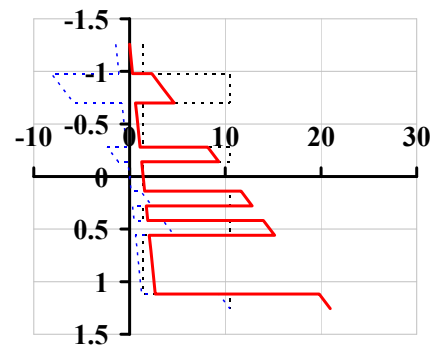

(h) $N N 1079 \rightarrow$ NN 1086:

$\left[ \pm / \mathrm{O}_{2} / \pm /-/ \mathrm{O} / \pm / \mathrm{O} /+/ \mathrm{O} / \pm_{2} / \mathrm{O}\right]_{\mathrm{T}}$

Figure 3 - Through the thickness stress distribution for fully isotropic, unrestrained laminates (a) - (d) $N N 1073$ - NN 1075 and NN 1077, subject to combined in-plane load $\mathrm{N}_{\mathrm{x}}$ and bending moment $\mathrm{M}_{\mathrm{x}}$, and (e) - (h) $N N 1076, N N$ 1078 - NN 1080, resulting from those of Fig. 2 when - and $\bigcirc$ plies inter-changed, respectively; (g), (f) and (e) giving rise to sequences \#1,\#3 and \#4 of Ref. 8, respectively. Note the identical stress distribution of (e) and (g). 
Figures $1-3$ represent the through the thickness stress distributions for unrestrained fully isotropic laminated plates subject to combined in-plane load $\mathrm{N}_{\mathrm{x}}(=4.2 \mathrm{~N} / \mathrm{mm})$ and bending moment $\mathrm{M}_{\mathrm{x}}(=10.0 \mathrm{~N} \cdot \mathrm{mm} / \mathrm{mm})$. Individual stress distribution profiles arising from the application of $\mathrm{N}_{\mathrm{x}}$ and $\mathrm{M}_{\mathrm{x}}$ (dashed lines) are illustrated together with the combined stress distribution profile (solid lines). Material properties and constant ply thickness, $t$, used in the calculation of these stress distributions, are given in the example calculations that follow.

Wu and Avery ${ }^{5}$ obtained FILs by varying, or shuffling, the stacking sequences of fully uncoupled EILs in order to produce bending isotropy. Eighty-nine stacking sequences were presented as the symmetric halves of 36-ply laminates with fully isotropic properties, deemed to be the minimum number of plies for $\pi / 3$ FILs. Limited details of 54-ply sequences for FILs with $\pi / 3$ isotropy are also provided, together with $\pi / 4, \pi / 5$ and $\pi / 6$ isotropy for 48-, 50- and 72-ply sequences, respectively. The symmetry assumption, on which this work is based, precluded the possibility that the listings would contain non-symmetric 18-ply FILs. However, inspection of this list reveals that nine of these stacking sequences represent 18-ply non-symmetric FILs; the nine sequences are reproduced in Table 1 with the original reference numbers and formatting.

Table 1 - Stacking sequences for 18-ply non-symmetric FILs, representing the symmetric halves of 36-ply FILs (after Ref. 5)

\begin{tabular}{|c|c|c|c|c|c|c|c|c|c|c|c|c|c|c|c|c|c|c|}
\hline Ref. & & & & $\theta_{1}$ & & & & & & $\theta_{2}$ & & & & & & $\theta_{3}$ & & \\
\hline 57 & 1 & 4 & 11 & 12 & 14 & 15 & 2 & 5 & 9 & 10 & 13 & 18 & 3 & 6 & 7 & 8 & 16 & 17 \\
\hline 65 & 1 & 5 & 9 & 12 & 14 & 16 & 2 & 6 & 7 & 10 & 15 & 17 & 3 & 4 & 8 & 11 & 13 & 18 \\
\hline 66 & 1 & 5 & 9 & 12 & 14 & 16 & 2 & 6 & 7 & 11 & 13 & 18 & 3 & 4 & 8 & 10 & 15 & 17 \\
\hline 69 & 1 & 6 & 8 & 11 & 15 & 16 & 2 & 4 & 9 & 12 & 13 & 17 & 3 & 5 & 7 & 10 & 14 & 18 \\
\hline 70 & 1 & 6 & 8 & 11 & 15 & 16 & 2 & 5 & 9 & 10 & 13 & 18 & 3 & 4 & 7 & 12 & 14 & 17 \\
\hline 73 & 1 & 6 & 8 & 12 & 13 & 17 & 2 & 4 & 9 & 11 & 15 & 16 & 3 & 5 & 7 & 10 & 14 & 18 \\
\hline 76 & 1 & 6 & 9 & 10 & 14 & 17 & 2 & 3 & 11 & 12 & 13 & 16 & 4 & 5 & 7 & 8 & 15 & 18 \\
\hline 77 & 1 & 6 & 9 & 10 & 14 & 17 & 2 & 5 & 7 & 12 & 15 & 16 & 3 & 4 & 8 & 11 & 13 & 18 \\
\hline 78 & 1 & 7 & 8 & 11 & 12 & 18 & 2 & 3 & 10 & 13 & 14 & 15 & 4 & 5 & 6 & 9 & 16 & 17 \\
\hline
\end{tabular}

Each ply number, 1 through 18 , appears under the appropriate ply-angle heading, $\theta_{1}, \theta_{2}$ or $\theta_{3}$ in row 1 of Table 1 . Sequences $57,65,66,70$ and 78 , correspond to the 5 mechanically and mathematically distinct sequences derived independently by Vannucci and Verchery ${ }^{8}$ some ten years later, whilst sequence 69 is sequence 65 with the order reversed and with $\theta_{3}, \theta_{2}$ and $\theta_{1}$ in row 1 . Similarly, sequences 73,76 and 77 are, respectively, 66, 57 and 70 with the order reversed and with $\theta_{2}, \theta_{3}$ and $\theta_{1}$ in row 1 .

Sequence $A C$ 127, which is discussed in detail in section V, has special significance: It is a QHOL and validates the unique angle-ply laminate containing four ply orientations, i.e. +,-, $\mathrm{O}$ and $\boldsymbol{\bullet}$, alluded to in Ref. 16 for a 20 ply laminate satisfying Eq. (7), and Eq. (5) when ply orientations satisfy the $\pi / 4$ condition, but not Eq. (6). Note that $A C$ 127 and $A C 128$ are identical when cross-plies are interchanged, $\mathrm{O}$ with $\bullet$. All other QHOLs with up to 21 plies contain either two or three ply orientations, i.e. +,- or +,- and O, respectively.

\section{Stacking sequence listings}

The following Tables provide summaries of the numbers of fully uncoupled EIL and QHOL stacking sequences with up to 21 plies together with cross-references to the Tables of the full sequence listings and non-dimensional parameters, given in the appendix. Note that percentage values to indicate the relative proportion $\left(n_{ \pm} / n, n_{0} / n\right.$ and $\left.n_{\bullet} / n\right)$ and relative contribution to bending stiffness $\left(\zeta_{ \pm} / \zeta_{,}, \zeta_{0} / \zeta\right.$ and $\left.\zeta_{\bullet} / \zeta\right)$ of each ply sub-sequences within the laminate have been omitted for reasons of compactness, together with other parameters that are common within a given table. These missing parameters are readily calculated from the expressions provided within the table captions. 
Table 2 - Number of fully uncoupled $\pi / 3$ EILs [ $\pi / 4$ EILs] for 7- through 21-ply laminates, corresponding to prefix

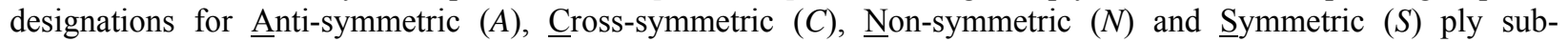
sequences, listed in abridged form in Tables 7 and 8. Subscripts arranged before and after the prefix designations denote angle $(+,-)$ and cross plies $(\mathrm{O})$, and correspond to the orientations of the top and bottom plies of the laminate respectively.

\begin{tabular}{|c|c|c|c|c|c|c|c|c|c|c|c|c|c|c|c|c|}
\hline \multirow{2}{*}{ Prefix: } & \multicolumn{15}{|c|}{ Number of plies, $n$} & \multirow{2}{*}{ Table: } \\
\hline & 7 & 8 & 9 & 10 & 11 & 12 & 13 & 14 & 15 & 16 & 17 & 18 & 19 & 20 & 21 & \\
\hline$A C$ & - & - & - & - & - & - & - & - & - & {$[2]$} & - & - & - & - & - & $-/[8(a)]$ \\
\hline AS & - & - & 1 & - & - & 5 & - & - & 6 & {$[2]$} & - & 46 & - & - & 115 & $7(\mathrm{a}) /[8(\mathrm{~b})]$ \\
\hline$S C$ & - & - & - & - & - & - & - & - & - & {$[2]$} & - & - & - & - & - & $-/[8(c)]$ \\
\hline${ }_{+} N N_{+}$ & - & - & - & - & - & - & - & - & - & - & - & 16 & - & - & 90 & $7(b) /-$ \\
\hline${ }_{+} N N_{-}$ & - & - & - & - & - & - & - & - & - & - & - & 26 & - & - & 182 & $7(\mathrm{c}) /-$ \\
\hline${ }_{+} N N_{\circ}$ & - & - & - & - & - & - & - & - & - & {$[6]$} & - & 31 & - & - & 207 & $7(d) /[8(d)]$ \\
\hline SS & - & - & - & - & - & - & - & - & - & {$[6]$} & - & - & - & - & - & $-/[8(\mathrm{e})]$ \\
\hline
\end{tabular}

Table 3 - Number of QHOLs containing no cross-ply orientations for 7- through 21-ply laminates, corresponding to prefix designations for Anti-symmetric $(A)$, Non-symmetric $(N)$ and Symmetric $(S)$ ply sub-sequences, listed in Table 9. Subscripts arranged before and after the prefix designations denote angle $(+,-)$ plies and correspond to the orientations of the top and bottom plies of the laminate respectively.

\begin{tabular}{cccccccccccccccccc}
\hline \hline \multirow{2}{*}{ Prefix: } & 7 & 8 & 9 & 10 & 11 & 12 & 13 & 14 & 15 & 16 & 17 & 18 & 19 & 20 & 21 & Table: \\
\hline AS & - & 1 & - & - & - & 1 & - & - & - & 4 & - & - & - & 10 & - & $9(\mathrm{a})$ \\
${ }_{+} N S_{+}$ & - & - & - & - & - & - & - & - & - & 2 & - & - & - & 6 & - & $9(\mathrm{~b})$ \\
${ }_{+} N S_{-}$ & - & - & - & - & - & - & - & - & - & - & - & - & - & 8 & - & $9(\mathrm{c})$ \\
SS & - & - & - & - & - & - & - & - & - & 1 & - & - & - & - & - & $9(\mathrm{~d})$ \\
\hline \hline
\end{tabular}

Table 4 - Number of QHOLs containing one [both] cross-ply orientation[s] for 7- through 21-ply laminates, corresponding to prefix designations for Anti-symmetric $(A)$, Cross-symmetric $(C)$, Non-symmetric $(N)$ and Symmetric $(S)$ ply sub-sequences, listed in Table 10. Subscripts arranged before and after the prefix designations denote angle $(+,-)$ and cross plies $(\mathrm{O})$, and correspond to the orientations of the top and bottom plies of the laminate respectively.

\begin{tabular}{cccccccccccccccccc}
\hline \hline \multirow{2}{*}{ Prefix: } & & & 8 & 9 & 10 & 11 & 12 & 13 & 14 & 15 & 16 & 17 & 18 & 19 & 20 & 21 & Table: \\
\hline$A C$ & - & - & - & - & - & - & - & - & - & - & - & - & - & {$[2]$} & - & - \\
$A S$ & - & - & - & - & - & - & - & 3 & - & 4 & - & - & 2 & 4 & 6 & $10(\mathrm{a})$ \\
& ${ }_{+} N S_{+}$ & - & - & - & - & - & - & - & - & - & - & 4 & - & - & - & - & $10(\mathrm{~b})$ \\
${ }_{+} N N_{+}$ & - & - & - & - & - & - & - & - & 4 & - & - & - & - & - & 4 & $10(\mathrm{c})$ \\
${ }_{+} N N_{-}$ & - & - & - & - & - & - & - & - & - & - & - & - & - & 4 & - & $10(\mathrm{~d})$ \\
${ }_{+} N N_{\circ}$ & - & - & - & - & - & - & - & - & - & - & 1 & - & 5 & 17 & 19 & $10(\mathrm{e})$ \\
& $S S$ & - & - & - & - & - & - & - & - & - & - & - & - & - & - & 4 & $10(\mathrm{f})$ \\
\hline \hline
\end{tabular}




\section{Calculation of membrane and bending stiffness terms}

The calculation procedure for the elements $\left(\mathrm{A}_{\mathrm{ij}}\right.$ and $\left.\mathrm{D}_{\mathrm{ij}}\right)$ of the extensional (A) and bending (D) stiffness matrices, using the dimensionless parameters provided in Tables 7 - 10, are as follows:

$$
\begin{gathered}
\mathrm{A}_{\mathrm{ij}}=\left\{n_{ \pm} / 2 \times \mathrm{Q}_{\mathrm{ij}+}^{\prime}+n_{ \pm} / 2 \times \mathrm{Q}_{\mathrm{ij}-}^{\prime}+n_{\mathrm{O}} \mathrm{Q}_{\mathrm{ij} \mathrm{O}}^{\prime}+n_{\bullet} \mathrm{Q}_{\mathrm{ij} \bullet}^{\prime}\right\} \times t \\
\mathrm{D}_{\mathrm{ij}}=\left\{\zeta_{ \pm} / 2 \times \mathrm{Q}_{\mathrm{ij}+}^{\prime}+\zeta_{ \pm} / 2 \times \mathrm{Q}_{\mathrm{ij}-}^{\prime}+\zeta_{\mathrm{O}} \mathrm{Q}_{\mathrm{ij} \mathrm{O}}^{\prime}+\zeta_{\bullet} \mathrm{Q}_{\mathrm{ij} \bullet}^{\prime}\right\} \times t^{3} / 12
\end{gathered}
$$

The form of Eqs. (15) and (16) was chosen because they are readily modified to account for laminates with extensional and bending anisotropy by replacing $n_{ \pm} / 2 \times \mathrm{Q}_{\mathrm{ij}+}^{\prime}$ with $n_{ \pm}\left(n_{+} / n_{ \pm}\right) \mathrm{Q}_{\mathrm{ij}+}^{\prime}$ and $n_{ \pm} / 2 \times \mathrm{Q}_{\mathrm{ij}-}^{\prime}$ with $n_{ \pm}(1-$ $\left.n_{+} / n_{ \pm}\right) \mathrm{Q}_{\mathrm{ij}-}^{\prime}$, and $\zeta_{ \pm} / 2 \times \mathrm{Q}_{\mathrm{ij}+}^{\prime}$ with $\zeta_{ \pm}\left(\zeta_{+} / \zeta_{ \pm}\right) \times \mathrm{Q}^{\prime}{ }_{\mathrm{ij}+}$ and $\zeta_{ \pm} / 2 \times \mathrm{Q}_{\mathrm{ij}-}^{\prime}$ with $\zeta_{ \pm}\left(1-\zeta_{+} / \zeta_{ \pm}\right) \times \mathrm{Q}_{\mathrm{ij}-}^{\prime}$. The use of these modified equation requires the calculation of an additional stiffness parameter, $n_{+}$and $\zeta_{+}$, relating to the extensional and bending stiffness contribution of positive $(\theta)$ angle plies, respectively.

The transformed reduced stiffness terms in Eqs. (15) and (16) are given by:

$$
\begin{gathered}
\mathrm{Q}_{11}^{\prime}=\mathrm{Q}_{11} \cos ^{4} \theta+2\left(\mathrm{Q}_{12}+2 \mathrm{Q}_{66}\right) \cos ^{2} \theta \sin ^{2} \theta+\mathrm{Q}_{22} \sin ^{4} \theta \\
\mathrm{Q}^{\prime}{ }_{12}=\mathrm{Q}_{21}^{\prime}=\left(\mathrm{Q}_{11}+\mathrm{Q}_{22}-4 \mathrm{Q}_{66}\right) \cos ^{2} \theta \sin ^{2} \theta+\mathrm{Q}_{12}\left(\cos ^{4} \theta+\sin ^{4} \theta\right) \\
\mathrm{Q}^{\prime}{ }_{16}=\mathrm{Q}_{61}^{\prime}=\left\{\left(\mathrm{Q}_{11}-\mathrm{Q}_{12}-2 \mathrm{Q}_{66}\right) \cos ^{2} \theta+\left(\mathrm{Q}_{12}-\mathrm{Q}_{22}+2 \mathrm{Q}_{66}\right) \sin ^{2} \theta\right\} \cos \theta \sin \theta \\
\mathrm{Q}_{22}^{\prime}=\mathrm{Q}_{11} \sin ^{4} \theta+2\left(\mathrm{Q}_{12}+2 \mathrm{Q}_{66}\right) \cos ^{2} \theta \sin ^{2} \theta+\mathrm{Q}_{22} \cos ^{4} \theta \\
\mathrm{Q}_{26}^{\prime}=\mathrm{Q}_{62}^{\prime}=\left\{\left(\mathrm{Q}_{11}-\mathrm{Q}_{12}-2 \mathrm{Q}_{66}\right) \sin ^{2} \theta+\left(\mathrm{Q}_{12}-\mathrm{Q}_{22}+2 \mathrm{Q}_{66}\right) \cos ^{2} \theta\right\} \cos \theta \sin \theta \\
\mathrm{Q}_{66}^{\prime}=\left(\mathrm{Q}_{11}+\mathrm{Q}_{22}-2 \mathrm{Q}_{12}-2 \mathrm{Q}_{66}\right) \cos ^{2} \theta \sin ^{2} \theta+\mathrm{Q}_{66}\left(\cos ^{4} \theta+\sin ^{4} \theta\right)
\end{gathered}
$$

and the reduced stiffness terms by:

$$
\begin{gathered}
\mathrm{Q}_{11}=\mathrm{E}_{1} /\left(1-v_{12} v_{21}\right) \\
\mathrm{Q}_{12}=v_{12} \mathrm{E}_{2} /\left(1-v_{12} v_{21}\right)=v_{21} \mathrm{E}_{1} /\left(1-v_{12} v_{21}\right) \\
\mathrm{Q}_{22}=\mathrm{E}_{2} /\left(1-v_{12} v_{21}\right) \\
\mathrm{Q}_{66}=\mathrm{G}_{12}
\end{gathered}
$$

For optimum design of angle-ply laminates, lamination parameters are often preferred, since these allow the stiffness terms to be expressed as linear variables. The optimized lamination parameters may then be matched against a corresponding set of stacking sequences with given laminate thickness $H(=n \times t)$. In the context of the parameters presented in the current article, only four of the twelve lamination parameters are required, and these are related through the following expressions:

$$
\begin{aligned}
& \xi_{1}=\xi_{1}^{\mathrm{A}}=\left\{n_{ \pm}\left(n_{+} / n_{ \pm}\right) \cos \left(2 \theta_{+}\right)+n_{ \pm}\left(1-n_{+} / n_{ \pm}\right) \cos \left(2 \theta_{-}\right)+n_{\odot} \cos \left(2 \theta_{\odot}\right)+n_{\bullet} \cos \left(2 \theta_{\bullet}\right)\right\} / n \\
& \xi_{2}=\xi_{2}^{\mathrm{A}}=\left\{n_{ \pm}\left(n_{+} / n_{ \pm}\right) \cos \left(4 \theta_{+}\right)+n_{ \pm}\left(1-n_{+} / n_{ \pm}\right) \cos \left(4 \theta_{-}\right)+n_{\odot} \cos \left(4 \theta_{\odot}\right)+n_{\bullet} \cos \left(4 \theta_{\bullet}\right)\right\} / n
\end{aligned}
$$

and

$$
\begin{aligned}
& \xi_{9}=\xi_{1}{ }^{\mathrm{D}}=\left\{\zeta_{ \pm}\left(\zeta_{+} / \zeta_{ \pm}\right) \cos \left(2 \theta_{+}\right)+\zeta_{ \pm}\left(1-\zeta_{+} / \zeta_{ \pm}\right) \cos \left(2 \theta_{-}\right)+\zeta_{\bigcirc} \cos \left(2 \theta_{\odot}\right)+\zeta_{\bullet} \cos \left(2 \theta_{\bullet}\right)\right\} / \zeta \\
& \xi_{10}=\xi_{2}{ }^{\mathrm{D}}=\left\{\zeta_{ \pm}\left(\zeta_{+} / \zeta_{ \pm}\right) \cos \left(4 \theta_{+}\right)+\zeta_{ \pm}\left(1-\zeta_{+} / \zeta_{ \pm}\right) \cos \left(4 \theta_{-}\right)+\zeta_{\bigcirc} \cos \left(4 \theta_{\odot}\right)+\zeta_{\bullet} \cos \left(4 \theta_{\bullet}\right)\right\} / \zeta
\end{aligned}
$$


where the extensional stiffness parameter $n_{+}=\left(n_{-}=\right) n_{ \pm} / 2$ and bending stiffness parameters $\zeta_{+}\left(=\zeta_{-}\right)=\zeta_{ \pm} / 2$ for FOLs, QHOLs, EILs and FILs, hence Eqs. (19) and (20) reduce to:

$$
\begin{aligned}
& \xi_{1}=\left\{n_{ \pm} \cos \left(2 \theta_{ \pm}\right)+n_{\odot} \cos \left(2 \theta_{\odot}\right)+n_{\bullet} \cos \left(2 \theta_{\bullet}\right)\right\} / n \\
& \xi_{2}=\left\{n_{ \pm} \cos \left(4 \theta_{ \pm}\right)+n_{\odot} \cos \left(4 \theta_{\odot}\right)+n_{\bullet} \cos \left(4 \theta_{\bullet}\right)\right\} / n
\end{aligned}
$$

and

$$
\begin{aligned}
& \xi_{9}=\left\{\zeta_{ \pm} \cos \left(2 \theta_{ \pm}\right)+\zeta_{\bigcirc} \cos \left(2 \theta_{\odot}\right)+\zeta_{\bullet} \cos \left(2 \theta_{\bullet}\right)\right\} / \zeta \\
& \xi_{10}=\left\{\zeta_{ \pm} \cos \left(4 \theta_{ \pm}\right)+\zeta_{\bigcirc} \cos \left(4 \theta_{\odot}\right)+\zeta_{\bullet} \cos \left(4 \theta_{\bullet}\right)\right\} / \zeta
\end{aligned}
$$

Elements of the extensional and bending stiffness matrices are related to the lamination parameters, respectively, by:

$$
\begin{gathered}
\mathrm{A}_{11}=\left\{U_{1}+\xi_{1} U_{2}+\xi_{2} U_{3}\right\} \times H \\
\mathrm{~A}_{12}=\mathrm{A}_{21}=\left\{-\xi_{2} U_{3}+U_{4}\right\} \times H \\
\mathrm{~A}_{22}=\left\{U_{1}-\xi_{1} U_{2}+\xi_{2} U_{3}\right\} \times H \\
\mathrm{~A}_{66}=\left\{-\xi_{2} U_{3}+U_{5}\right\} \times H
\end{gathered}
$$

and

$$
\begin{gathered}
\mathrm{D}_{11}=\left\{U_{1}+\xi_{9} U_{2}+\xi_{10} U_{3}\right\} \times H^{3} / 12 \\
\mathrm{D}_{12}=\left\{U_{4}-\xi_{10} U_{3}\right\} \times H^{3} / 12 \\
\mathrm{D}_{22}=\left\{U_{1}-\xi_{9} U_{2}+\xi_{10} U_{3}\right\} \times H^{3} / 12 \\
\mathrm{D}_{66}=\left\{-\xi_{10} U_{3}+U_{5}\right\} \times H^{3} / 12
\end{gathered}
$$

where the laminate invariants are given in terms of the reduced stiffnesses of Eq. (18) by:

$$
\begin{gathered}
\mathrm{U}_{1}=\left\{3 \mathrm{Q}_{11}+3 \mathrm{Q}_{22}+2 \mathrm{Q}_{12}+4 \mathrm{Q}_{66}\right\} / 8 \\
\mathrm{U}_{2}=\left\{\mathrm{Q}_{11}-\mathrm{Q}_{22}\right\} / 2 \\
\mathrm{U}_{3}=\left\{\mathrm{Q}_{11}+\mathrm{Q}_{22}-2 \mathrm{Q}_{12}-4 \mathrm{Q}_{66}\right\} / 8 \\
\mathrm{U}_{4}=\left\{\mathrm{Q}_{11}+\mathrm{Q}_{22}+6 \mathrm{Q}_{12}-4 \mathrm{Q}_{66}\right\} / 8 \\
\mathrm{U}_{5}=\left\{\mathrm{Q}_{11}+\mathrm{Q}_{22}-2 \mathrm{Q}_{12}+4 \mathrm{Q}_{66}\right\} / 8
\end{gathered}
$$




\section{Results and Discussion}

Figure 4(a) - (d) illustrates the feasible domains of lamination parameters for all EIL and QHOL sub-sets from the definitive list of FOLs, in which the $+/-/ \bigcirc / \bigcirc$ of Tables $7-10$ correspond to $45 /-45 / 0 / 90^{\circ}$, respectively, or $60 /-$ $60 / 0^{\circ}$ for laminates with only one cross-ply orientation, e.g. $\pi / 3$ EILs. All membrane (extensional) lamination parameters are bounded by the parabola $\xi_{2}=2 \xi_{1}{ }^{2}-1$ with limits $-1 \leq \xi_{1} \leq 1$ and $-1 \leq \xi_{2} \leq 1$; for flexural (bending) lamination parameters, $\xi_{9}$ and $\xi_{10}$ replace $\xi_{1}$ and $\xi_{2}$, respectively. Stacking sequences lying along the broken line drawn between $\left(\xi_{1}, \xi_{2}\right)=(1,1)$ and $(0,-1)$ on Fig. $4\left(\right.$ a), contain only $0^{\circ}$ and $\pm 45^{\circ}$ plies, whereas any sequences lying along the line between $(0,-1)$ and $(-1,1)$ would consist of \pm 45 and $90^{\circ}$ plies only. Similarly, any stacking sequences corresponding to the points $(-1,1),(0,-1)$ or $(1,1)$, would contain only $90^{\circ}$ plies, $\pm 45^{\circ}$ plies or $0^{\circ}$ plies, respectively. A $\pi / 3$ EIL with $2 n_{ \pm}=n_{\odot}$ plies, lies at the $1 / 3^{\text {rd }}$ point along the line defining a laminate containing only $\pm 60^{\circ}$ and $0^{\circ}$ plies, i.e. $\left(\xi_{1}, \xi_{2}\right)=(0,0)$. The flexural lamination parameters corresponding to uncoupled $\pi / 3$ EILs have orthotropic properties which lie along the line defined by $\left(\xi_{9}, \xi_{10}\right)=(1,1)$ and $(-0.5,-0.5)$ on Fig. 4(b), since the three ply orientations $+/-1 \bigcirc$ have been equated to $60 /-60 / 0^{\circ}$. The flexural lamination parameters corresponding to uncoupled $\pi / 4$ EILs, illustrated on Fig. 4(c), are contained within the domain defined by the three points corresponding to the $90, \pm 45$ and $0^{\circ}$ plies that these sequences contain, cf. Fig. 4(a).

All $\pi / 3$ FILs, with $2 \zeta_{ \pm}=\zeta_{\circ}$, correspond to the point $\left(\xi_{1}, \xi_{2}\right)=\left(\xi_{9}, \xi_{10}\right)=(0,0)$. QHOLs correspond to any point satisfying $\left(\xi_{1}, \xi_{2}\right)=\left(\xi_{9}, \xi_{10}\right) \neq(0,0)$. Degenerative QHOLs therefore result from FILs when the $\pi / 3$ angle separation is relaxed, e.g. where the three ply orientations $+/-/ \bigcirc$ correspond to $45 /-45 / 0^{\circ}$ rather than $60 /-60 / 0^{\circ}$ : Such sequences are illustrated by the locus of $1 / 3^{\text {rd }}$ points shown by the broken-line parabola on Fig. 4(a), representing arbitrary angle-ply $\pm \theta$.

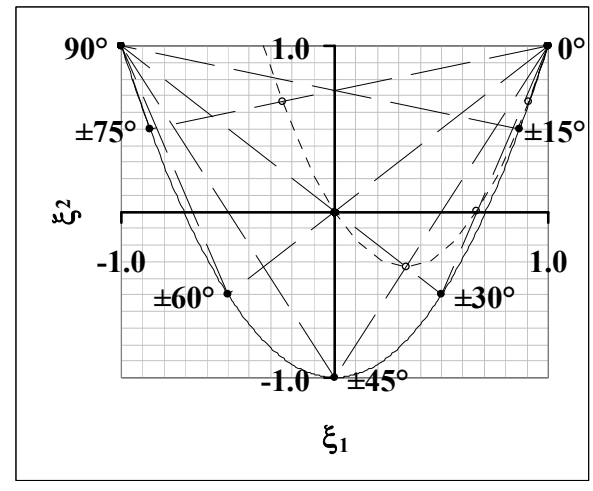

(a) Domains of membrane lamination parameters for EILs (and FILs with $\xi_{1}=\xi_{2}=0$ ) and locus (broken-line parabola) for degenerative QHOLs

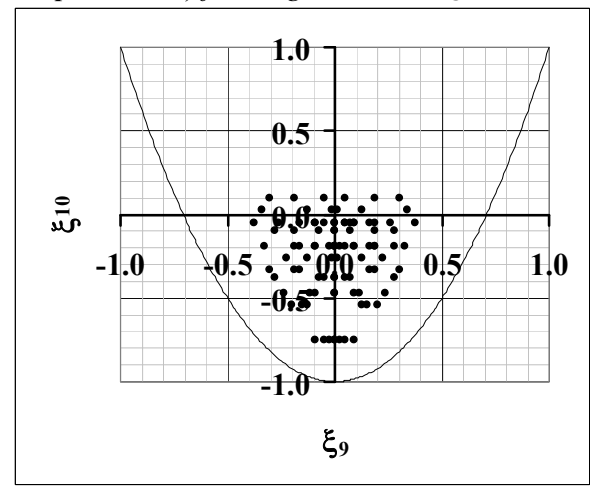

(c) Flexural lamination parameters for EILs - $\pi / 4(92)$

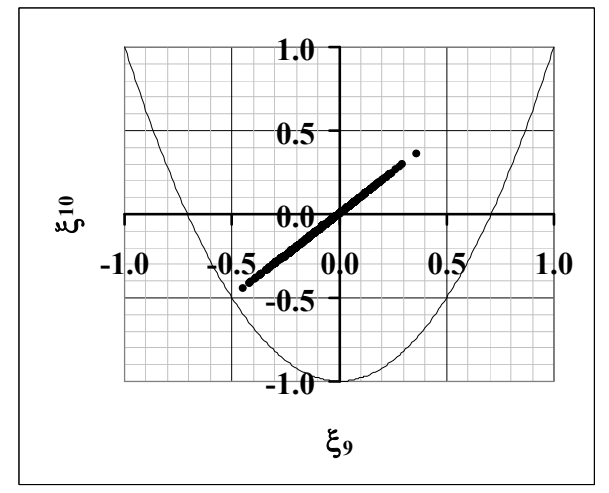

(b) Flexural lamination parameters for EILs - $\pi / 3$ (973)

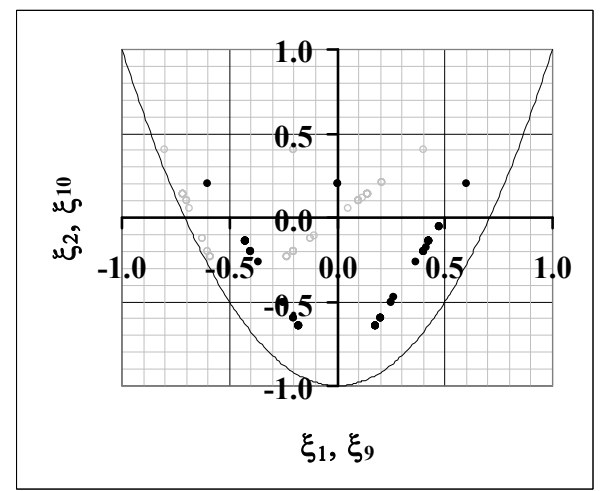

(d) Membrane and Flexural lamination parameters for QHOLs (82) with $\pm \theta=45^{\circ}(\bullet)$ and $\pm 60^{\circ}(\circ)$

Figure 4 - Feasible domains of lamination parameters, in the form of Eqs. (22), for: (a) - (c) EILs, including form and number of sequences represented and; (d) the sub-set of QHOLs from the definitive list of FOLs. 
For IM7/8552 carbon-fiber/epoxy material with Young's moduli $\mathrm{E}_{1}=161.0 \mathrm{GPa}$ and $\mathrm{E}_{2}=11.38 \mathrm{GPa}$, shear modulus $\mathrm{G}_{12}=5.17 \mathrm{GPa}$ and Poison ratio $v_{12}=0.38$, lamina thickness $t=0.1397 \mathrm{~mm}$ and stacking sequence AC 127: $\left[+/ \bigcirc / \bullet_{2} /-/ O /-/ O /-/-/+/ O / \bigcirc /+/ \bigcirc /+/ O_{2} / \bullet /-\right]_{\mathrm{T}}$, the non-dimensional parameters are verified by the calculations presented in Table 5, where the first two columns provide the ply number and orientation, respectively. Subsequent columns illustrate the summations, for each ply orientation, of $\left(z_{k}-z_{k-1}\right),\left(z_{k}^{2}-z_{k-1}{ }^{2}\right) / 2$ and $\left(z_{k}^{3}-z_{k-1}{ }^{3}\right) / 3$, relating to the $\mathbf{A}, \mathbf{B}$ and $\mathbf{D}$ matrices, respectively. The distance from the laminate mid-plane, $z$, is expressed in term of ply thickness $t$, which is set to unit value in the non-dimensional expressions.

Table 5 - Calculation procedure for the non-dimensional parameters of the ABD relation.

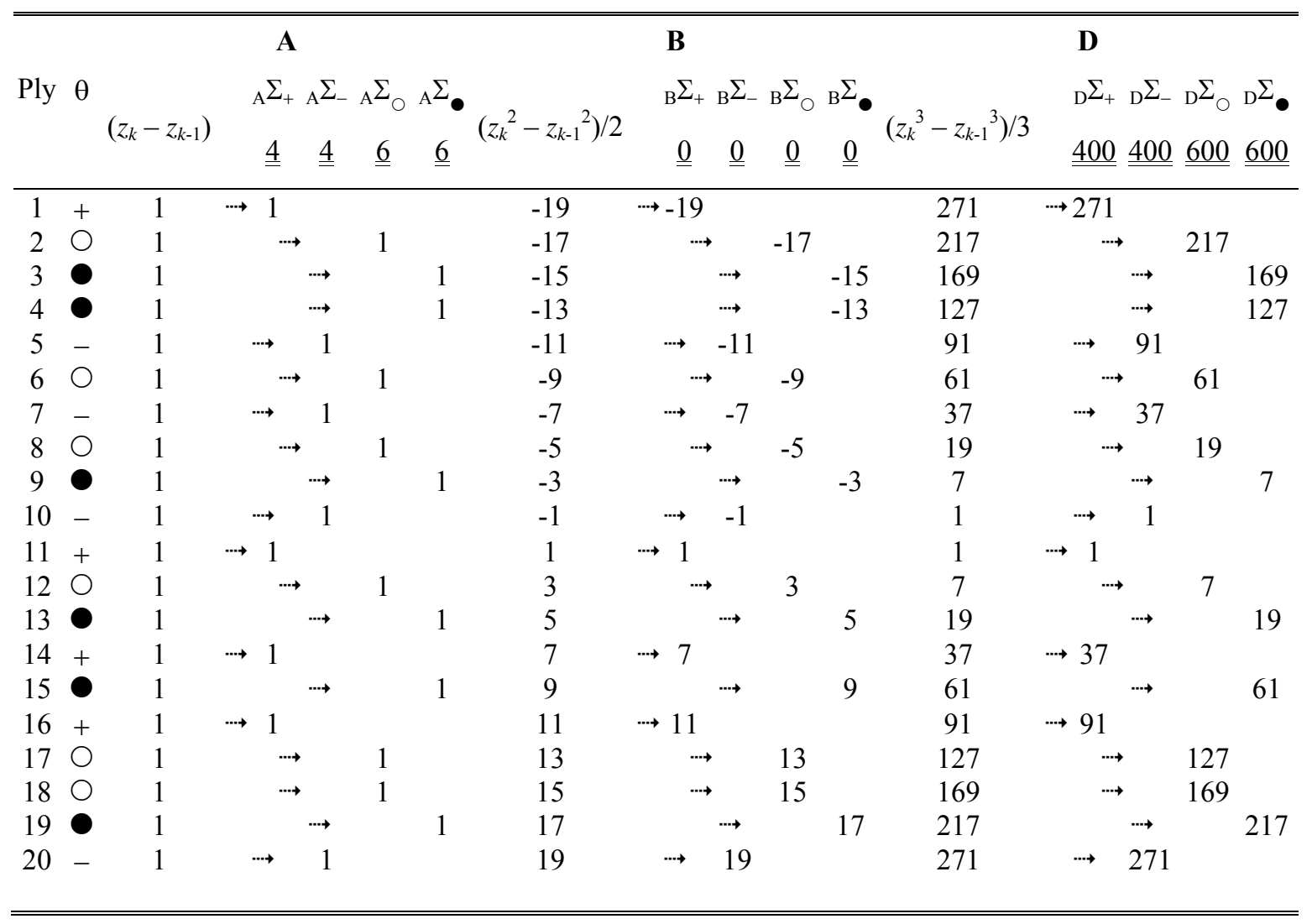

The non-dimensional parameters arising from the summations of Table 5 are: $n_{+}\left(={ }_{A} \Sigma_{+}\right)=n_{ \pm} / 2=4, n_{-}=4, n_{\circ}=6$ and $n_{\bullet}=6$, and $\zeta_{+}\left(=4 \times{ }_{\mathrm{D}} \Sigma_{+}\right)=1600, \zeta_{-}=1600, \zeta_{\mathrm{O}}=2400$ and $\zeta_{\bullet}=2400$, where $n^{3}=20^{3}=\zeta_{=}=\zeta_{+}+\zeta_{-}+\zeta_{\mathrm{O}}+\zeta_{\bullet}$ $=8000$ and $\zeta_{ \pm}=\zeta_{+}+\zeta_{-}=3200$. The $\mathbf{B}$ matrix summations confirm that $\mathrm{B}_{\mathrm{ij}}=0$ for this laminate.

For fiber angles $\theta= \pm 45^{\circ}, 0^{\circ}$ and $90^{\circ}$ in place of symbols,$\pm \bigcirc$ and $\bullet$ respectively, the transformed reduced stiffnesses are given in Table 6, which are readily calculated using Eqs. (17). 
Table 6 - Transformed reduced stiffnesses $\left(\mathrm{N} / \mathrm{mm}^{2}\right)$ for IM7/8552 carbon-fiber/epoxy with ply angle $\theta$.

\begin{tabular}{ccccccc}
\hline \hline$\theta$ & $\mathrm{Q}^{\prime}{ }_{11}$ & $\mathrm{Q}^{\prime}{ }_{12}$ & $\mathrm{Q}^{\prime}{ }_{16}$ & $\mathrm{Q}^{\prime}{ }_{22}$ & $\mathrm{Q}^{\prime}{ }_{26}$ & $\mathrm{Q}^{\prime}{ }_{66}$ \\
\hline-45 & 50,894 & 40,554 & $-37,791$ & 50,894 & $-37,791$ & 41,355 \\
45 & 50,894 & 40,554 & 37,791 & 50,894 & 37,791 & 41,355 \\
0 & 162,660 & 4,369 & 0 & 11,497 & 0 & 5,170 \\
90 & 11,497 & 4,369 & 0 & 162,660 & 0 & 5,170 \\
\hline \hline
\end{tabular}

and through Eqs. (15) and (16), the final stiffness matrices are derived for the laminate:

$$
\begin{aligned}
& {\left[\begin{array}{ccc}
\mathrm{A}_{11} & \mathrm{~A}_{12} & \mathrm{~A}_{16} \\
& \mathrm{~A}_{22} & \mathrm{~A}_{26} \\
\text { Sym. } & & \mathrm{A}_{66}
\end{array}\right]=\left[\begin{array}{ccc}
202,858 & 52,647 & 0 \\
& 202,858 & 0 \\
\text { Sym. } & & 54,885
\end{array}\right] \mathrm{N} / \mathrm{mm}} \\
& {\left[\begin{array}{ccc}
\mathrm{D}_{11} & \mathrm{D}_{12} & \mathrm{D}_{16} \\
& \mathrm{D}_{22} & \mathrm{D}_{26} \\
\text { Sym. } & & \mathrm{D}_{66}
\end{array}\right]=\left[\begin{array}{ccc}
131,966 & 34,249 & 0 \\
& 131,966 & 0 \\
\text { Sym. } & & 35,705
\end{array}\right] \mathrm{N} \cdot \mathrm{mm}}
\end{aligned}
$$

given that:

$$
\begin{gathered}
\mathrm{A}_{16}=\left\{n_{+} \mathrm{Q}_{16+}^{\prime}+n_{-} \mathrm{Q}^{\prime}{ }_{16-}+n_{\circ} \mathrm{Q}^{\prime}{ }_{16}{ }_{\circ}+n_{\bullet} \mathrm{Q}^{\prime}{ }_{16}\right\} \times t \\
\mathrm{~A}_{16}=\mathrm{A}_{26}=\{4 \times 37,791+4 \times-37,791+6 \times 0+6 \times 0\} \times 0.1397=0 \mathrm{~N} / \mathrm{mm} \\
\mathrm{D}_{16}=\left\{\zeta_{ \pm} / 2 \times \mathrm{Q}^{\prime}{ }_{16+}+\zeta_{ \pm} / 2 \times \mathrm{Q}^{\prime}{ }_{16-}+\zeta_{{ }_{0}} \mathrm{Q}^{\prime}{ }_{16}{ }_{\circ}+\zeta_{\bullet} \mathrm{Q}^{\prime}{ }_{16}\right\} \times t^{3} / 12 \\
\mathrm{D}_{16}=\mathrm{D}_{26}=\{1600 \times 37,791+1600 \times-37,791+2400 \times 0+2400 \times 0\} \times 0.1397^{3} / 12=0 \mathrm{~N} . \mathrm{mm}
\end{gathered}
$$

This laminate appears to be fully isotropic, since $A_{11}=A_{22}$ and $D_{i j} \propto A_{i j}$, but calculation reveals that whilst Eqs. (5) and (7) are satisfied, Eq. (6) is not. Hence this is a Quasi Homogeneous Orthotropic angle-ply Laminate, or QHOL, containing four ply orientations.

The lamination parameters for this laminate, i.e. the co-ordinates $\left(\xi_{1}, \xi_{2}\right)=\left(\xi_{9}, \xi_{10}\right)=(0.0,0.2)$ on Fig. $4(\mathrm{~d})$, are derived from Eqs. (21):

$$
\begin{gathered}
\xi_{1}=\left\{n_{ \pm} \cos \left(2 \theta_{ \pm}\right)+n_{\circ} \cos \left(2 \theta_{\odot}\right)+n_{\bullet} \cos \left(2 \theta_{\bullet}\right)\right\} / n \\
\xi_{1}=\left\{8 \times \cos \left(90^{\circ}\right)+6 \times \cos \left(0^{\circ}\right)+6 \times \cos \left(180^{\circ}\right)\right\} / 20=0.0 \\
\xi_{2}=\left\{n_{ \pm} \cos \left(4 \theta_{ \pm}\right)+n_{\circ} \cos \left(4 \theta_{\odot}\right)+n_{\bullet} \cos \left(4 \theta_{\bullet}\right)\right\} / n \\
\xi_{2}=\left\{8 \times \cos \left(180^{\circ}\right)+6 \times \cos \left(0^{\circ}\right)+6 \times \cos \left(360^{\circ}\right)\right\} / 20=0.2
\end{gathered}
$$

and Eqs. (22):

$$
\begin{gathered}
\xi_{9}=\left\{\zeta_{ \pm} \cos \left(2 \theta_{ \pm}\right)+\zeta_{\bigcirc} \cos \left(2 \theta_{\odot}\right)+\zeta_{\bullet} \cos \left(2 \theta_{\bullet}\right)\right\} / \zeta \\
\xi_{9}=\left\{3200 \times \cos \left(90^{\circ}\right)+2400 \times \cos \left(0^{\circ}\right)+2400 \times \cos \left(180^{\circ}\right)\right\} / 8000=0.0 \\
\xi_{10}=\left\{\zeta_{ \pm} \cos \left(4 \theta_{ \pm}\right)+\zeta_{\bigcirc} \cos \left(4 \theta_{\odot}\right)+\zeta_{\bullet} \cos \left(4 \theta_{\bullet}\right)\right\} / \zeta \\
\xi_{10}=\left\{3200 \times \cos \left(180^{\circ}\right)+2400 \times \cos \left(0^{\circ}\right)+2400 \times \cos \left(360^{\circ}\right)\right\} / 8000=0.2
\end{gathered}
$$




\section{Conclusions}

This article presents the definitive set of stacking sequences for (82) Quasi-Homogeneous Orthotropic Laminates (QHOLs), (973) $\pi / 3$ and (92) $\pi / 4$ Extensionally Isotropic Laminates (EILs) and (36) $\pi / 3$ Fully Isotropic Laminates (FOLs), all of which are sub-sets from a definitive list of $(69,506)$ stacking sequences for Fully Orthotropic Laminates (FOLs) with up to 21 plies. The great majority of sequences are non-symmetric in form and many are without any sub-sequence patterns, e.g. symmetry or repeating groups, which is contrary to the assumptions on which many previous studies have been based.

Standard ply angles $\left( \pm 45^{\circ} / 0^{\circ} / 90^{\circ}\right.$ for $\pi / 4$ isotropy and $\pm 60^{\circ} / 0^{\circ}$ for $\pi / 3$ isotropy) have been assumed in the presentation of the feasible domains of lamination parameters commonly adopted in the optimum design of composite laminates, however the stacking sequences are otherwise generic in the sense that any orientation may be assigned to the angle-ply sub-sequence, and the two cross-ply orientations may be arbitrarily switched. For EIL or FIL properties of course, the choice of these arbitrary ply angles must ensure that $\pi / 3$ or $\pi / 4$ ply separation is maintained; the stacking sequences otherwise degenerate into FOLs and QHOLs respectively. The ABD relation has been shown to be readily calculated for any general orthotropic fiber/matrix material using the non-dimensional stiffness parameters provided.

FILs provide an important set of benchmark configurations, which permit like with like comparisons for laminates with other characteristics.

\section{References}

${ }^{1}$ Engineering Sciences Data Unit, "Stiffnesses of laminated plates”, ESDU Item No. 94003, 1994.

${ }^{2}$ York, C. B., "On composite laminates with extensional-anisotropy," Proc. 49th AIAA/ASME/ASCE/AHS/ASC Structures, Structural Dynamics, and Materials Conf., Schaumburg, Illinois, 2008, Accepted for publication.

${ }^{3}$ York, C. B., "Laminate stacking sequences for special orthotropy," University of Glasgow, Department of Aerospace Engineering Research Report No. 06-02, 2006.

${ }^{4}$ York, C. B., "Characterization of non-symmetric forms of fully orthotropic laminates." AIAA Journal of Aircraft, Accepted for publication. See also, York, C. B. "Characterization and ply mixing rules for non-symmetric forms of fully orthotropic laminates," Proc. 48th AIAA/ASME/ASCE/AHS/ASC Structures, Structural Dynamics, and Materials Conf., AIAA-2007-2083, Honolulu, Hawaii, 2007.

${ }^{5} \mathrm{Wu}, \mathrm{K} ., \mathrm{M}$. and Avery, B. L., "Fully isotropic laminates and quasi-homogeneous anisotropic laminates", Journal of Composite Materials, Vol. 26, No. 14, 1992, pp. 2107-2117.

${ }^{6}$ Fukunaga, H., Sekine, H., Sato, M. and Iino, A., "Buckling design of symmetrically laminated plates using lamination parameters" Computers and Structures, Vol. 57, No. 4, 1995, pp. 643-649.

${ }^{7}$ Valot, E. and Vannucci, P., "Some exact solutions for fully orthotropic laminates," Composite Structures, Vol. 69, 2005, pp. 157-66.

${ }^{8}$ Vannucci, P. and Verchery, G., "A new method for generating fully isotropic laminates," Composite Structures, Vol. 58, 2002, pp. 75-82.

${ }^{9}$ Caprino, G. and Crivelli-Visconti, I., “A note on specially orthotropic laminates,” Journal of Composite Materials, Vol. 16, No. 5, 1982, 395-399.

${ }^{10}$ Vannucci, P. and Verchery, G., "Stiffness design of laminates using the polar method," International Journal of Solids and Structures, Vol. 38, 2001, pp. 9281-94.

${ }^{11}$ Tsai, S. W. and Pagano, N. J., Composite materials workshop, in: Tsai S. W. et al., editors, Technomic, USA, 1968.

${ }^{12}$ Bartholomew, P., "Ply stacking sequences for laminated plates having in-plane and bending orthotropy," Royal Aircraft Establishment Technical Report No. 76003, 1976.

${ }^{13}$ Bartholomew, P., "Ply stacking sequences for laminated plates having in-plane and bending orthotropy," Fibre Science and Technology, Vol. 10, No. 4, 1977, pp. 239-253.

${ }^{14}$ Engineering Sciences Data Unit, "Laminate stacking sequences for special orthotropy (Application to fibre reinforced composites)", ESDU Item No. 82013, 1982.

${ }^{15}$ Fukunaga, H., and Vanderplaats, G. N., "Stiffness optimization of orthotropic laminated composites using lamination parameters", AIAA Journal, Vol. 29, No. 4, 1991, pp. 641-646.

${ }^{16}$ Vannucci, P. and Verchery, G., "A special class of uncoupled and quasi-homogeneous laminates," Composites Science and Technology, Vol. 61, 2001, pp. 1465-1473.

${ }^{17}$ York, C. B., "Buckling interaction in regular arrays of rigidly supported composite laminated plates with orthogrid, isogrid and anisogrid planform," AHS Journal, Vol. 52, No. 4, 2007, pp. 343-359.

${ }^{18}$ York, C. B., "Buckling analysis and minimum mass design procedures for composite wing box structures," AIAA Journal of Aircraft, Vol. 43, No. 2, 2006, pp. 528-536. 


\section{Appendix}

Table 7 - Fully uncoupled EILs, with $\pi / 3$ isotropy, for 7 through 21 ply laminates corresponding to prefix designations: (a) AS for Anti-symmetric (A) angle-plies and Symmetric $(S)$ cross-plies; (b) $+N N_{+}$for Non-symmetric $(N)$ angle-plies and Non-symmetric $(N)$ cross-plies; (c) ${ }_{+} N N_{-}$and; (d) ${ }_{+} N N_{\circ}$. For all sequences, $n_{ \pm}=2 n_{\circ}, n=n_{ \pm}+n_{\circ}$ and $\zeta=n^{3}=\zeta_{ \pm}+\zeta_{\circ}$.

(a)

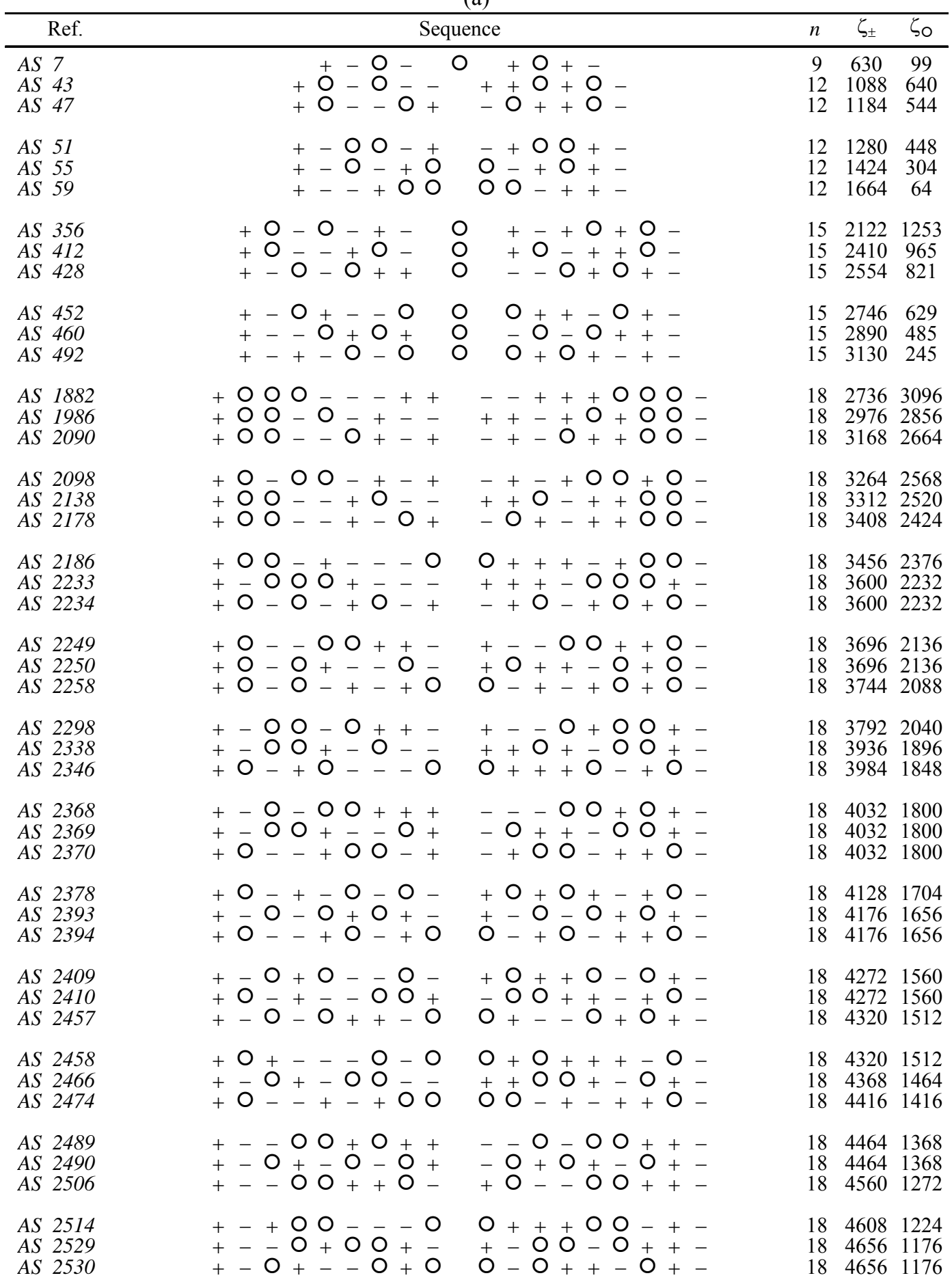

Continued 
Continued

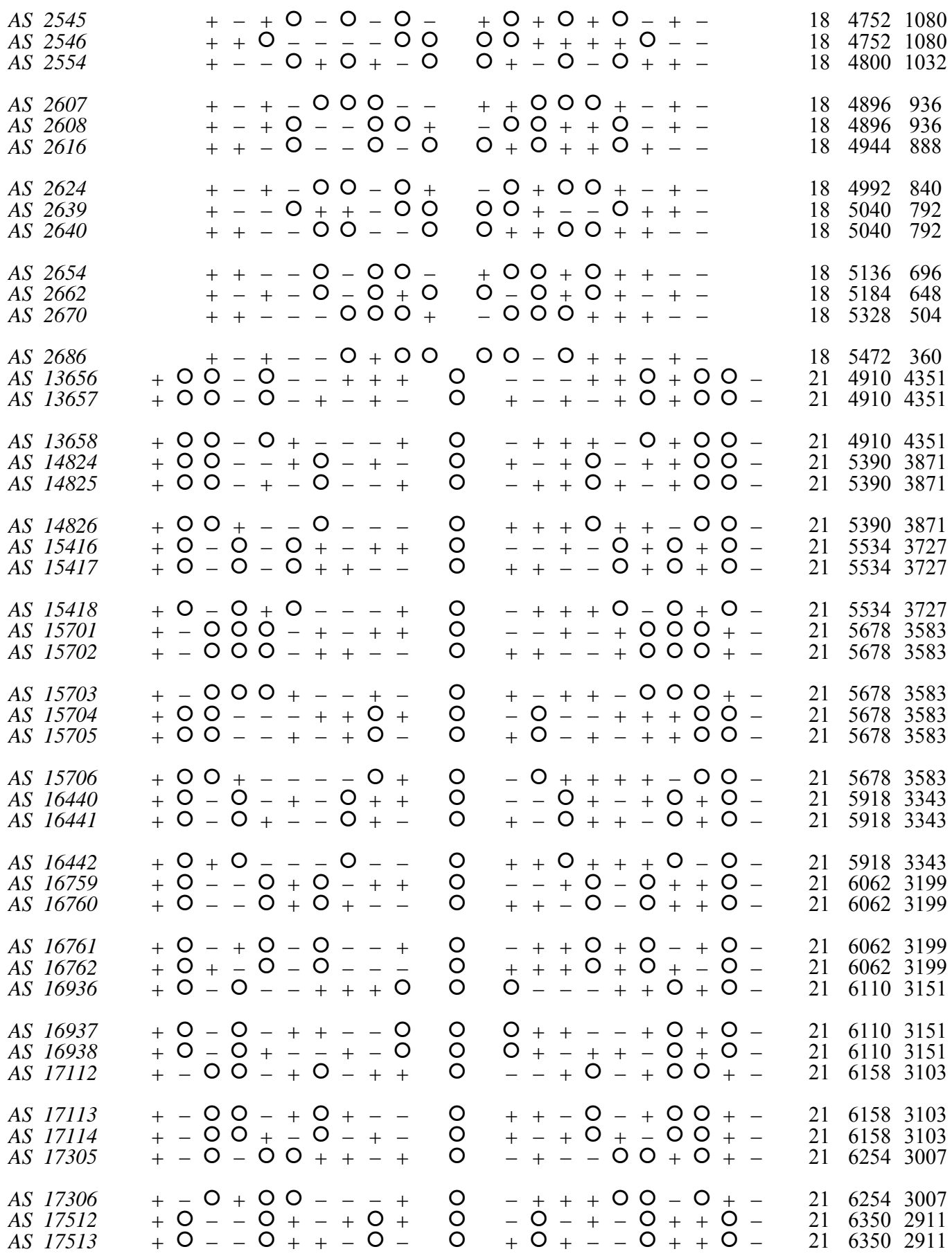

Continued 
Continued

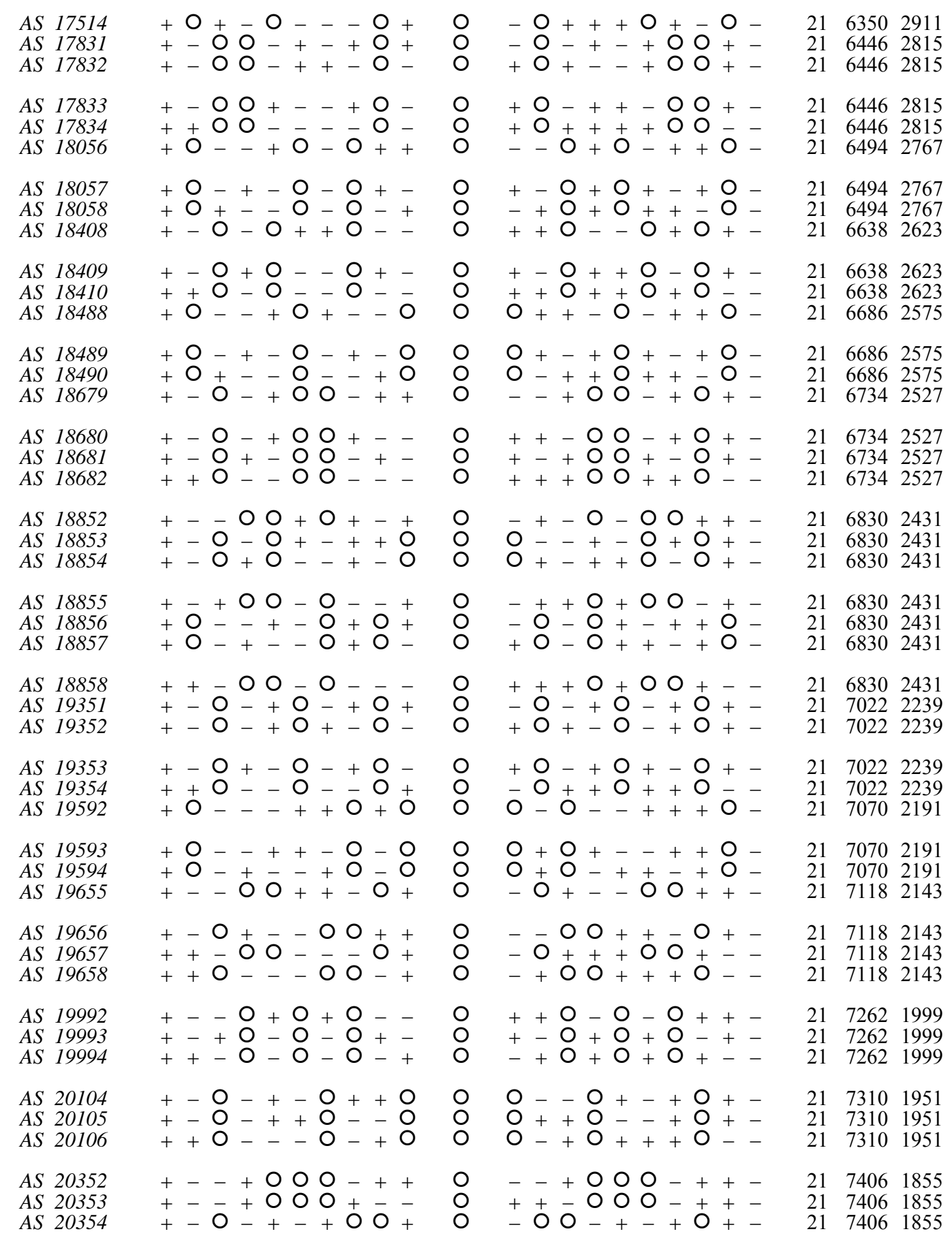

Continued 
Continued

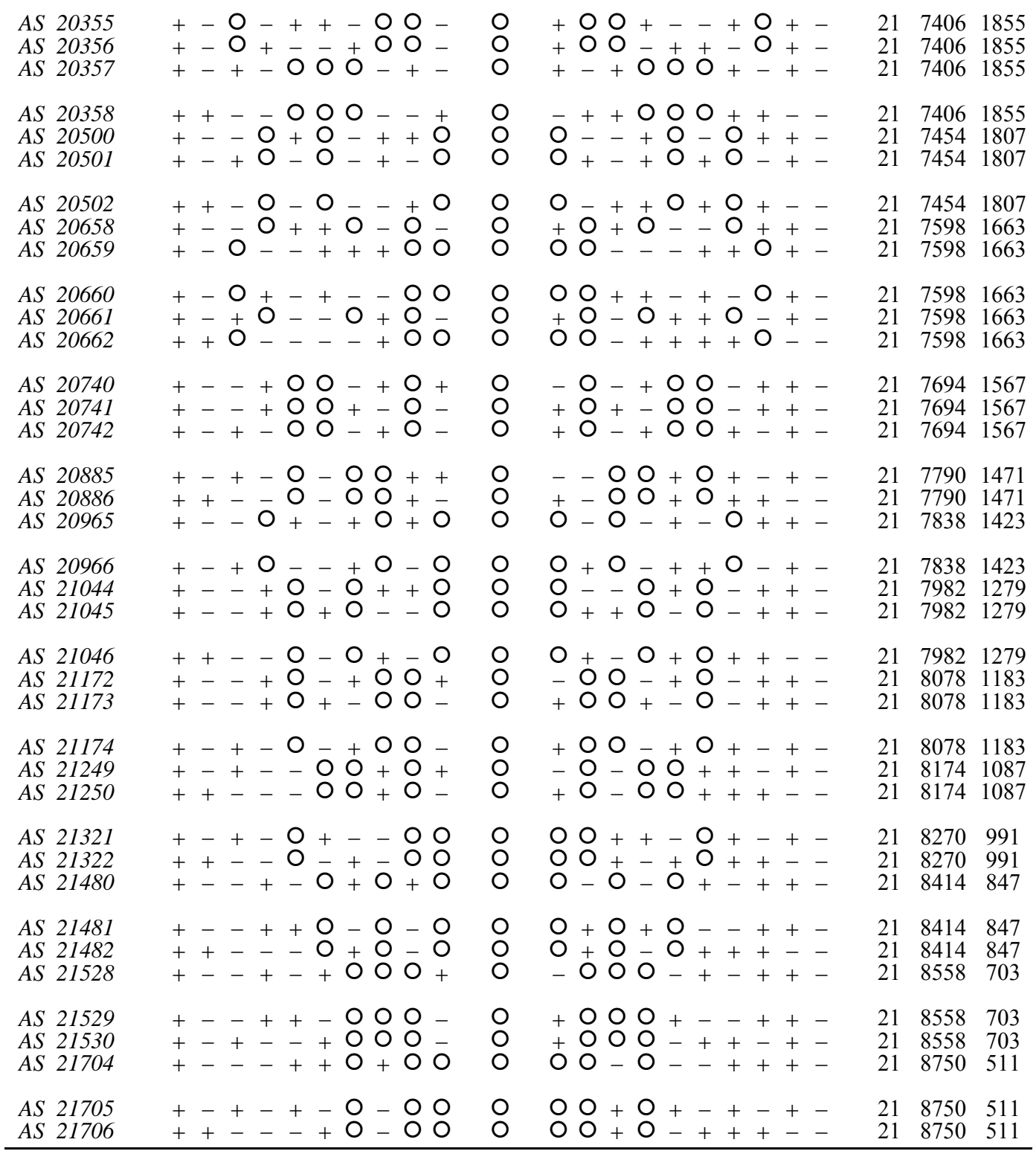

Concluded 
(b)

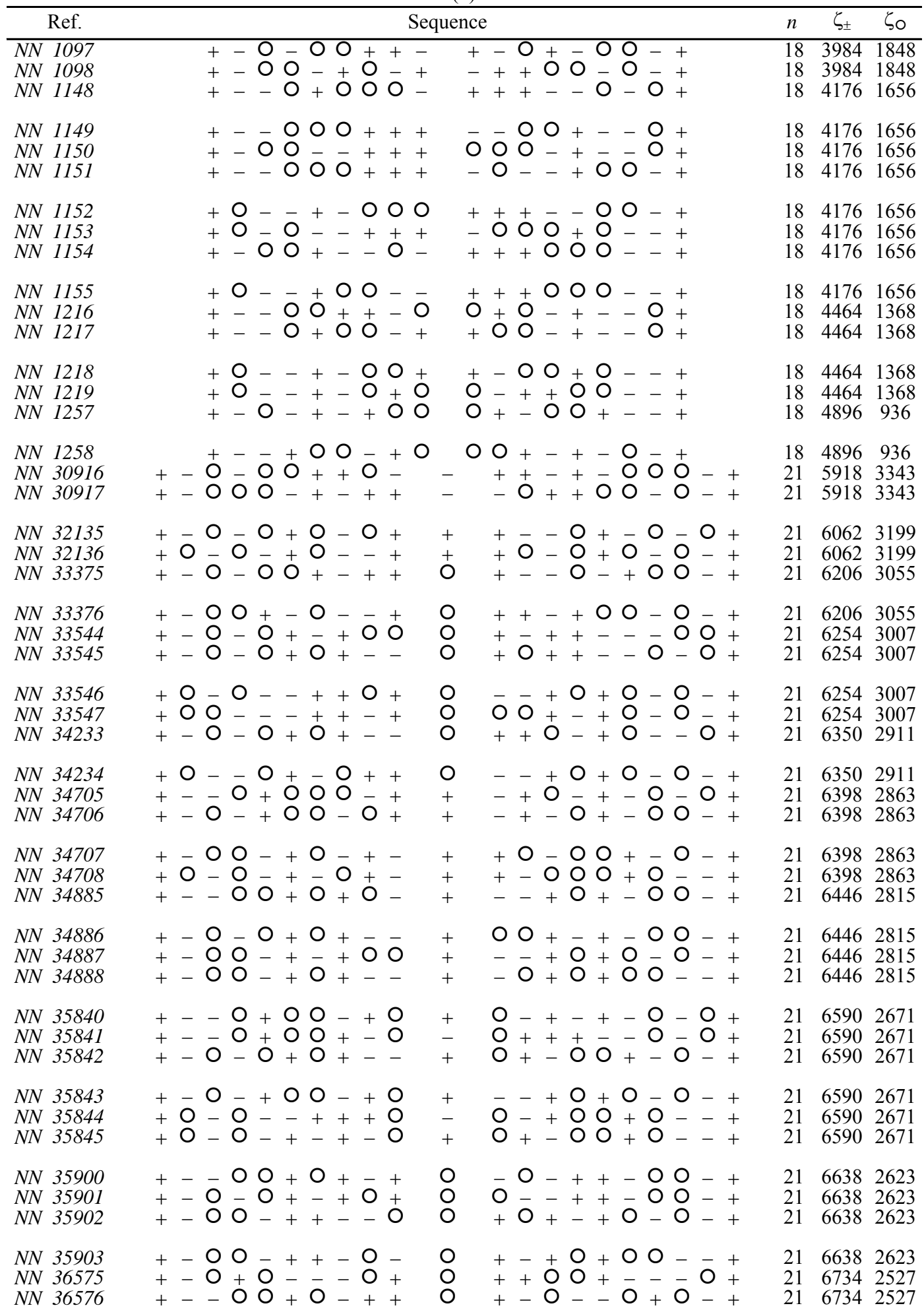

Continued 
Continued

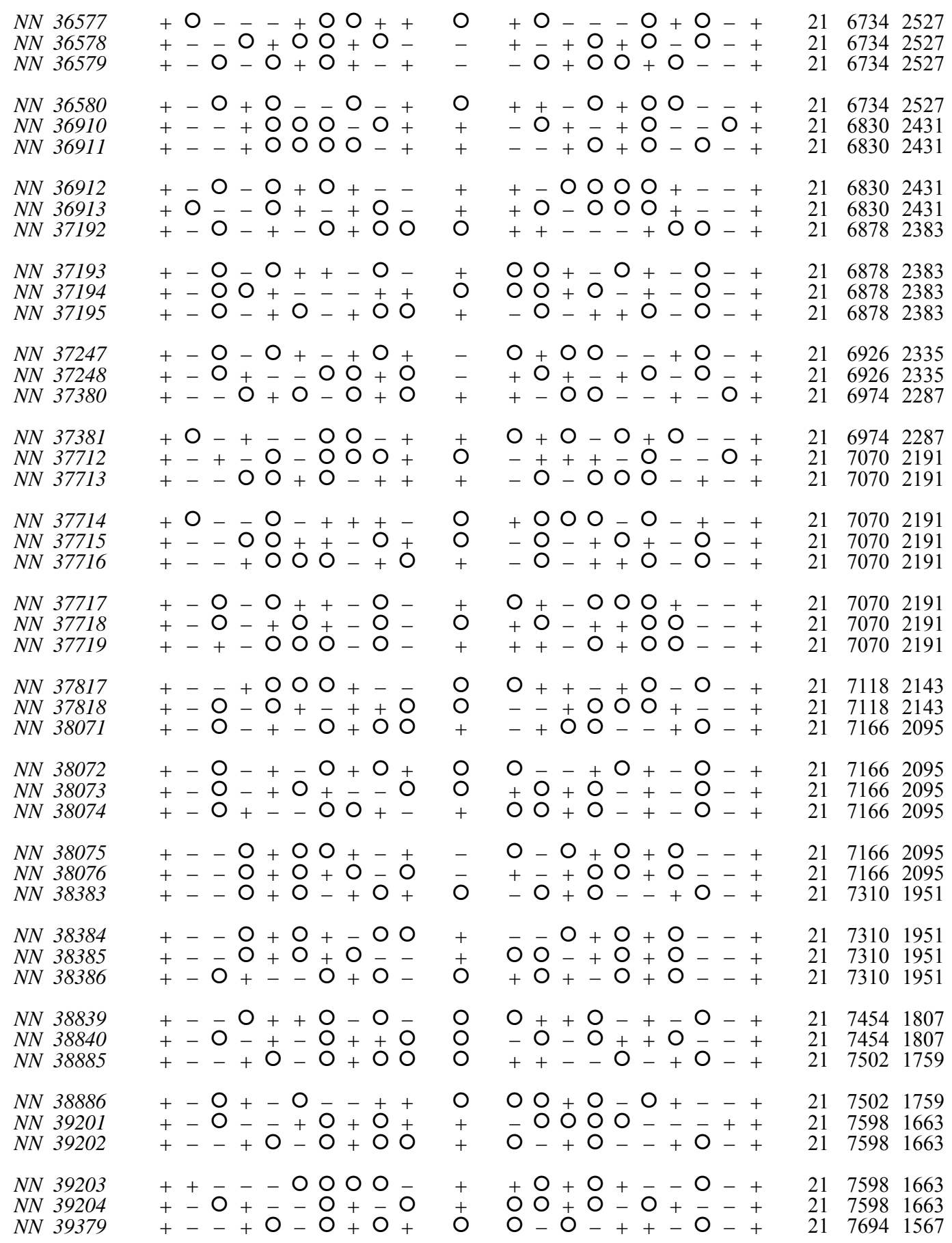

Continued 


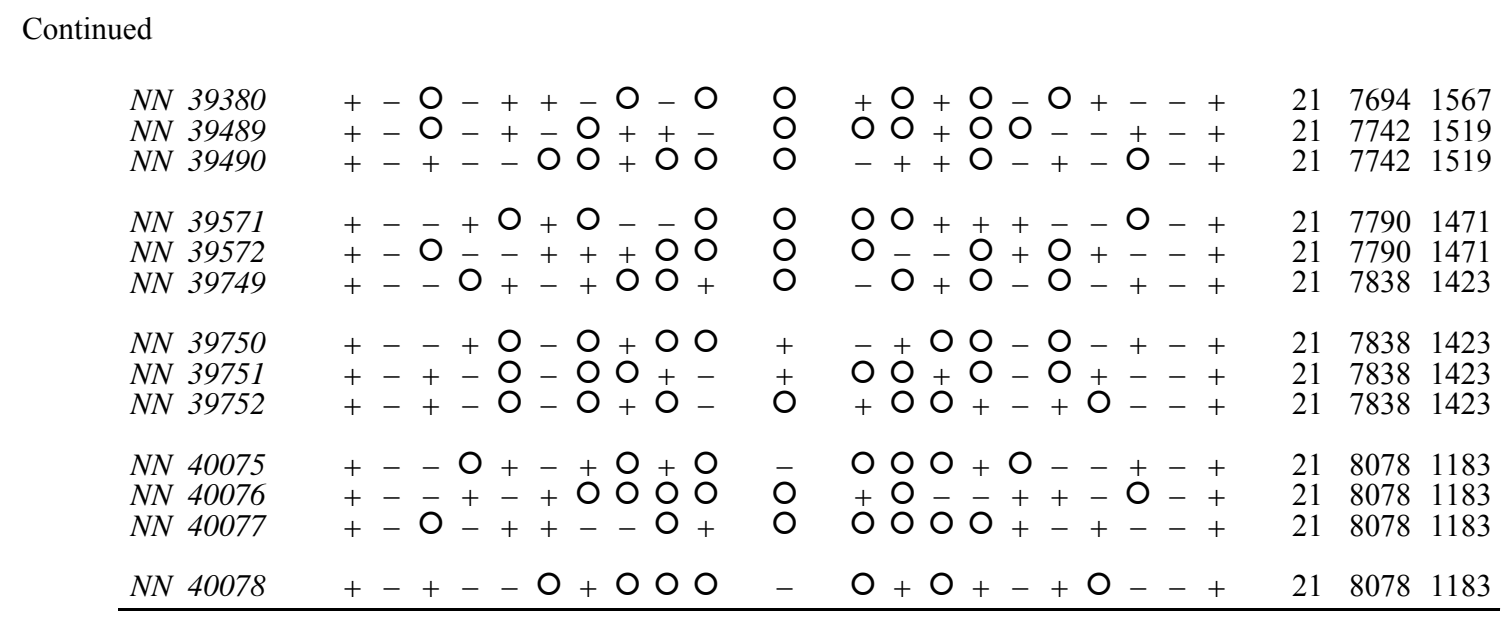

Concluded 
(c)

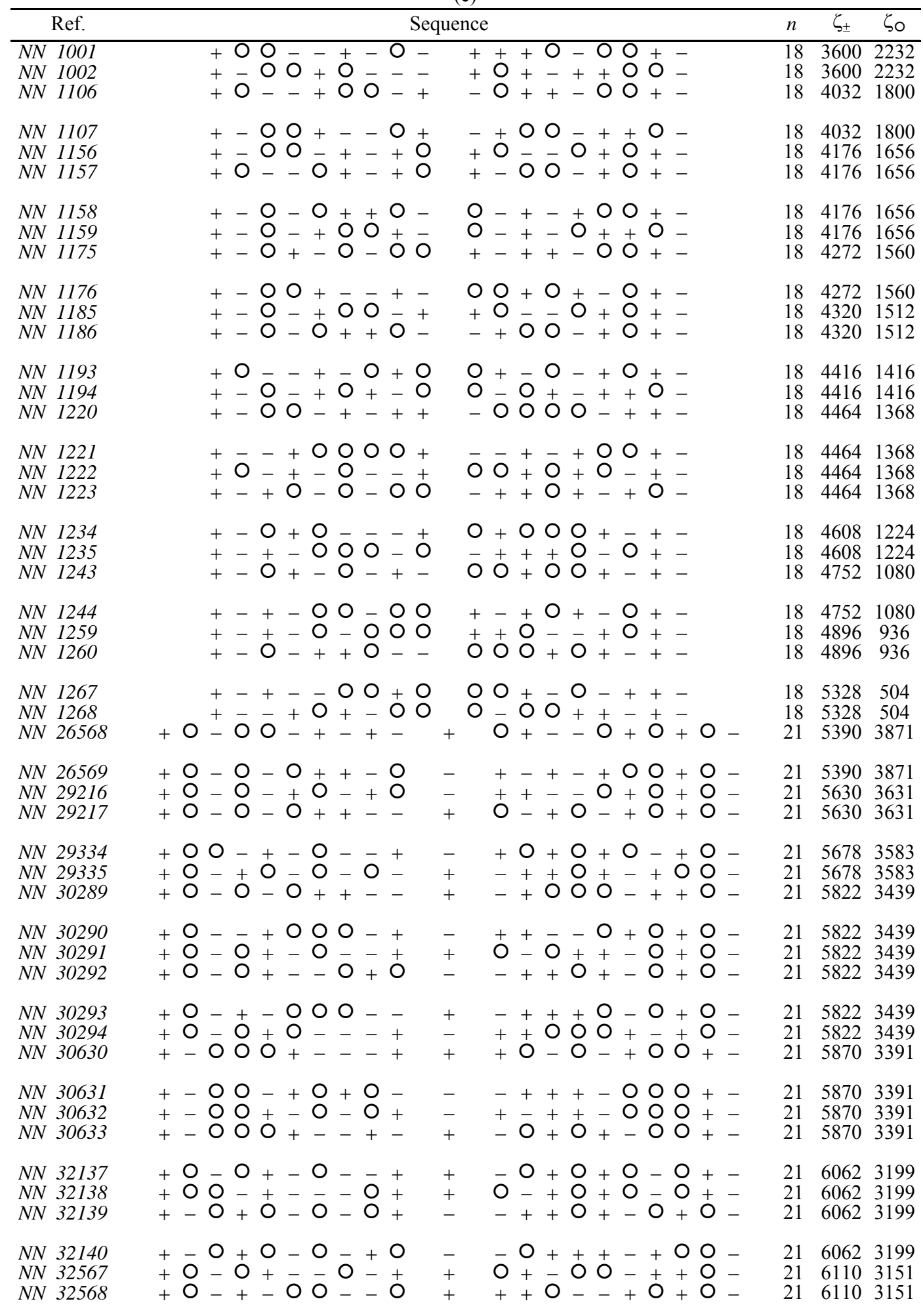

Continued 
Continued

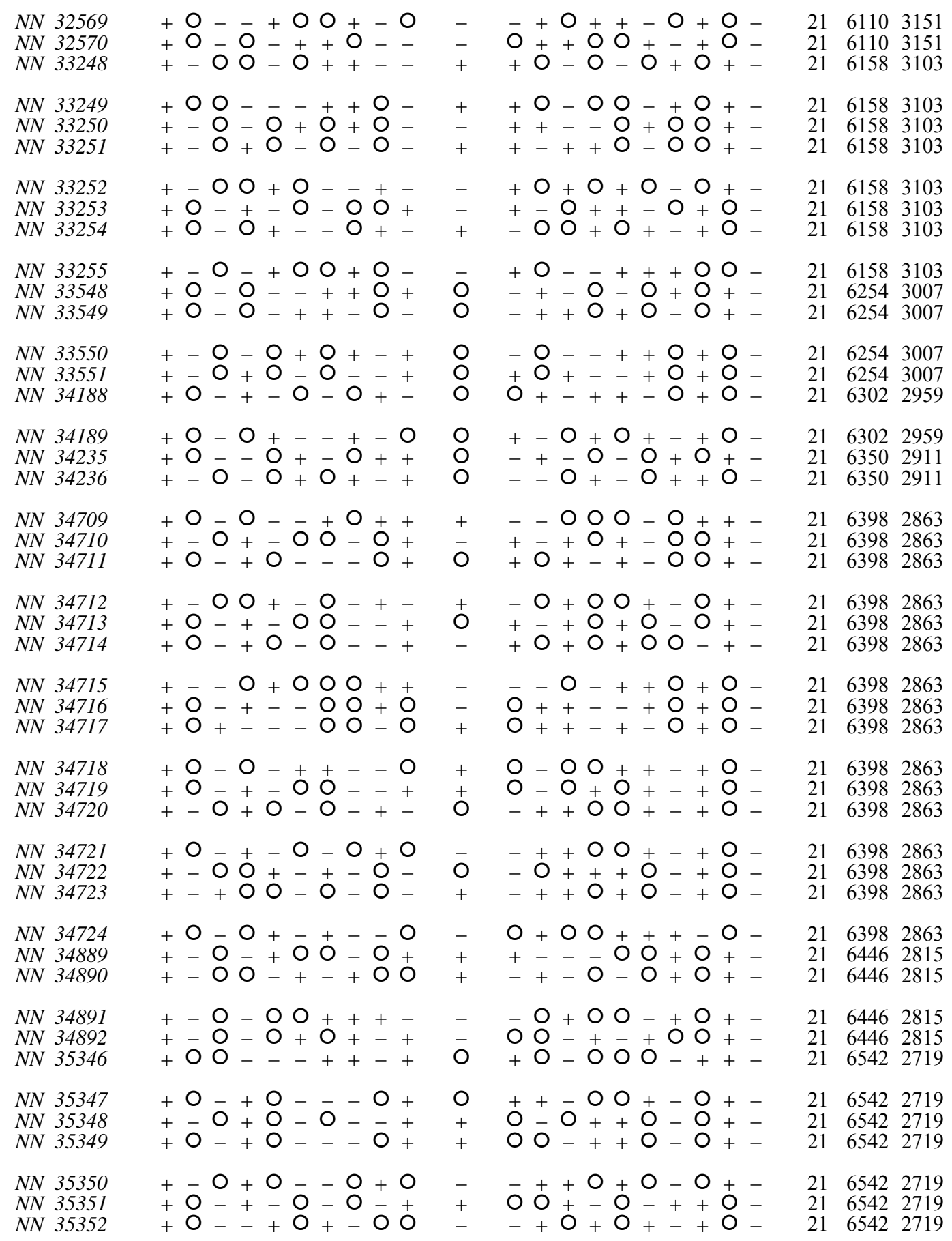

Continued 
Continued

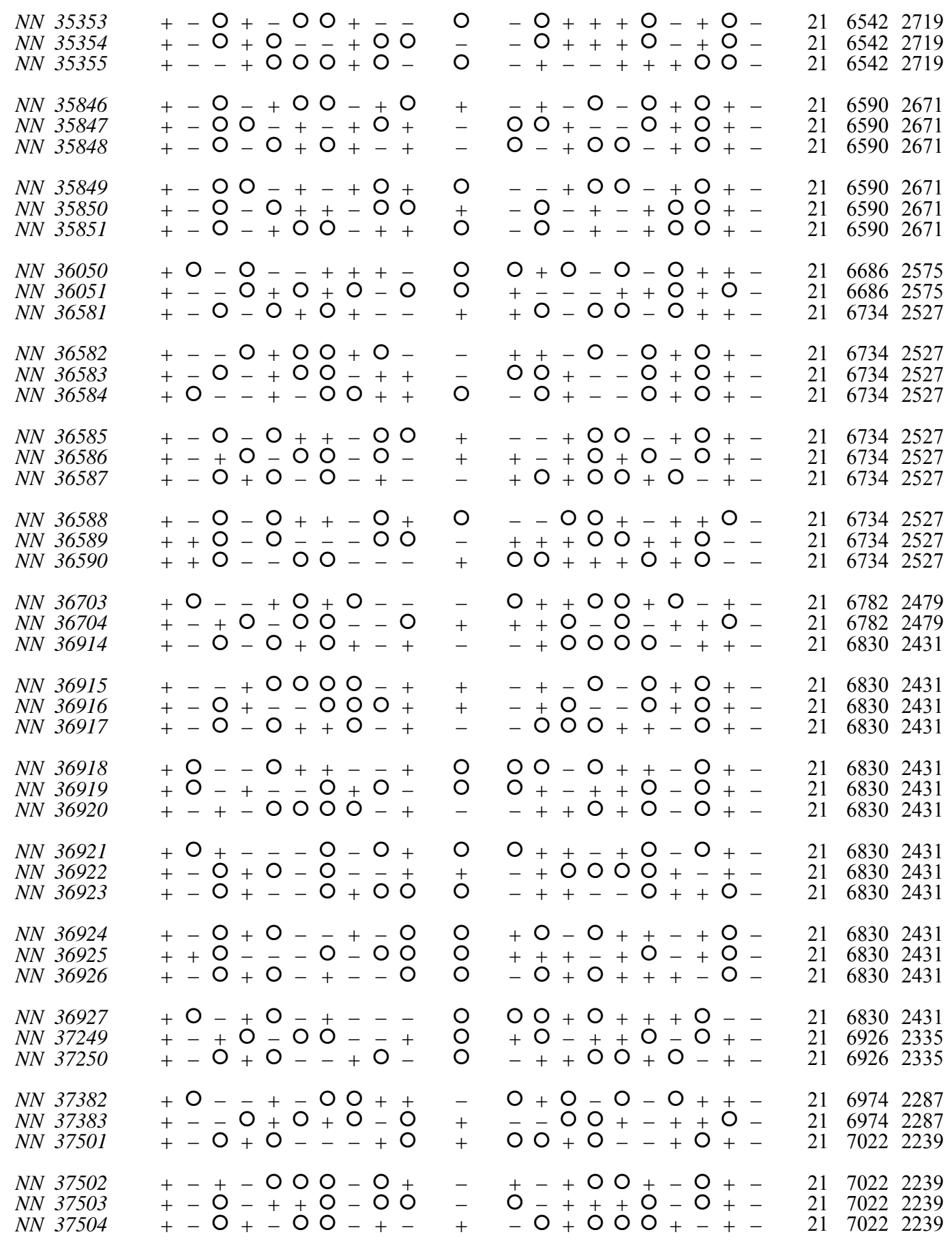

Continued 
Continued

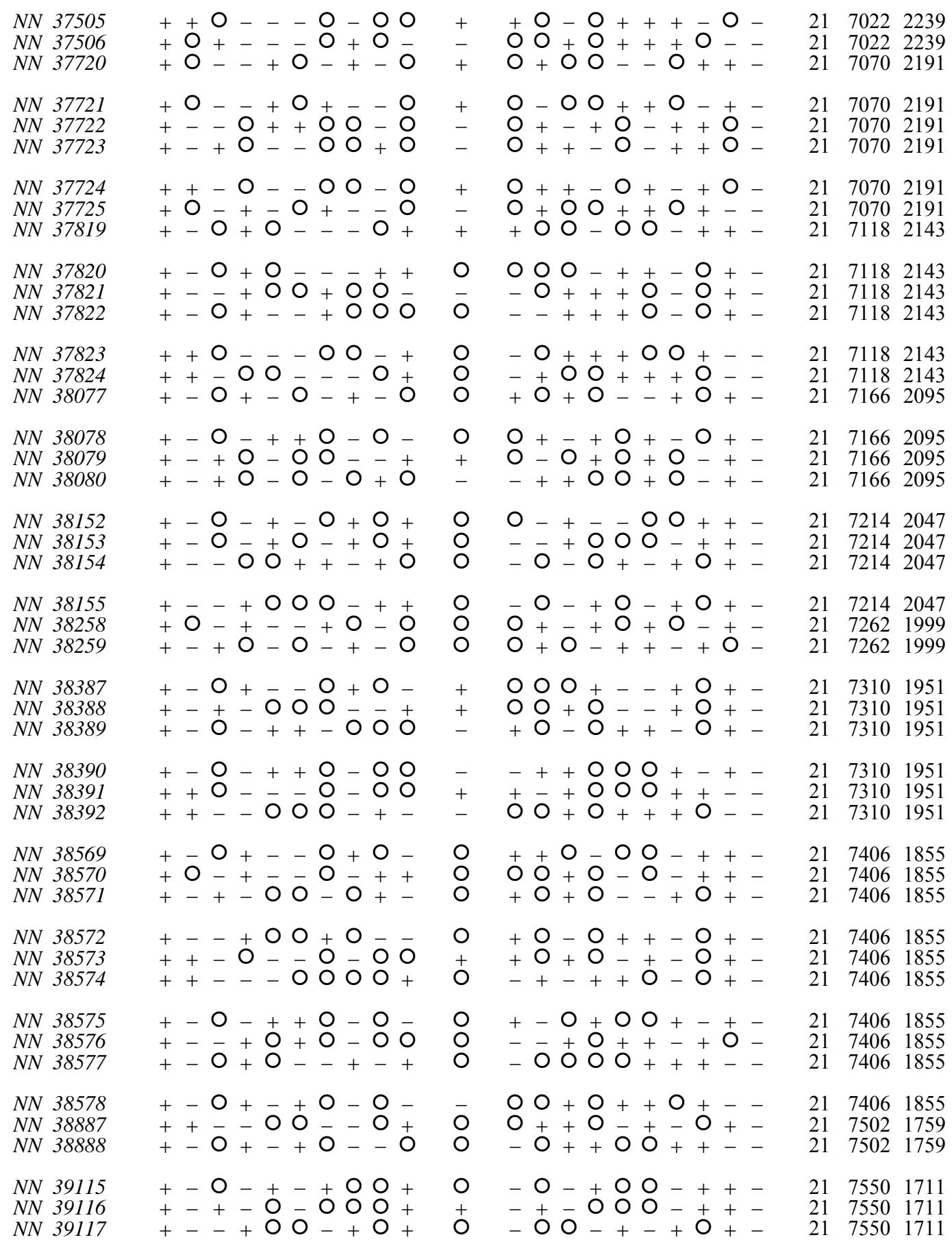

Continued 
Continued

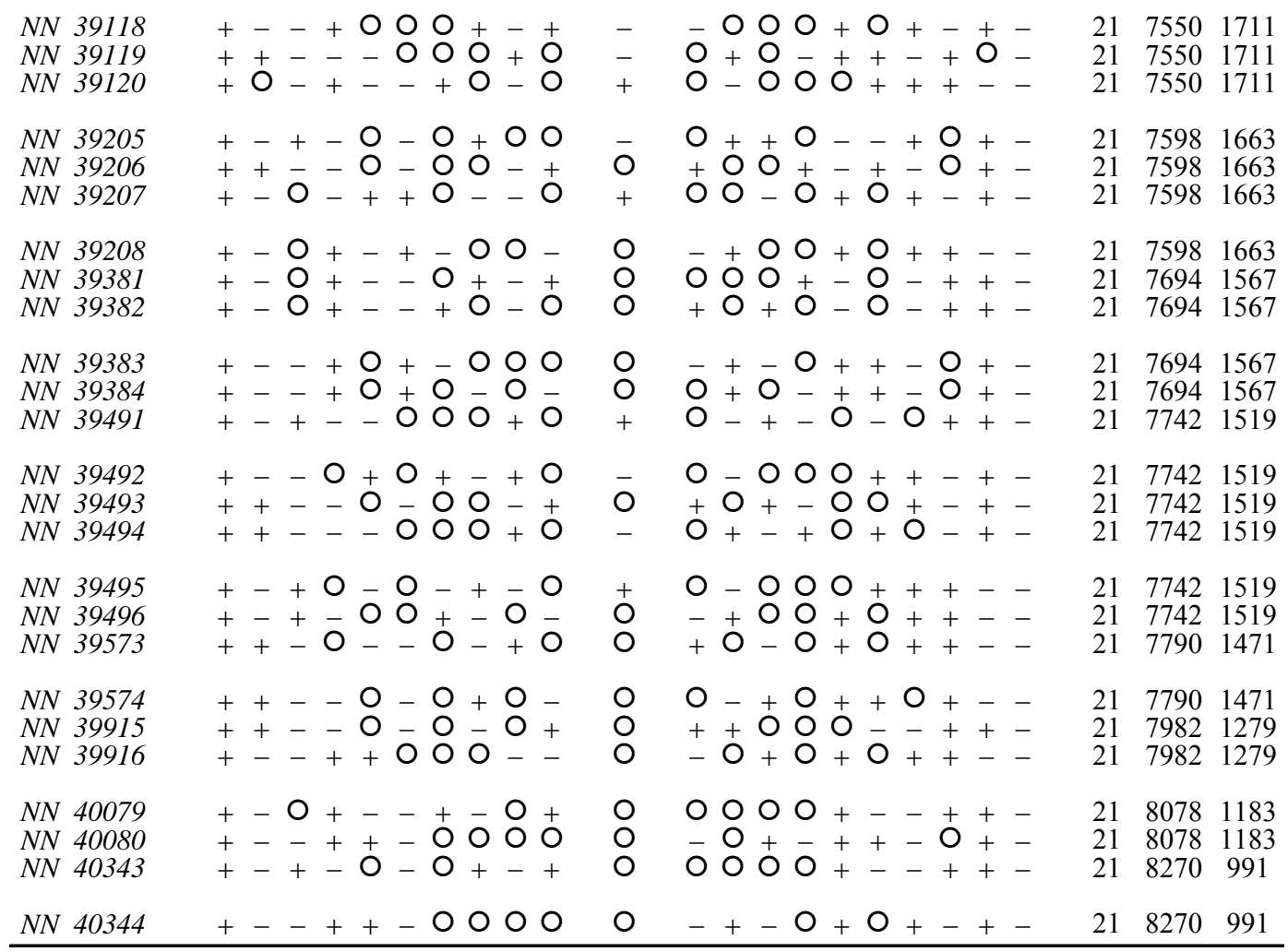

Concluded 
(d)

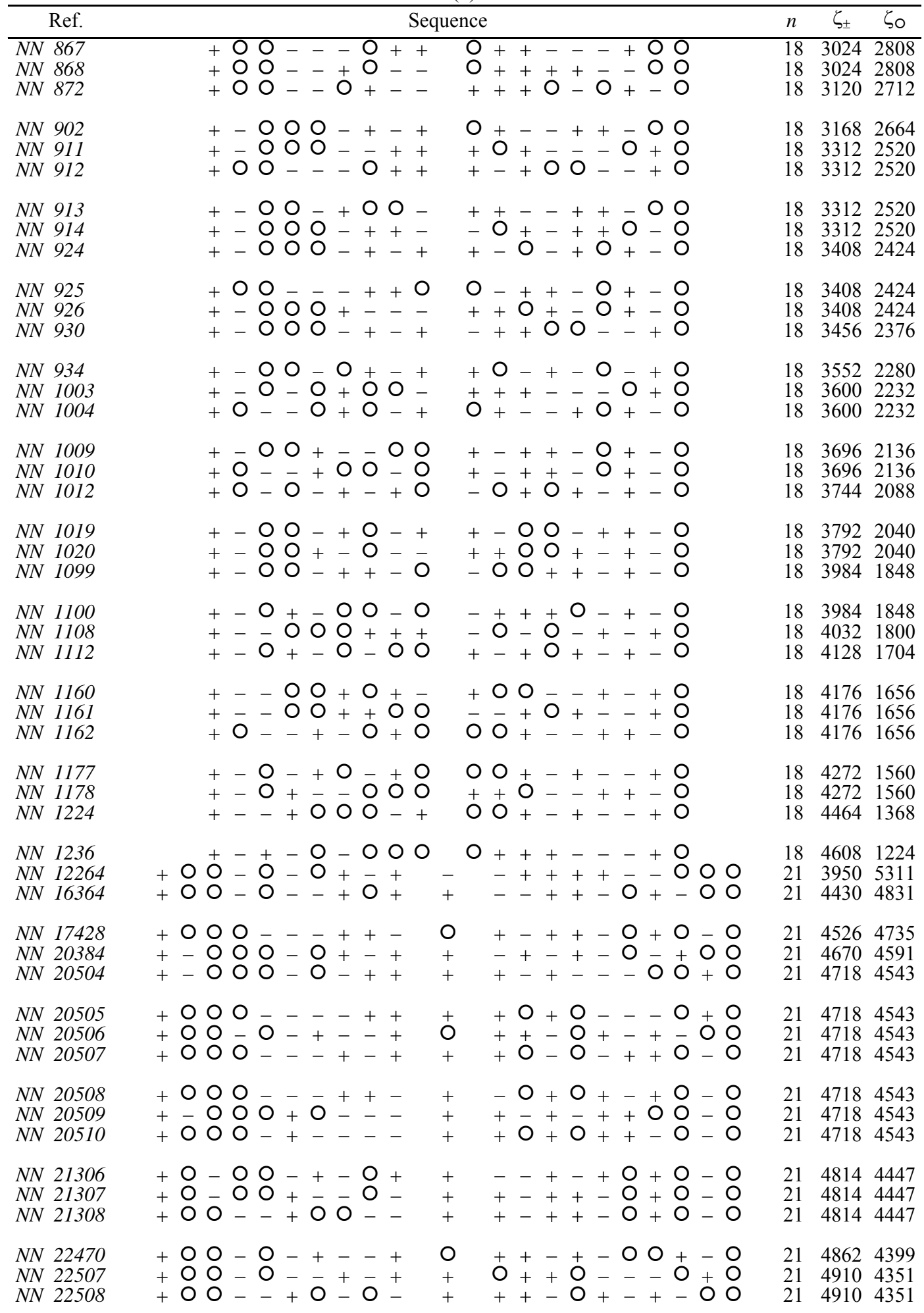

Continued 
Continued

\begin{tabular}{|c|c|c|c|c|c|c|c|c|c|c|c|c|c|}
\hline $\begin{array}{ll}N N & 23460 \\
N N & 23461 \\
N N & 23462\end{array}$ & $\begin{array}{l}+-O O- \\
+-O O- \\
+O O-\end{array}$ & $\begin{array}{ll}0 & 0 \\
0 & 0 \\
- & 0\end{array}$ & 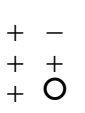 & $\begin{array}{l}+ \\
- \\
+\end{array}$ & $\begin{array}{l}+ \\
- \\
+\end{array}$ & $\begin{array}{l}+ \\
+ \\
+\end{array}$ & $\begin{array}{l}- \\
+ \\
-\end{array}$ & $\begin{array}{ll}- & + \\
+ & - \\
- & +\end{array}$ & $\begin{array}{l}- \\
\overline{0}\end{array}$ & $\begin{array}{l}0-0+0 \\
0-0+0 \\
-0-0+0\end{array}$ & $\begin{array}{l}21 \\
21 \\
21\end{array}$ & $\begin{array}{l}5006 \\
5006 \\
5006\end{array}$ & $\begin{array}{l}4255 \\
4255 \\
4255\end{array}$ \\
\hline $\begin{array}{ll}N N & 23815 \\
N N & 23816 \\
N N & 23817\end{array}$ & $\begin{array}{l}+-000 \\
+-000 \\
+00-\end{array}$ & $\begin{array}{l}-+ \\
+\bar{O}\end{array}$ & $\begin{array}{l}-0 \\
-0 \\
-0\end{array}$ & $\begin{array}{l}+ \\
+ \\
-\end{array}$ & $\begin{array}{l}+ \\
- \\
+\end{array}$ & $\begin{array}{l}- \\
+ \\
+\end{array}$ & $\begin{array}{l}+ \\
- \\
+\end{array}$ & $\begin{array}{l}-0 \\
+0 \\
- \\
-\end{array}$ & & $\begin{array}{l}--+00 \\
-\overline{0}+0 \\
\overline{0}+-0\end{array}$ & $\begin{array}{l}21 \\
21 \\
21\end{array}$ & $\begin{array}{l}5054 \\
5054 \\
5054\end{array}$ & $\begin{array}{l}4207 \\
4207 \\
4207\end{array}$ \\
\hline $\begin{array}{ll}\text { NN } & 23818 \\
\text { NN } & 23832 \\
\text { NN } & 23833\end{array}$ & $\begin{array}{l}+O O-\bar{O} \\
+O \bar{O} \\
+O O-\end{array}$ & $\begin{array}{l}0+ \\
-\quad+ \\
-\quad 0\end{array}$ & $\begin{array}{ll}- & + \\
- & - \\
+ & +\end{array}$ & $\begin{array}{l}- \\
+ \\
+\end{array}$ & $\begin{array}{l}0 \\
0 \\
0\end{array}$ & $\begin{array}{l}+ \\
+\end{array}$ & $\begin{array}{l}+ \\
+ \\
0\end{array}$ & $\begin{array}{l}-0 \\
+0 \\
+\quad-\end{array}$ & & $\begin{array}{l}++0-0 \\
--0+0 \\
--+00\end{array}$ & $\begin{array}{l}21 \\
21 \\
21\end{array}$ & $\begin{array}{l}5054 \\
5102 \\
5102\end{array}$ & $\begin{array}{l}4207 \\
4159 \\
4159\end{array}$ \\
\hline $\begin{array}{ll}N N & 23834 \\
N N & 25010 \\
N N & 25195\end{array}$ & 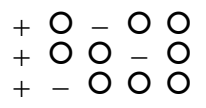 & $\begin{array}{ll}- & + \\
- & + \\
+ & -\end{array}$ & $\begin{array}{ll}+ & - \\
- & + \\
- & 0\end{array}$ & $\begin{array}{l}- \\
- \\
+\end{array}$ & $\begin{array}{l}0 \\
- \\
-\end{array}$ & $\begin{array}{l}- \\
+ \\
+\end{array}$ & $\begin{array}{l}+ \\
+ \\
-\end{array}$ & $\begin{array}{l}+\stackrel{0}{0} \\
0 \\
+\quad+\end{array}$ & & $\begin{array}{l}-0+0-0 \\
0-1+0 \\
00+-0\end{array}$ & $\begin{array}{l}21 \\
21 \\
21\end{array}$ & $\begin{array}{l}5102 \\
5150 \\
5198\end{array}$ & $\begin{array}{l}4159 \\
4111 \\
4063\end{array}$ \\
\hline $\begin{array}{ll}N N & 25196 \\
N N & 26013 \\
N N & 26173\end{array}$ & 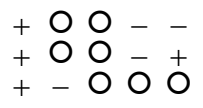 & 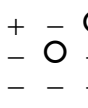 & 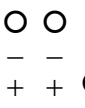 & $\begin{array}{l}+ \\
+ \\
+\end{array}$ & $\begin{array}{l}\bar{O} \\
+\end{array}$ & $\begin{array}{l}+ \\
- \\
+\end{array}$ & $\begin{array}{l}+ \\
+ \\
-\end{array}$ & $\begin{array}{l}-0 \\
0 \\
0 \\
-\end{array}$ & & $\begin{array}{l}++0-0 \\
+-0-0 \\
--O+O\end{array}$ & $\begin{array}{l}21 \\
21 \\
21\end{array}$ & $\begin{array}{l}5198 \\
5246 \\
5294\end{array}$ & $\begin{array}{l}4063 \\
4015 \\
3967\end{array}$ \\
\hline $\begin{array}{ll}\text { NN } & 26174 \\
N N & 26175 \\
N N & 26176\end{array}$ & $\begin{array}{l}+-0-0 \\
+00 \overline{0} \\
+-O\end{array}$ & $\begin{array}{l}0 \\
0 \\
- \\
+\end{array}$ & 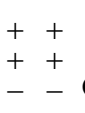 & $\begin{array}{l}+ \\
+ \\
0\end{array}$ & $\begin{array}{l}- \\
- \\
+\end{array}$ & $\begin{array}{l}\bar{O} \\
+\end{array}$ & $\begin{array}{l}\bar{O} \\
+\end{array}$ & $\begin{array}{l}+\quad+ \\
+\quad+ \\
+0\end{array}$ & $\begin{array}{l}0 \\
- \\
-\end{array}$ & $\begin{array}{l}--0+0 \\
--0+0 \\
--0+0\end{array}$ & $\begin{array}{l}21 \\
21 \\
21\end{array}$ & $\begin{array}{l}5294 \\
5294 \\
5294\end{array}$ & $\begin{array}{l}3967 \\
3967 \\
3967\end{array}$ \\
\hline $\begin{array}{ll}N N & 26177 \\
N N & 26178 \\
N N & 26179\end{array}$ & $\begin{array}{l}+0-0- \\
+\bar{O} O \\
+O-O\end{array}$ & $\begin{array}{l}+0 \\
- \\
+\end{array}$ & $\begin{array}{l}-0 \\
+\overline{0}\end{array}$ & $\begin{array}{l}\bar{O} \\
+\end{array}$ & $\begin{array}{l}+ \\
- \\
+\end{array}$ & $\begin{array}{l}+ \\
+ \\
-\end{array}$ & $\begin{array}{l}+ \\
- \\
-\end{array}$ & $\begin{array}{l}+0 \\
+0 \\
+0\end{array}$ & & $\begin{array}{l}--0+0 \\
++0-0 \\
++0-0\end{array}$ & $\begin{array}{l}21 \\
21 \\
21\end{array}$ & $\begin{array}{l}5294 \\
5294 \\
5294\end{array}$ & $\begin{array}{l}3967 \\
3967 \\
3967\end{array}$ \\
\hline $\begin{array}{ll}\text { NN } 26180 \\
\text { NN } 26181 \\
\text { NN } 26182\end{array}$ & $\begin{array}{l}+00-- \\
+O \bar{O}+ \\
+00--\end{array}$ & $\begin{array}{l}+0 \\
-0 \\
+0\end{array}$ & $\begin{array}{l}-\bar{O} \\
-\quad-\end{array}$ & $\begin{array}{l}+ \\
- \\
-\end{array}$ & $\begin{array}{l}+ \\
+ \\
-\end{array}$ & $\begin{array}{l}0 \\
+ \\
0\end{array}$ & $\begin{array}{l}0 \\
\overline{0}\end{array}$ & $\begin{array}{l}+\bar{O} \\
+0 \\
+\quad+\end{array}$ & $\begin{array}{l}+ \\
+\end{array}$ & $\begin{array}{l}++0-0 \\
-+0-0 \\
+-0-0\end{array}$ & $\begin{array}{l}21 \\
21 \\
21\end{array}$ & $\begin{array}{l}5294 \\
5294 \\
5294\end{array}$ & $\begin{array}{l}3967 \\
3967 \\
3967\end{array}$ \\
\hline $\begin{array}{ll}\text { NN } 26570 \\
\text { NN } 26571 \\
\text { NN } 26572\end{array}$ & 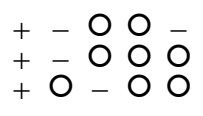 & $\begin{array}{l}0+ \\
-\quad- \\
-\quad+\end{array}$ & $\begin{array}{ll}- & 0 \\
+ & + \\
- & -\end{array}$ & $\begin{array}{l}+ \\
+ \\
+\end{array}$ & $\begin{array}{l}+ \\
+ \\
+\end{array}$ & $\begin{array}{l}+ \\
- \\
+\end{array}$ & $\begin{array}{l}- \\
+ \\
0\end{array}$ & $\begin{array}{l}-0 \\
-\bar{O}\end{array}$ & $\begin{array}{l}+ \\
+ \\
+\end{array}$ & $\begin{array}{l}--0+0 \\
-0+0+0 \\
0--+0\end{array}$ & $\begin{array}{l}21 \\
21 \\
21\end{array}$ & $\begin{array}{l}5390 \\
5390 \\
5390\end{array}$ & $\begin{array}{l}3871 \\
3871 \\
3871\end{array}$ \\
\hline $\begin{array}{ll}\text { NN } 26573 \\
\text { NN } 26574 \\
\text { NN } 26575\end{array}$ & $\begin{array}{l}+0-0- \\
+0-\overline{0} \\
+0-00\end{array}$ & $\begin{array}{ll}- & + \\
+ & 0 \\
- & +\end{array}$ & $\begin{array}{l}0 \\
- \\
- \\
+\end{array}$ & $\begin{array}{l}0 \\
+ \\
-\end{array}$ & $\begin{array}{l}+ \\
+ \\
-\end{array}$ & $\begin{array}{l}0 \\
- \\
+\end{array}$ & $\begin{array}{l}+ \\
0 \\
0\end{array}$ & $\begin{array}{l}-\overline{-} \\
+\bar{O} \\
+\end{array}$ & $\begin{array}{l}- \\
+ \\
+\end{array}$ & $\begin{array}{l}+-+00 \\
\overline{0}-+00 \\
0-+-0\end{array}$ & $\begin{array}{l}21 \\
21 \\
21\end{array}$ & $\begin{array}{l}5390 \\
5390 \\
5390\end{array}$ & $\begin{array}{l}3871 \\
3871 \\
3871\end{array}$ \\
\hline $\begin{array}{ll}N N & 26576 \\
N N & 26577 \\
N N & 26578\end{array}$ & $\begin{array}{l}+0-00 \\
+0-0-0 \\
+00--\end{array}$ & $\begin{array}{l}+\bar{O} \\
+0 \\
+-\end{array}$ & $\begin{array}{l}\bar{O}- \\
O_{+}^{+}\end{array}$ & - & $\begin{array}{l}+ \\
\bar{O}\end{array}$ & $\begin{array}{l}- \\
+ \\
+\end{array}$ & $\begin{array}{l}0 \\
\bar{O}\end{array}$ & $\begin{array}{l}+0 \\
+0 \\
+\quad-\end{array}$ & $\begin{array}{l}+ \\
- \\
-\end{array}$ & $\begin{array}{l}0-+1-0 \\
++0-0 \\
++0-0\end{array}$ & $\begin{array}{l}21 \\
21 \\
21\end{array}$ & $\begin{array}{l}5390 \\
5390 \\
5390\end{array}$ & $\begin{array}{l}3871 \\
3871 \\
3871\end{array}$ \\
\hline $\begin{array}{ll}N N & 26579 \\
N N & 26580 \\
N N & 27962\end{array}$ & 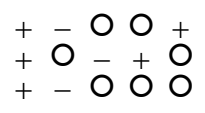 & $\begin{array}{l}0 \overline{0} \\
-\quad+\end{array}$ & $\begin{array}{ll}- & 0 \\
0 & - \\
- & +\end{array}$ & $\begin{array}{l}+ \\
- \\
-\end{array}$ & $\begin{array}{l}- \\
- \\
+\end{array}$ & $\stackrel{-}{+}$ & $\begin{array}{l}+ \\
+ \\
0\end{array}$ & $\begin{array}{l}+0 \\
+0 \\
+\quad+\end{array}$ & $\begin{array}{l}+ \\
+ \\
-\end{array}$ & $\begin{array}{l}-+0-0 \\
+-0-0 \\
--0+0\end{array}$ & $\begin{array}{l}21 \\
21 \\
21\end{array}$ & $\begin{array}{l}5390 \\
5390 \\
5438\end{array}$ & $\begin{array}{l}3871 \\
3871 \\
3823\end{array}$ \\
\hline $\begin{array}{ll}N N & 27963 \\
N N & 27964 \\
N N & 27965\end{array}$ & $\begin{array}{l}+-00 \\
+ \\
+\end{array}$ & $\begin{array}{l}-0 \\
-\quad+ \\
-\quad+\end{array}$ & $\begin{array}{l}-0 \\
+\bar{O}\end{array}$ & $\begin{array}{l}- \\
\bar{O}\end{array}$ & $\begin{array}{l}+ \\
+ \\
+\end{array}$ & $\begin{array}{l}+ \\
+ \\
-\end{array}$ & $\begin{array}{l}0 \\
0 \\
0\end{array}$ & $\begin{array}{ll}+ & + \\
- & + \\
- & +\end{array}$ & - & $\begin{array}{l}--+00 \\
++0-0 \\
++0-0\end{array}$ & $\begin{array}{l}21 \\
21 \\
21\end{array}$ & $\begin{array}{l}5438 \\
5438 \\
5438\end{array}$ & $\begin{array}{l}3823 \\
3823 \\
3823\end{array}$ \\
\hline $\begin{array}{ll}N N & 27966 \\
N N & 27988 \\
N N & 27989\end{array}$ & 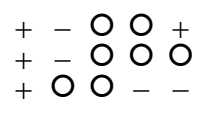 & $\begin{array}{l}-0 \\
+- \\
+-\end{array}$ & $\begin{array}{l}0 \\
- \\
+\end{array}$ & - & $\begin{array}{l}+ \\
0 \\
0\end{array}$ & $\begin{array}{l}+ \\
+ \\
+\end{array}$ & $\begin{array}{l}+ \\
- \\
+\end{array}$ & $\begin{array}{l}-0 \\
+0 \\
- \\
-\end{array}$ & $t$ & $\begin{array}{l}++0-0 \\
-0+0-0 \\
-+0-0\end{array}$ & $\begin{array}{l}21 \\
21 \\
21\end{array}$ & $\begin{array}{l}5438 \\
5486 \\
5486\end{array}$ & $\begin{array}{l}3823 \\
3775 \\
3775\end{array}$ \\
\hline $\begin{array}{ll}N N & 27990 \\
N N & 28855 \\
N N & 28856\end{array}$ & $\begin{array}{l}+0-0+ \\
+-0-0 \\
+0-+0\end{array}$ & $\begin{array}{l}-0 \\
+0 \\
-0\end{array}$ & $\begin{array}{ll}- & - \\
& + \\
- & 0\end{array}$ & - & $\begin{array}{l}0 \\
+ \\
+\end{array}$ & $\begin{array}{l}- \\
-\end{array}$ & $\begin{array}{l}0 \\
0 \\
+\end{array}$ & $\begin{array}{l}-+ \\
\overline{0}+ \\
+\end{array}$ & $\begin{array}{l}- \\
+\end{array}$ & $\begin{array}{l}-+0-0 \\
++-00 \\
+-0-0\end{array}$ & $\begin{array}{l}21 \\
21 \\
21\end{array}$ & $\begin{array}{l}5486 \\
5534 \\
5534\end{array}$ & $\begin{array}{l}3775 \\
3727 \\
3727\end{array}$ \\
\hline
\end{tabular}

Continued 
Continued

\begin{tabular}{|c|c|c|c|c|c|c|c|c|c|c|c|c|c|c|c|}
\hline $\begin{array}{ll}N N & 28971 \\
N N & 28972 \\
N N & 28973\end{array}$ & $\begin{array}{l}+-\overline{0} \\
+-00 \\
+-00\end{array}$ & $\begin{array}{l}000+ \\
-0-+ \\
-0++\end{array}$ & $\begin{array}{l}+ \\
+ \\
-\end{array}$ & $\begin{array}{l}\overline{0} \\
0\end{array}$ & $\begin{array}{l}+\bar{O} \\
+0 \\
+0\end{array}$ & & $\begin{array}{l}0 \\
- \\
+\end{array}$ & $\begin{array}{l}- \\
-\end{array}$ & $\begin{array}{l}+ \\
+ \\
-\end{array}$ & $\begin{array}{l}-0 \\
-0 \\
-0\end{array}$ & & $\begin{array}{l}+0 \\
+0 \\
+0\end{array}$ & 21 & $\begin{array}{l}5582 \\
5582 \\
5582\end{array}$ & $\begin{array}{l}3679 \\
3679 \\
3679\end{array}$ \\
\hline $\begin{array}{ll}N N & 28974 \\
N N & 28975 \\
N N & 28976\end{array}$ & $\begin{array}{l}+00- \\
+\bar{O} 0 \\
+00-\end{array}$ & $\begin{array}{l}-\bar{O}+ \\
+0 \bar{O}- \\
+-0-\end{array}$ & $\begin{array}{l}+ \\
- \\
-\end{array}$ & & $\begin{array}{l}+0 \\
+0 \\
+0\end{array}$ & & $\begin{array}{l}0 \\
\bar{O}\end{array}$ & 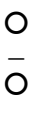 & $\begin{array}{l}+ \\
+ \\
+\end{array}$ & $\begin{array}{l}- \\
+\bar{O} \\
+-\end{array}$ & & $\begin{array}{l}+0 \\
+0 \\
-0\end{array}$ & 21 & $\begin{array}{l}5582 \\
5582 \\
5582\end{array}$ & $\begin{array}{l}367 \\
367 \\
367\end{array}$ \\
\hline $\begin{array}{ll}N N & 29336 \\
N N & 29337 \\
N N & 29338\end{array}$ & $\begin{array}{l}+-0 \\
+-O \\
+-O \\
+-O\end{array}$ & $\begin{array}{l}0+00 \\
-+0- \\
-+0-\end{array}$ & $\begin{array}{l}- \\
+ \\
0\end{array}$ & & $\begin{array}{ll}- & + \\
+ & 0 \\
- & +\end{array}$ & & $\stackrel{+}{0}$ & $\begin{array}{l}+ \\
- \\
+\end{array}$ & $\begin{array}{l}- \\
- \\
-\end{array}$ & $\begin{array}{l}-0 \\
-0 \\
0-\end{array}$ & & $\begin{array}{l}+0 \\
+0 \\
+0\end{array}$ & 1 & $\begin{array}{l}5678 \\
5678 \\
5678\end{array}$ & $\begin{array}{l}358 \\
358 \\
358\end{array}$ \\
\hline $\begin{array}{ll}\text { NN } & 29339 \\
N N & 29340 \\
N N & 29341\end{array}$ & $\begin{array}{l}+-0- \\
+-O \overline{0} \\
+-O\end{array}$ & $\begin{array}{l}\mathrm{O}+\mathrm{O}+ \\
\mathrm{O}+\mathrm{O}+ \\
-+\mathrm{O}+\end{array}$ & $\begin{array}{l}- \\
\overline{0}\end{array}$ & 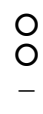 & $\begin{array}{ll}- & + \\
+ & - \\
- & +\end{array}$ & & $\begin{array}{l}- \\
+ \\
0\end{array}$ & $\begin{array}{l}+ \\
- \\
+\end{array}$ & & $\begin{array}{l}- \\
+ \\
+ \\
0\end{array}$ & & $\begin{array}{l}00 \\
0 \\
0 \\
-0\end{array}$ & 21 & $\begin{array}{l}5678 \\
5678 \\
5678\end{array}$ & $\begin{array}{l}358 \\
358\end{array}$ \\
\hline $\begin{array}{ll}\text { NN } & 29342 \\
\text { NN } & 29343 \\
\text { NN } & 29344\end{array}$ & $\begin{array}{l}+-00 \\
+0-0 \\
+0-O\end{array}$ & $\begin{array}{l}+-O- \\
-+O \\
+- \\
+\end{array}$ & $\begin{array}{l}0 \\
- \\
-\end{array}$ & 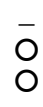 & $\begin{array}{ll}+ & - \\
- & + \\
+ & -\end{array}$ & & $\begin{array}{l}0 \\
0 \\
0\end{array}$ & $\begin{array}{l}+ \\
+\end{array}$ & $\begin{array}{l}\bar{O} \\
0\end{array}$ & $\begin{array}{l}0+ \\
-\quad+ \\
-\quad+\end{array}$ & & $\begin{array}{r}0 \\
-0\end{array}$ & 1 & $\begin{array}{l}5678 \\
5678 \\
5678\end{array}$ & $\begin{array}{l}358 \\
358\end{array}$ \\
\hline $\begin{array}{ll}N N & 29345 \\
N N & 29346 \\
N N & 29347\end{array}$ & $\begin{array}{l}+-00 \\
+0-+ \\
+0-+\end{array}$ & $\begin{array}{l}\overline{0}+0+ \\
0-0 \\
0-0-\end{array}$ & $\overline{0}$ & - & $\begin{array}{l}+0 \\
\bar{O}-\end{array}$ & & $\begin{array}{l}+ \\
+ \\
+\end{array}$ & $\begin{array}{l}- \\
+ \\
+\end{array}$ & $\begin{array}{l}+ \\
+ \\
+\end{array}$ & $\begin{array}{l}+0 \\
-0 \\
-0\end{array}$ & & $\begin{array}{r}0 \\
-0\end{array}$ & 1 & $\begin{array}{l}5678 \\
5678 \\
5678\end{array}$ & $\begin{array}{l}358 \\
358\end{array}$ \\
\hline $\begin{array}{ll}\text { NN } & 29605 \\
N N & 29606 \\
N N & 29607\end{array}$ & $\begin{array}{l}+-0 \\
+-00 \\
+-00\end{array}$ & $\begin{array}{l}00+- \\
0-+1- \\
+-0-\end{array}$ & $\begin{array}{l}+ \\
+ \\
0\end{array}$ & $\begin{array}{l}+ \\
+ \\
+\end{array}$ & $\begin{array}{l}+0 \\
+0 \\
++\end{array}$ & & + & ? & $\begin{array}{l}+ \\
+ \\
0\end{array}$ & 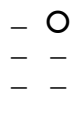 & & $\begin{array}{l}+0 \\
+0 \\
+0\end{array}$ & 1 & $\begin{array}{l}5726 \\
5726 \\
5726\end{array}$ & $\begin{array}{l}353 \\
353\end{array}$ \\
\hline $\begin{array}{ll}\text { NN } & 29608 \\
N N & 29609 \\
N N & 29610\end{array}$ & 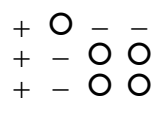 & $\begin{array}{l}00+- \\
0+-\overline{0} \\
+--0\end{array}$ & $\begin{array}{l}+ \\
+ \\
0\end{array}$ & $\begin{array}{l}+ \\
+\end{array}$ & 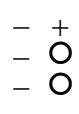 & & + & - & $\begin{array}{l}0 \\
+ \\
+\end{array}$ & $\begin{array}{l}+ \\
- \\
- \\
+\end{array}$ & & $\begin{array}{l}-0 \\
-0 \\
-0\end{array}$ & & $\begin{array}{r}5726 \\
5726 \\
5726\end{array}$ & 353 \\
\hline $\begin{array}{ll}\text { NN } & 29611 \\
\text { NN } & 29612 \\
\text { NN } & 29982\end{array}$ & $\begin{array}{l}+0-\bar{O} \\
+-0 \\
+-O\end{array}$ & 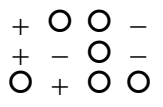 & $\begin{array}{l}0 \\
+ \\
+\end{array}$ & $\stackrel{+}{0}$ & $\begin{array}{l}-0 \\
0+ \\
+\quad+\end{array}$ & & $\overline{\mathrm{O}}$ & $\begin{array}{l}- \\
+\end{array}$ & $\begin{array}{l}+ \\
+ \\
-\end{array}$ & $\begin{array}{l}+0 \\
+0 \\
0\end{array}$ & & $\begin{array}{l}-0 \\
-0 \\
+0\end{array}$ & 2 & $\begin{array}{l}5726 \\
5726 \\
5774\end{array}$ & $\begin{array}{l}353 \\
348\end{array}$ \\
\hline $\begin{array}{ll}N N & 29983 \\
N N & 29984 \\
\text { NN } & 30295\end{array}$ & $\begin{array}{l}+00- \\
+O O O- \\
+-O\end{array}$ & $\begin{array}{l}-\bar{t}+ \\
\bar{O}+\dot{0} \bar{O}\end{array}$ & $\begin{array}{l}0 \\
0 \\
-\end{array}$ & $\begin{array}{l}+ \\
- \\
+\end{array}$ & $\begin{array}{ll}0 & 0 \\
0 & 0 \\
- & +\end{array}$ & & + & $\begin{array}{l}+ \\
+ \\
0\end{array}$ & $\begin{array}{l}0 \\
\text { O } \\
0\end{array}$ & $\begin{array}{ll}- & - \\
+ & - \\
- & +\end{array}$ & & $\begin{array}{l}+0 \\
-0 \\
-0\end{array}$ & & $\begin{array}{l}5774 \\
5774 \\
5822\end{array}$ & $\begin{array}{l}348 \\
348 \\
343\end{array}$ \\
\hline $\begin{array}{ll}N N & 30634 \\
N N & 30635 \\
N N & 30636\end{array}$ & $\begin{array}{l}+-0- \\
+-0 \overline{0} \\
+-O\end{array}$ & $\begin{array}{l}O+O- \\
O+O+ \\
-+-+\end{array}$ & $\begin{array}{l}+ \\
\overline{0}\end{array}$ & + & $\begin{array}{l}\text { O - } \\
\text { O + } \\
-+\end{array}$ & & $\begin{array}{l}- \\
+ \\
+\end{array}$ & $\begin{array}{l}+ \\
- \\
-\end{array}$ & $\begin{array}{l}- \\
- \\
-\end{array}$ & $\begin{array}{l}-0 \\
-0 \\
-0\end{array}$ & & $\begin{array}{l}+0 \\
+0 \\
+0\end{array}$ & & $\begin{array}{l}5870 \\
5870 \\
5870\end{array}$ & $\begin{array}{l}339 \\
339 \\
339\end{array}$ \\
\hline $\begin{array}{ll}\text { NN } & 30637 \\
\text { NN } & 30638 \\
\text { NN } & 30639\end{array}$ & $\begin{array}{l}+-O \bar{O} \\
+-O \\
+-O O\end{array}$ & $\begin{array}{l}+000 \\
+-O \\
-+0-\end{array}$ & $\begin{array}{l}- \\
- \\
+\end{array}$ & $\overline{0}$ & $\begin{array}{l}+0 \\
+0 \\
-\end{array}$ & & $\begin{array}{l}+ \\
+ \\
0\end{array}$ & + & & $\begin{array}{l}-0 \\
\mathrm{O}\end{array}$ & & $\begin{array}{l}+0 \\
+0 \\
+0\end{array}$ & & $\begin{array}{l}5870 \\
5870 \\
5870\end{array}$ & $\begin{array}{l}339 \\
339 \\
339\end{array}$ \\
\hline $\begin{array}{ll}N N & 30640 \\
N N & 30641 \\
\text { NN } & 30642\end{array}$ & $\begin{array}{l}+-00 \\
+-0- \\
+-0+\end{array}$ & 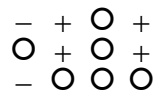 & $\begin{array}{l}- \\
- \\
-\end{array}$ & + & $\begin{array}{l}+0 \\
+0 \\
+0\end{array}$ & & $\begin{array}{l}- \\
-\end{array}$ & $\begin{array}{l}+ \\
-\end{array}$ & $\begin{array}{l}+ \\
+ \\
+\end{array}$ & $\begin{array}{l}0+ \\
+0 \\
+0\end{array}$ & & $-c$ & & $\begin{array}{l}5870 \\
5870 \\
5870\end{array}$ & $\begin{array}{l}339 \\
339 \\
339\end{array}$ \\
\hline $\begin{array}{l}N N 30643 \\
N N 30918 \\
N N \quad 30980\end{array}$ & $\begin{array}{l}+-00 \\
+-0- \\
+0--\end{array}$ & 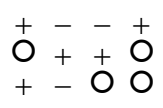 & $\begin{array}{l}0 \\
0 \\
0\end{array}$ & $\begin{array}{l}0 \\
\overline{0}\end{array}$ & $\begin{array}{l}\overline{0}+ \\
++\end{array}$ & & $\begin{array}{l}+ \\
+\end{array}$ & + & $\begin{array}{l}- \\
+ \\
-\end{array}$ & $\begin{array}{l}+0 \\
+0 \\
-0\end{array}$ & & $\begin{array}{l}-0 \\
-0 \\
+0\end{array}$ & & $\begin{array}{l}5870 \\
5918 \\
5966\end{array}$ & $\begin{array}{l}339 \\
334 \\
329\end{array}$ \\
\hline $\begin{array}{ll}N N & 30981 \\
N N & 30982 \\
N N & 30983\end{array}$ & $\begin{array}{l}+0-0 \\
+\bar{O} 0 \\
+0-0\end{array}$ & 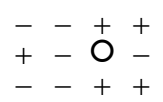 & $\begin{array}{l}0 \\
\bar{O}\end{array}$ & 0 & $\begin{array}{l}-0 \\
+\quad+ \\
-0\end{array}$ & & $\begin{array}{l}+ \\
- \\
-\end{array}$ & - & $\begin{array}{l}0 \\
0 \\
0\end{array}$ & $\begin{array}{ll}- & - \\
- & - \\
+ & +\end{array}$ & & $\begin{array}{l}+0 \\
+0 \\
-0\end{array}$ & & $\begin{array}{l}5966 \\
5966 \\
5966\end{array}$ & $\begin{array}{l}329 \\
329 \\
329\end{array}$ \\
\hline
\end{tabular}

Continued 
Continued

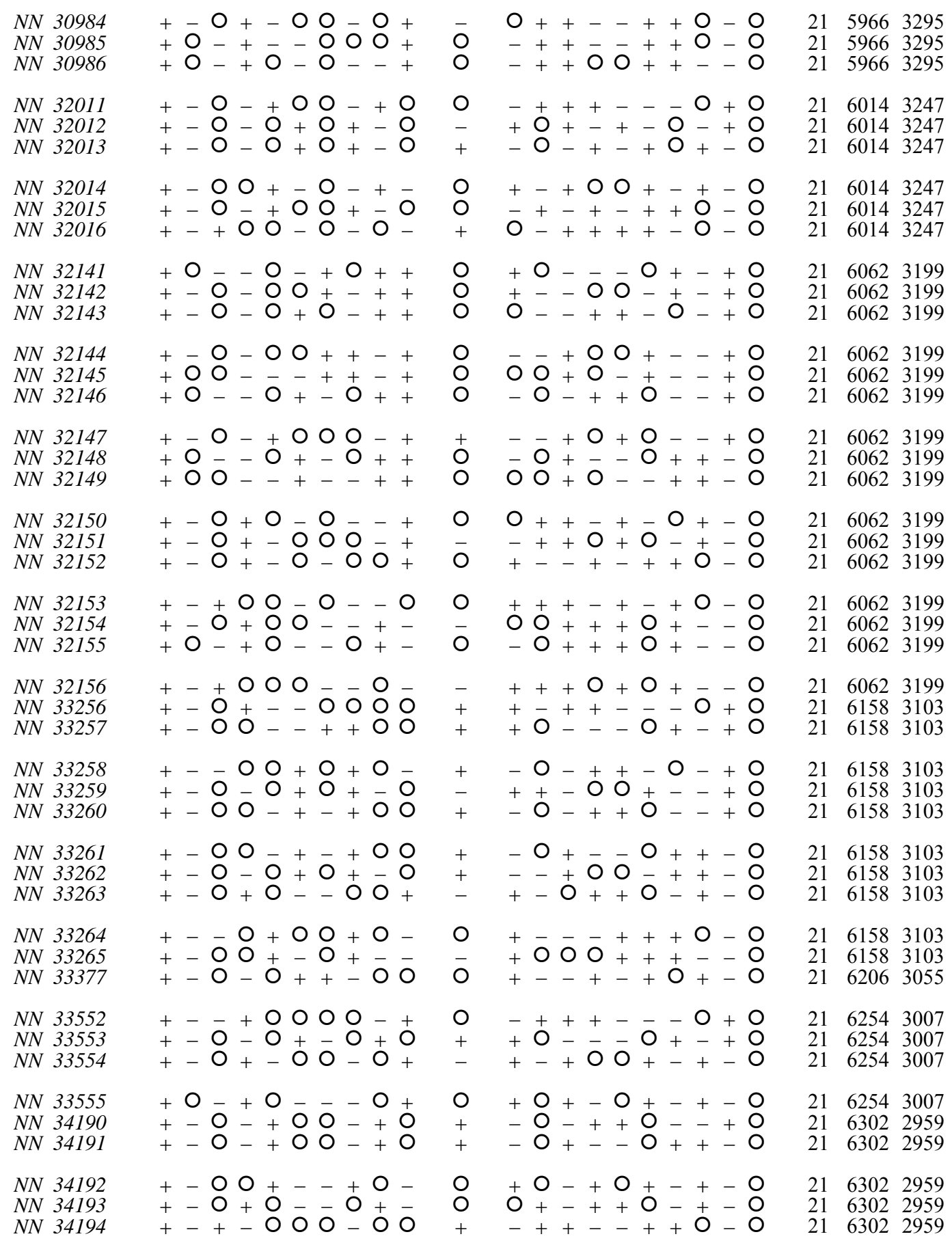

Continued 
Continued

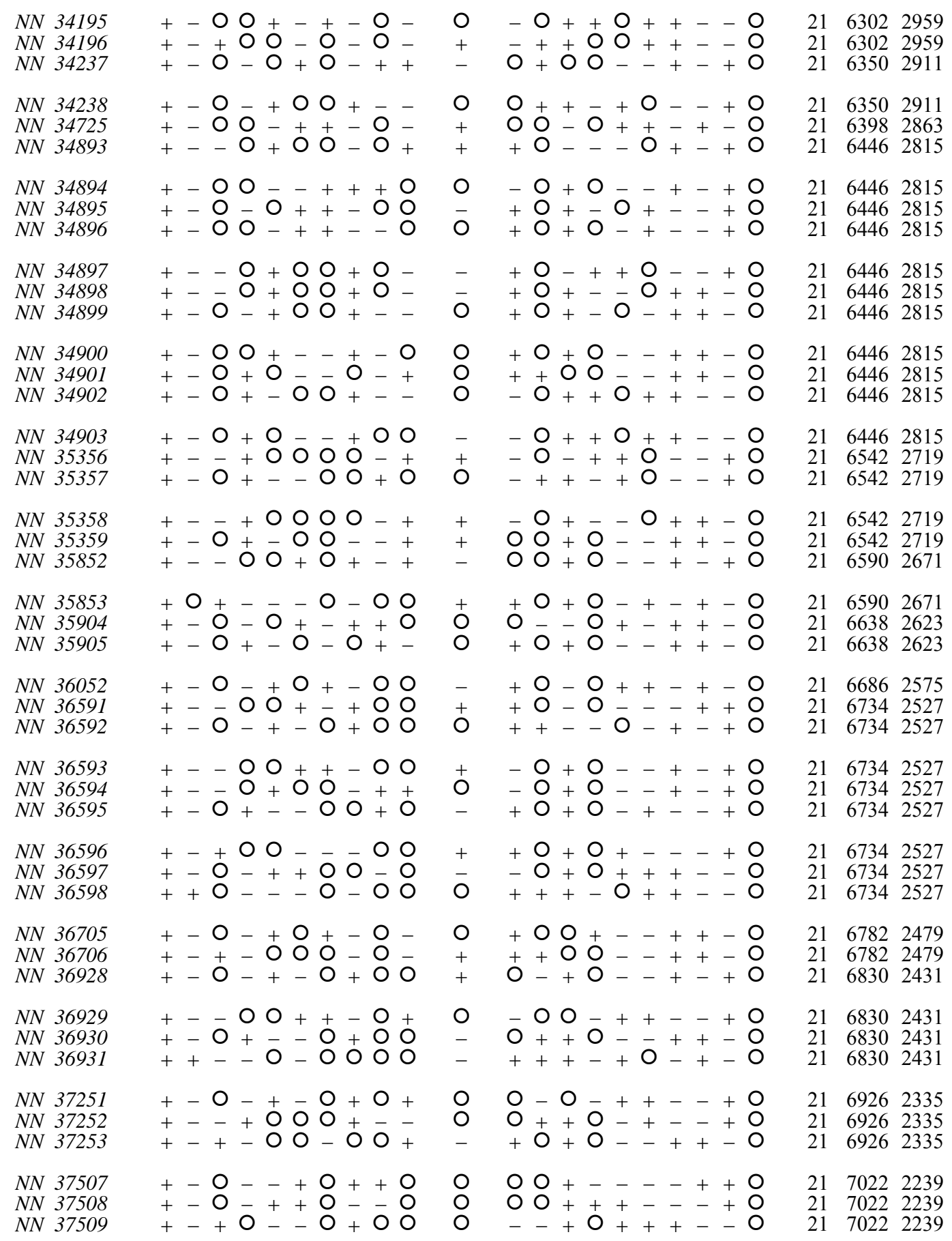

Continued 
Continued

$$
\begin{aligned}
& N N 37726+--+O \mathrm{O}+-\mathrm{O} O \mathrm{O}-++\mathrm{O}++-+-\mathrm{O} \quad 2170702191 \\
& \text { NN } 37727++--\mathrm{O}-\mathrm{O} \mathrm{O} \mathrm{O}-++\mathrm{O}++\mathrm{O}-+++-\mathrm{O} \quad 2170702191
\end{aligned}
$$

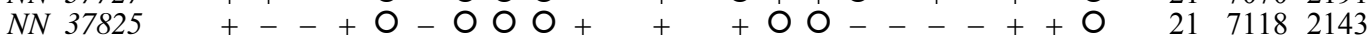

$$
\begin{aligned}
& \text { NN } 38081+-+\mathrm{O}-\overline{\mathrm{O}}+\mathrm{O}-\mathrm{O} \quad \mathrm{O} \mathrm{O}++-+++-\mathrm{O} \quad 2171662095 \\
& \text { NN } 38156+++--\mathrm{O} O \mathrm{O} \mathrm{O}+\mathrm{O}++-\mathrm{O}-\mathrm{O}_{+}+\mathrm{O}_{+} \mathrm{O} \quad 2172142047 \\
& \text { NN } 38260+-+-\mathrm{O}-\mathrm{O}+\mathrm{O} \mathrm{O} \mathrm{O}-+\mathrm{O}-++-+ \text { - O } 21272621999 \\
& N N 38393+--+\mathrm{O}-\mathrm{O}+\mathrm{O} \mathrm{O}+\mathrm{O} \mathrm{O}-+--+-+\mathrm{O} \quad 2173101951
\end{aligned}
$$

\begin{tabular}{|c|c|c|c|c|c|}
\hline Ref. & $\mathrm{Se}$ & nce & $n$ & $\zeta_{ \pm}$ & $\zeta_{0}$ \\
\hline $\begin{array}{ll}\text { SS } & 4 \\
\text { SS } & 150 \\
\text { SS } & 151\end{array}$ & 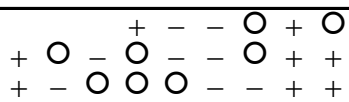 & 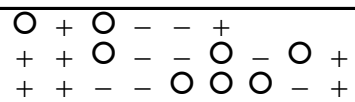 & $\begin{array}{l}12 \\
18 \\
18\end{array}$ & $\begin{array}{l}1568 \\
3600 \\
3600\end{array}$ & $\begin{array}{r}160 \\
2232 \\
2232\end{array}$ \\
\hline $\begin{array}{ll}\text { SS } & 159 \\
\text { SS } & 167 \\
\text { SS } & 175\end{array}$ & 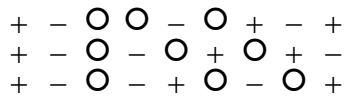 & $\begin{array}{l}+-+0-000-+ \\
-+0+0-0)+ \\
+0-0+-0-+\end{array}$ & $\begin{array}{l}18 \\
18 \\
18\end{array}$ & $\begin{array}{l}3792 \\
4176 \\
4464\end{array}$ & $\begin{array}{l}2040 \\
1656 \\
1368\end{array}$ \\
\hline $\begin{array}{ll}\text { SS } & 192 \\
\text { SS } & 193 \\
\text { SS } & 208\end{array}$ & $\begin{array}{l}+-0-\overline{0}+00 \\
+--0+0+0 \overline{0} \\
+--+00-+0\end{array}$ & $\begin{array}{l}00+-\bar{O}++ \\
\bar{O}+0+0--+ \\
0+-0+0+-+\end{array}$ & $\begin{array}{l}18 \\
18 \\
18\end{array}$ & $\begin{array}{l}4752 \\
4752 \\
5040\end{array}$ & $\begin{array}{r}1080 \\
1080 \\
792\end{array}$ \\
\hline SS 209 & $+--0++-00$ & $\mathrm{O} O{ }_{-}++\mathrm{O}_{-}-+$ & 18 & 5040 & 792 \\
\hline
\end{tabular}

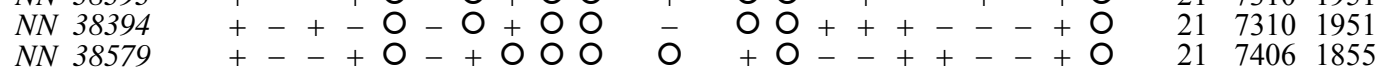

$$
\begin{aligned}
& \text { NN } 38580+--+\mathrm{O}+-\mathrm{O} O \mathrm{O} \quad \mathrm{O}-\mathrm{O}+-++-+-\mathrm{O} \quad 2174061855
\end{aligned}
$$

Concluded

(e) 
Table 8 - Fully uncoupled EILs, with $\pi / 4$ isotropy, for 7 through 21 ply laminates corresponding to prefix

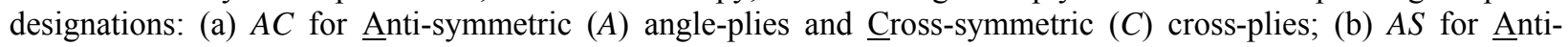
symmetric $(A)$ angle-plies and Symmetric $(S)$ cross-plies; (c) $N N$ for Non-symmetric $(N)$ angle-plies and Nonsymmetric $(N)$ cross-plies; (d) $S C$ for Symmetric $(S)$ angle-plies and Cross-symmetric $(C)$ cross-plies and; (e) $S S$ for Symmetric $(S)$ angle-plies and Symmetric $(S)$ cross-plies. For all sequences, $n_{ \pm}=8, n_{\circ}=n_{\bullet}=4$, and $\zeta=n^{3}=4096$.

(a)

\begin{tabular}{|c|c|c|c|c|c|c|}
\hline Ref. & \multicolumn{2}{|c|}{ Sequence } & $n$ & $\zeta_{ \pm}$ & $\zeta_{0}$ & $\zeta_{\bullet}$ \\
\hline $\begin{array}{l}A C 25 \\
A C 26 \\
A C 27\end{array}$ & 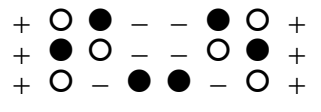 & $\begin{array}{l}-00++00- \\
-00++00- \\
-0+00+0-\end{array}$ & $\begin{array}{l}16 \\
16 \\
16\end{array}$ & $\begin{array}{l}2144 \\
2144 \\
2240\end{array}$ & $\begin{array}{l}976 \\
976 \\
928\end{array}$ & $\begin{array}{l}976 \\
976 \\
928\end{array}$ \\
\hline $\begin{array}{l}A C 28 \\
A C \quad 29 \\
A C \quad 30\end{array}$ & 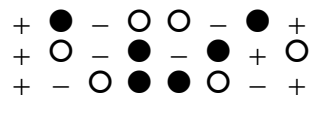 & $\begin{array}{l}-0+\bullet \bullet+0- \\
-00+0+0- \\
-+0000+-\end{array}$ & $\begin{array}{l}16 \\
16 \\
16\end{array}$ & $\begin{array}{l}2240 \\
2432 \\
2432\end{array}$ & $\begin{array}{l}928 \\
832 \\
832\end{array}$ & $\begin{array}{l}928 \\
832 \\
832\end{array}$ \\
\hline $\begin{array}{ll}A C & 31 \\
A C & 32 \\
A C & 33\end{array}$ & 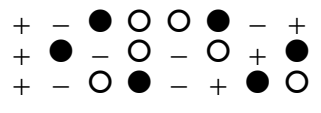 & 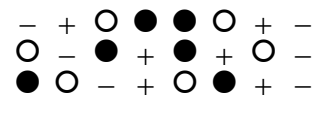 & $\begin{array}{l}16 \\
16 \\
16\end{array}$ & $\begin{array}{l}2432 \\
2432 \\
2816\end{array}$ & $\begin{array}{l}832 \\
832 \\
640\end{array}$ & $\begin{array}{l}832 \\
832 \\
640\end{array}$ \\
\hline $\begin{array}{l}A C 34 \\
A C \quad 35 \\
A C \quad 36 \\
\end{array}$ & 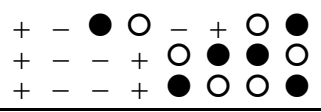 & 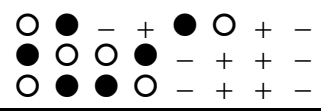 & $\begin{array}{l}16 \\
16 \\
16 \\
\end{array}$ & $\begin{array}{l}2816 \\
3584 \\
3584 \\
\end{array}$ & $\begin{array}{l}640 \\
256 \\
256\end{array}$ & $\begin{array}{l}640 \\
256 \\
256 \\
\end{array}$ \\
\hline
\end{tabular}


(b)

\begin{tabular}{|c|c|c|c|c|c|c|}
\hline Ref. & \multicolumn{2}{|c|}{ Sequence } & $n$ & $\zeta_{ \pm}$ & $\zeta_{0}$ & $\zeta_{\bullet}$ \\
\hline $\begin{array}{ll}\text { AS } & 512 \\
\text { AS } & 514 \\
\text { AS } & 516\end{array}$ & 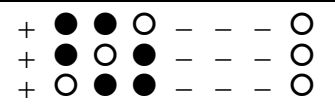 & 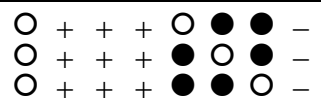 & $\begin{array}{l}16 \\
16 \\
16\end{array}$ & $\begin{array}{l}1856 \\
1856 \\
1856\end{array}$ & $\begin{array}{c}496 \\
736 \\
1024\end{array}$ & $\begin{array}{l}1744 \\
1504 \\
1216\end{array}$ \\
\hline $\begin{array}{ll}\text { AS } & 517 \\
\text { AS } & 519 \\
\text { AS } & 521\end{array}$ & $\begin{array}{l}+\bullet 0 \bigcirc---\bullet \\
+\circ 00---\bullet \\
+\circ 00---\bullet\end{array}$ & 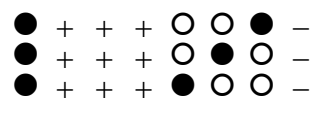 & $\begin{array}{l}16 \\
16 \\
16\end{array}$ & $\begin{array}{l}1856 \\
1856 \\
1856\end{array}$ & $\begin{array}{l}1216 \\
1504 \\
1744\end{array}$ & $\begin{array}{l}1024 \\
736 \\
496\end{array}$ \\
\hline $\begin{array}{ll}\text { AS } & 528 \\
\text { AS } & 530 \\
\text { AS } & 532\end{array}$ & $\begin{array}{l}+\bullet \bullet-0-0- \\
+\bullet 0-8-0- \\
+\bullet 0-0-0-\end{array}$ & $\begin{array}{l}+0+0+0 \bullet- \\
+0+0+0:- \\
+0+0+O \bullet-\end{array}$ & $\begin{array}{l}16 \\
16 \\
16\end{array}$ & $\begin{array}{l}2000 \\
2000 \\
2000\end{array}$ & $\begin{array}{c}352 \\
784 \\
1024\end{array}$ & $\begin{array}{l}1744 \\
1312 \\
1072\end{array}$ \\
\hline $\begin{array}{ll}\text { AS } & 533 \\
\text { AS } & 535 \\
\text { AS } & 537\end{array}$ & $\begin{array}{l}+\circ:-8-0- \\
+00-0-0- \\
+00-0-0-\end{array}$ & 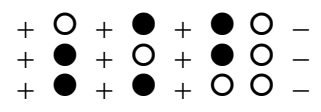 & $\begin{array}{l}16 \\
16 \\
16\end{array}$ & $\begin{array}{l}2000 \\
2000 \\
2000\end{array}$ & $\begin{array}{l}1072 \\
1312 \\
1744\end{array}$ & $\begin{array}{l}1024 \\
784 \\
352\end{array}$ \\
\hline $\begin{array}{ll}\text { AS } & 546 \\
\text { AS } & 548 \\
\text { AS } & 550\end{array}$ & 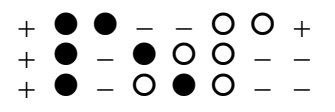 & 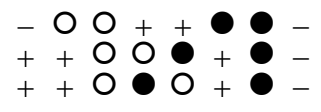 & $\begin{array}{l}16 \\
16 \\
16\end{array}$ & $\begin{array}{l}2144 \\
2144 \\
2144\end{array}$ & $\begin{array}{l}208 \\
448 \\
640\end{array}$ & $\begin{array}{l}1744 \\
1504 \\
1312\end{array}$ \\
\hline $\begin{array}{ll}\text { AS } & 552 \\
\text { AS } & 553 \\
\text { AS } & 554\end{array}$ & 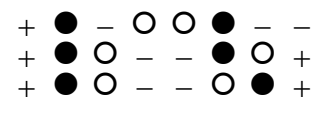 & 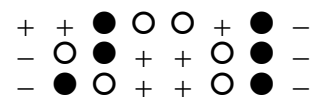 & $\begin{array}{l}16 \\
16 \\
16\end{array}$ & $\begin{array}{l}2144 \\
2144 \\
2144\end{array}$ & $\begin{array}{l}784 \\
784 \\
880\end{array}$ & $\begin{array}{l}1168 \\
1168 \\
1072\end{array}$ \\
\hline $\begin{array}{ll}\text { AS } & 559 \\
\text { AS } & 560 \\
\text { AS } & 561\end{array}$ & 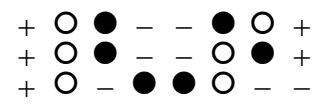 & 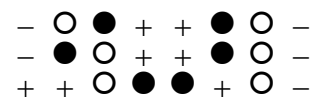 & $\begin{array}{l}16 \\
16 \\
16\end{array}$ & $\begin{array}{l}2144 \\
2144 \\
2144\end{array}$ & $\begin{array}{l}1072 \\
1168 \\
1168\end{array}$ & $\begin{array}{l}880 \\
784 \\
784\end{array}$ \\
\hline $\begin{array}{ll}\text { AS } & 563 \\
\text { AS } & 565 \\
\text { AS } & 567\end{array}$ & 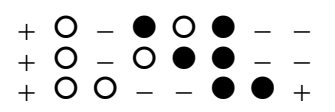 & 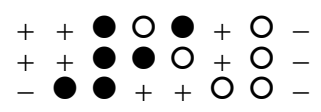 & $\begin{array}{l}16 \\
16 \\
16\end{array}$ & $\begin{array}{l}2144 \\
2144 \\
2144\end{array}$ & $\begin{array}{l}1312 \\
1504 \\
1744\end{array}$ & $\begin{array}{l}640 \\
448 \\
208\end{array}$ \\
\hline $\begin{array}{ll}\text { AS } & 576 \\
\text { AS } & 578 \\
\text { AS } & 579\end{array}$ & $\begin{array}{l}+:-00-0+ \\
+:-00-0+ \\
+\bullet-00-0+\end{array}$ & $\begin{array}{l}-0+00+\bullet- \\
-0+00+0- \\
-0+00+0-\end{array}$ & $\begin{array}{l}16 \\
16 \\
16\end{array}$ & $\begin{array}{l}2240 \\
2240 \\
2240\end{array}$ & $\begin{array}{l}352 \\
544 \\
784\end{array}$ & $\begin{array}{l}1504 \\
1312 \\
1072\end{array}$ \\
\hline $\begin{array}{ll}\text { AS } & 582 \\
\text { AS } & 583 \\
\text { AS } & 585\end{array}$ & $\begin{array}{l}+0-0 \bullet-0+ \\
+0=00-0+ \\
+0-0 \bullet-0+\end{array}$ & 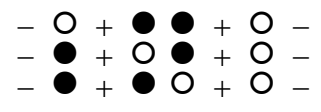 & $\begin{array}{l}16 \\
16 \\
16\end{array}$ & $\begin{array}{l}2240 \\
2240 \\
2240\end{array}$ & $\begin{array}{l}1072 \\
1312 \\
1504\end{array}$ & $\begin{array}{l}784 \\
544 \\
352\end{array}$ \\
\hline $\begin{array}{ll}\text { AS } & 598 \\
\text { AS } & 600 \\
\text { AS } & 603\end{array}$ & 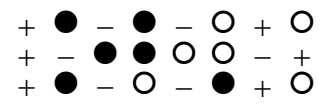 & 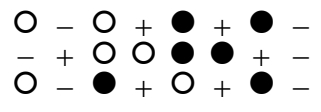 & $\begin{array}{l}16 \\
16 \\
16\end{array}$ & $\begin{array}{l}2432 \\
2432 \\
2432\end{array}$ & $\begin{array}{l}160 \\
448 \\
496\end{array}$ & $\begin{array}{l}1504 \\
1216 \\
1168\end{array}$ \\
\hline $\begin{array}{ll}\text { AS } & 604 \\
\text { AS } & 605 \\
\text { AS } & 608\end{array}$ & 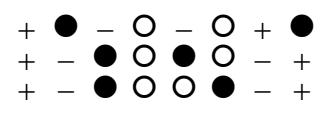 & 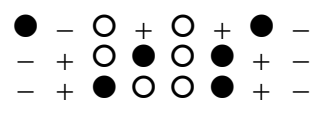 & $\begin{array}{l}16 \\
16 \\
16\end{array}$ & $\begin{array}{l}2432 \\
2432 \\
2432\end{array}$ & $\begin{array}{l}640 \\
640 \\
784\end{array}$ & $\begin{array}{l}1024 \\
1024 \\
880\end{array}$ \\
\hline $\begin{array}{ll}\text { AS } & 609 \\
\text { AS } & 612 \\
\text { AS } & 613\end{array}$ & $\begin{array}{l}+-0 \bullet: 0-+ \\
+-0: 0:-+ \\
+0-0-0+0\end{array}$ & 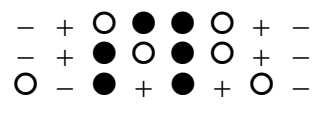 & $\begin{array}{l}16 \\
16 \\
16\end{array}$ & $\begin{array}{l}2432 \\
2432 \\
2432\end{array}$ & $\begin{array}{l}880 \\
1024 \\
1024\end{array}$ & $\begin{array}{l}784 \\
640 \\
640\end{array}$ \\
\hline $\begin{array}{ll}\text { AS } & 614 \\
\text { AS } & 617 \\
\text { AS } & 619\end{array}$ & $\begin{array}{l}+0-0-0+\bullet \\
+-000 \bullet-+ \\
+0-O-\bullet+\bullet\end{array}$ & 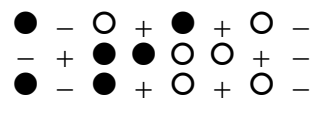 & $\begin{array}{l}16 \\
16 \\
16\end{array}$ & $\begin{array}{l}2432 \\
2432 \\
2432\end{array}$ & $\begin{array}{l}1168 \\
1216 \\
1504\end{array}$ & $\begin{array}{l}496 \\
448 \\
160\end{array}$ \\
\hline $\begin{array}{ll}\text { AS } & 628 \\
\text { AS } & 630 \\
\text { AS } & 632\end{array}$ & $\begin{array}{l}+-\bullet \bullet:-+O \\
+-\bullet: 00-+0 \\
+-O \bullet \bullet-+O\end{array}$ & 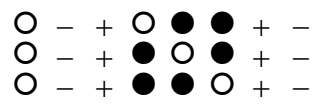 & $\begin{array}{l}16 \\
16 \\
16\end{array}$ & $\begin{array}{l}2576 \\
2576 \\
2576\end{array}$ & $\begin{array}{l}304 \\
496 \\
736\end{array}$ & $\begin{array}{l}1216 \\
1024 \\
784\end{array}$ \\
\hline $\begin{array}{ll}\text { AS } & 633 \\
\text { AS } & 635 \\
\text { AS } & 637\end{array}$ & $\begin{array}{l}+-0 \bigcirc \bigcirc-+\bullet \\
+-O \bigcirc \bigcirc-+\bullet \\
+-O \bigcirc \bullet-+\bullet\end{array}$ & 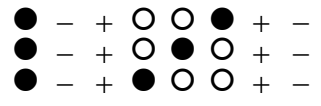 & $\begin{array}{l}16 \\
16 \\
16\end{array}$ & $\begin{array}{l}2576 \\
2576 \\
2576\end{array}$ & $\begin{array}{c}784 \\
1024 \\
1216\end{array}$ & $\begin{array}{l}736 \\
496 \\
304\end{array}$ \\
\hline
\end{tabular}

Continued

36

American Institute of Aeronautics and Astronautics 
Continued

\begin{tabular}{|c|c|c|c|c|c|c|c|}
\hline $\begin{array}{ll}\text { AS } & 648 \\
\text { AS } & 650 \\
\text { AS } & 651\end{array}$ & $\begin{array}{l}+0--0+0 \\
+8-0 \\
+0-0 \\
+0\end{array}$ & $\begin{array}{l}00-0++ \\
00-0++ \\
00-O++\end{array}$ & - & $\begin{array}{l}16 \\
16 \\
16\end{array}$ & $\begin{array}{l}2720 \\
2720 \\
2720\end{array}$ & $\begin{array}{c}64 \\
304 \\
352\end{array}$ & $\begin{array}{l}1312 \\
1072 \\
1024\end{array}$ \\
\hline $\begin{array}{ll}\text { AS } & 654 \\
\text { AS } & 655 \\
\text { AS } & 657\end{array}$ & $\begin{array}{l}+0--0+ \\
+0-0+9 \\
+0-0+9\end{array}$ & $\begin{array}{l}-0++ \\
0-0++ \\
-O++\end{array}$ & $\begin{array}{l}0- \\
0- \\
0-\end{array}$ & $\begin{array}{l}16 \\
16 \\
16\end{array}$ & $\begin{array}{l}2720 \\
2720 \\
2720\end{array}$ & $\begin{array}{l}1024 \\
1072 \\
1312\end{array}$ & $\begin{array}{c}352 \\
304 \\
64\end{array}$ \\
\hline $\begin{array}{ll}\text { AS } & 664 \\
\text { AS } & 666 \\
\text { AS } & 667\end{array}$ & $\begin{array}{l}+-00-+C \\
+-00-+8 \\
+-00-+C\end{array}$ & $\begin{array}{l}00-+0 \\
00-+00 \\
00-+00\end{array}$ & $\begin{array}{l}+ \\
+ \\
+\end{array}$ & $\begin{array}{l}16 \\
16 \\
16\end{array}$ & $\begin{array}{l}2816 \\
2816 \\
2816\end{array}$ & $\begin{array}{c}64 \\
496 \\
544\end{array}$ & $\begin{array}{l}1216 \\
784 \\
736\end{array}$ \\
\hline $\begin{array}{ll}\text { AS } & 670 \\
\text { AS } & 671 \\
\text { AS } & 673\end{array}$ & $\begin{array}{l}+-00-+ \\
+-00- \\
+-00-\end{array}$ & $\begin{array}{l}-+00 \\
-+00 \\
-+00\end{array}$ & $\begin{array}{l}+ \\
+ \\
+\end{array}$ & $\begin{array}{l}16 \\
16 \\
16\end{array}$ & $\begin{array}{l}2816 \\
2816 \\
2816\end{array}$ & $\begin{array}{c}736 \\
784 \\
1216\end{array}$ & $\begin{array}{c}544 \\
496 \\
64\end{array}$ \\
\hline $\begin{array}{l}\text { AS } 700 \\
\text { AS } 702 \\
\text { AS } 703\end{array}$ & $\begin{array}{l}+-0-+00 \\
+-O-+00 \\
+-O-+00\end{array}$ & 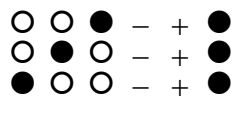 & $\begin{array}{l}+ \\
+ \\
+\end{array}$ & $\begin{array}{l}16 \\
16 \\
16\end{array}$ & $\begin{array}{l}3152 \\
3152 \\
3152\end{array}$ & $\begin{array}{c}64 \\
160 \\
208\end{array}$ & $\begin{array}{l}880 \\
784 \\
736\end{array}$ \\
\hline $\begin{array}{l}\text { AS } 706 \\
\text { AS } 707 \\
\text { AS } 709\end{array}$ & $\begin{array}{l}+-0-+0 \\
+-O-+0 \\
+-O-+0\end{array}$ & $\begin{array}{l}0-+0 \\
0-+0 \\
0-+0\end{array}$ & $\begin{array}{l}+ \\
+ \\
+ \\
+\end{array}$ & $\begin{array}{l}16 \\
16 \\
16\end{array}$ & $\begin{array}{l}3152 \\
3152 \\
3152\end{array}$ & $\begin{array}{l}736 \\
784 \\
880\end{array}$ & $\begin{array}{c}208 \\
160 \\
64\end{array}$ \\
\hline $\begin{array}{ll}\text { AS } & 736 \\
\text { AS } & 738 \\
\text { AS } & 739\end{array}$ & $\begin{array}{l}+--+9000 \\
+--+900 \\
+--+000\end{array}$ & $\begin{array}{l}000-+ \\
000-+ \\
000-+\end{array}$ & $\begin{array}{l}+ \\
+ \\
+ \\
+\end{array}$ & $\begin{array}{l}16 \\
16 \\
16\end{array}$ & $\begin{array}{l}3584 \\
3584 \\
3584\end{array}$ & $\begin{array}{c}64 \\
160 \\
208\end{array}$ & $\begin{array}{l}448 \\
352 \\
304\end{array}$ \\
\hline $\begin{array}{l}\text { AS } 742 \\
\text { AS } 743 \\
\text { AS } 745\end{array}$ & $\begin{array}{l}+--+00 \\
+--+00 \\
+--+00\end{array}$ & $\begin{array}{l}00-+ \\
00-+ \\
00-+\end{array}$ & $\begin{array}{l}+- \\
+- \\
+\end{array}$ & $\begin{array}{l}16 \\
16 \\
16\end{array}$ & $\begin{array}{l}3584 \\
3584 \\
3584\end{array}$ & $\begin{array}{l}304 \\
352 \\
448\end{array}$ & $\begin{array}{c}208 \\
160 \\
64\end{array}$ \\
\hline
\end{tabular}

(c)

\begin{tabular}{|c|c|c|c|c|c|c|}
\hline Ref. & & ence & $n$ & $\zeta_{ \pm}$ & $\zeta_{0}$ & $\zeta_{\bullet}$ \\
\hline $\begin{array}{ll}N N & 43 \\
N N & 44 \\
N N & 46\end{array}$ & $\begin{array}{l}+-0000-+ \\
+-0000-+ \\
+-0000-+\end{array}$ & $\begin{array}{l}0-0++8-0 \\
0-0++9-0 \\
0-0++0-0\end{array}$ & $\begin{array}{l}16 \\
16 \\
16\end{array}$ & $\begin{array}{l}2144 \\
2144 \\
2144\end{array}$ & $\begin{array}{l}1072 \\
1120 \\
1360\end{array}$ & $\begin{array}{l}880 \\
832 \\
592\end{array}$ \\
\hline $\begin{array}{ll}N N & 55 \\
N N & 56 \\
N N & 58\end{array}$ & $\begin{array}{l}+0-000+ \\
+0-000+ \\
+0-000+\end{array}$ & $\begin{array}{l}0+80--+0 \\
0+80-+0 \\
0+00--+0\end{array}$ & $\begin{array}{l}16 \\
16 \\
16\end{array}$ & $\begin{array}{l}2432 \\
2432 \\
2432\end{array}$ & $\begin{array}{c}928 \\
1216 \\
1408\end{array}$ & $\begin{array}{l}736 \\
448 \\
256\end{array}$ \\
\hline
\end{tabular}

(d)

\begin{tabular}{|c|c|c|c|c|c|c|}
\hline Ref. & & nce & $n$ & $\zeta_{ \pm}$ & $\zeta_{0}$ & $\zeta \bullet$ \\
\hline $\begin{array}{ll}S C & 1 \\
S C & 2\end{array}$ & $\begin{array}{l}+-0-0+0 \\
+-0-0+00\end{array}$ & $\begin{array}{l}00 \\
0 \\
0\end{array}$ & $\begin{array}{l}16 \\
16\end{array}$ & $\begin{array}{l}3008 \\
3008\end{array}$ & $\begin{array}{l}544 \\
544\end{array}$ & $\begin{array}{l}544 \\
544\end{array}$ \\
\hline
\end{tabular}

(e)

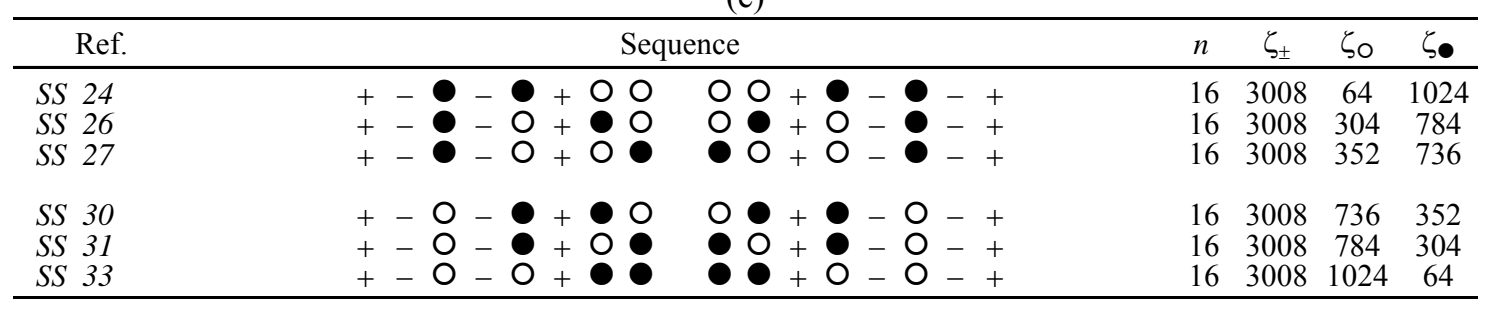


Table 9 - QHOLs with two ply angle orientations for 7 through 21 ply laminates corresponding to prefix designations: (a) AS for Anti-symmetric $(A)$ angle-plies and Symmetric $(S)$ cross-plies; (b) ${ }_{+} N S_{+}$for Non-symmetric $(N)$ angle-plies and Non-symmetric $(N)$ cross-plies; (c) ${ }_{+} N S_{-}$and; (d) SS for Symmetric $(S)$ angle-plies and Symmetric (S) cross-plies. For all sequences, $n_{ \pm}=n$ and $\zeta=n^{3}=\zeta_{ \pm}$.

(a)

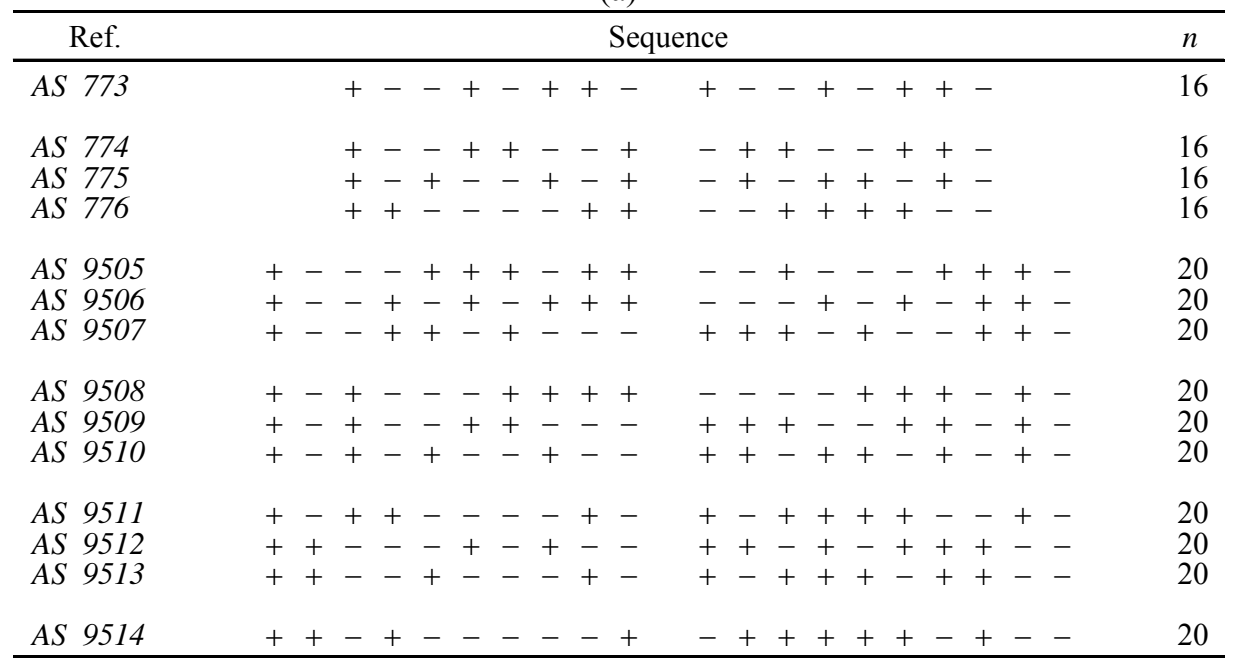

(b)

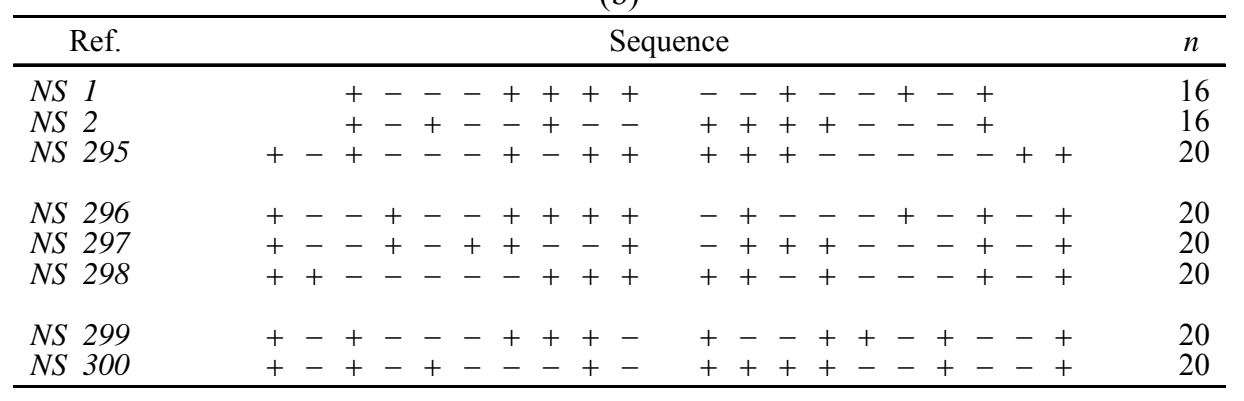

(c)

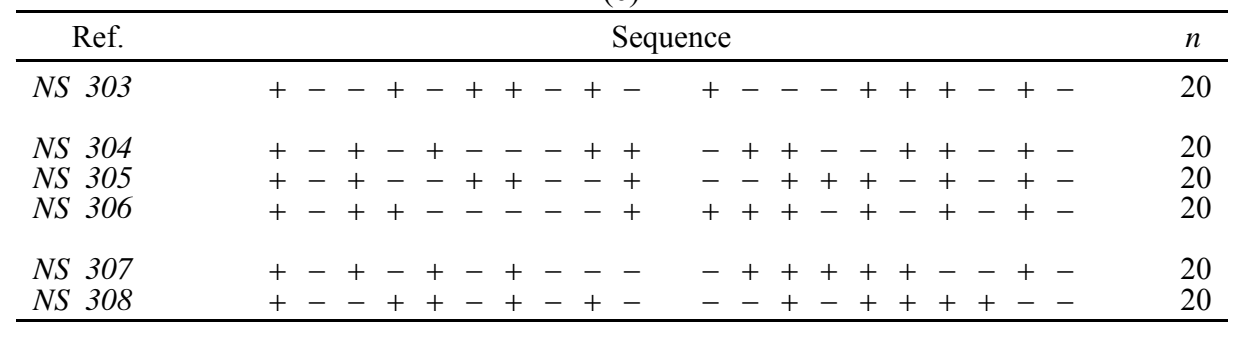

(d)

\begin{tabular}{|c|c|c|c|}
\hline Ref. & & & $n$ \\
\hline SS 53 & +--+-++- & -++-+--+ & 16 \\
\hline
\end{tabular}


Table 10 - QHOLs with three ply angle orientations for 7 through 21 ply laminates corresponding to prefix designations: (a) AS for Anti-symmetric (A) angle-plies and Symmetric $(S)$ cross-plies; (b) ${ }_{+} N S_{+}$for Non-symmetric $(N)$ angle-plies and Symmetric $(S)$ cross-plies; (b) ${ }_{+} N N_{+}$for Non-symmetric $(N)$ angle-plies and Non-symmetric $(N)$ cross-plies; (c) ${ }_{+} N N_{-}$and; (d) ${ }_{+} N N_{\circ}$. For all sequences, $n_{\bullet}=n-n_{ \pm}+n_{\circ}$ and $\zeta=n^{3}$.

(a)

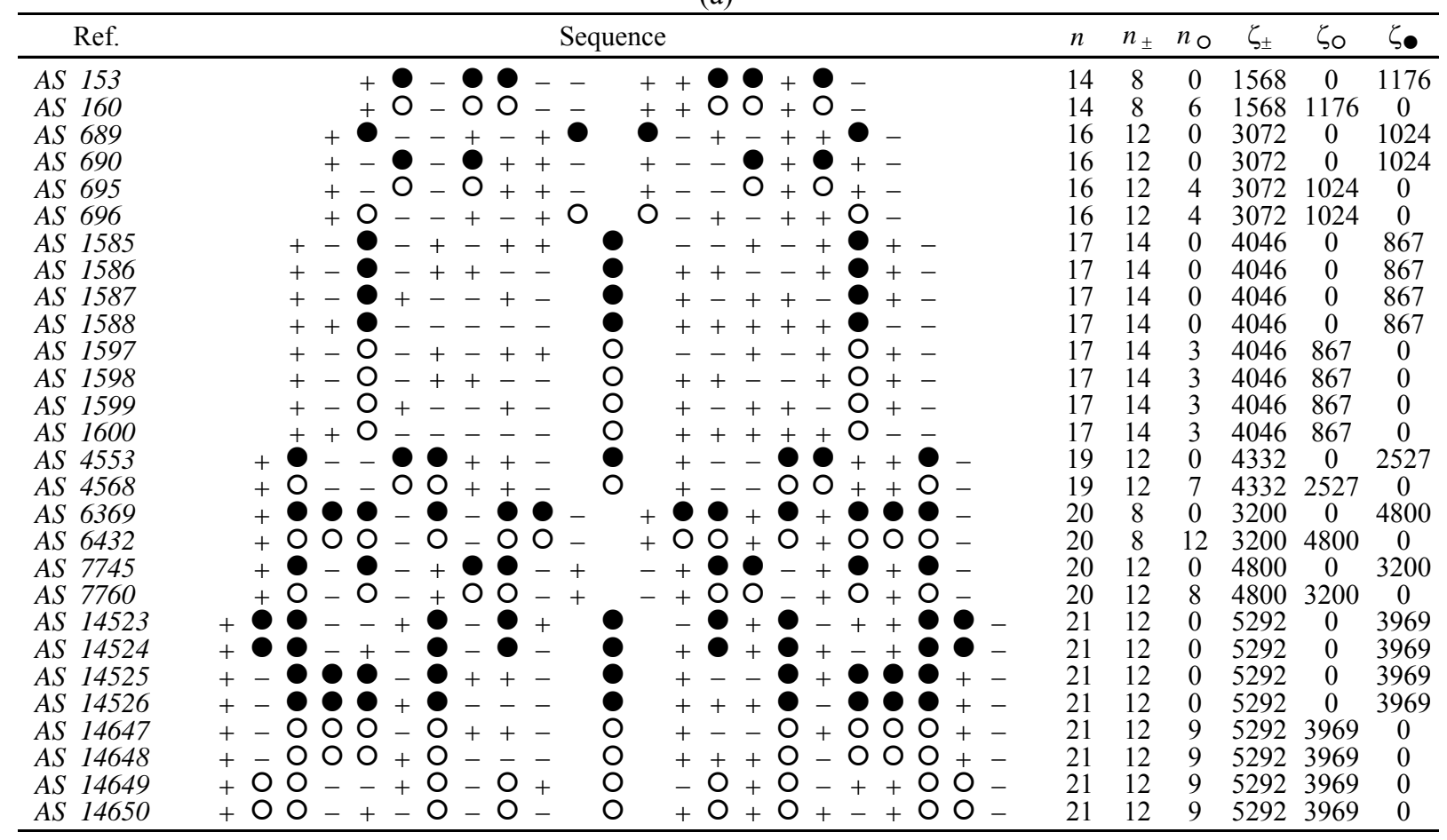

(b)

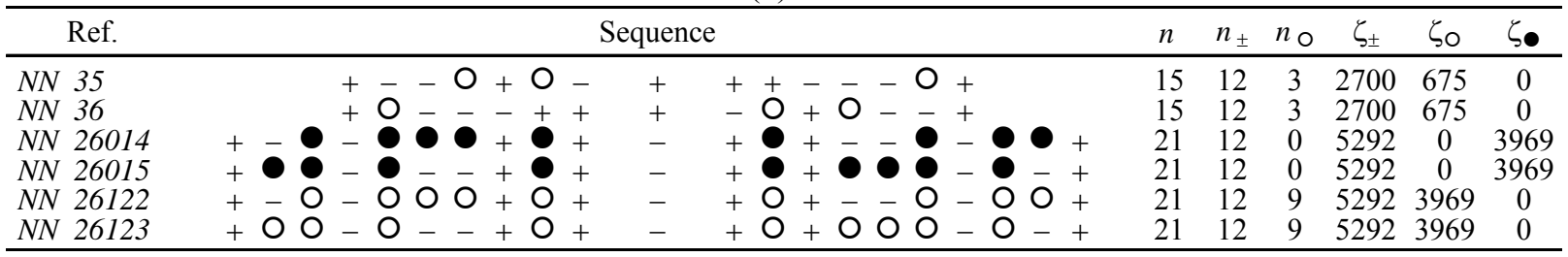

(c)

\begin{tabular}{|c|c|c|c|c|c|c|c|c|}
\hline Ref. & & & $n$ & $n_{ \pm}$ & $\overline{n_{0}}$ & $\overline{\zeta_{ \pm}}$ & $\zeta_{0}$ & $\zeta_{\bullet}$ \\
\hline $\begin{array}{l}N 6278 \\
N N 6279\end{array}$ & $\begin{array}{l}+00-0+-\overline{0}-\overline{0} \\
+-0\end{array}$ & 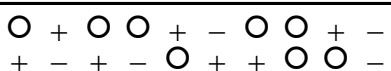 & $\begin{array}{l}20 \\
20\end{array}$ & $\begin{array}{l}12 \\
12\end{array}$ & $\begin{array}{l}8 \\
8\end{array}$ & $\begin{array}{l}4800 \\
4800\end{array}$ & $\begin{array}{l}3200 \\
3200\end{array}$ & $\begin{array}{l}0 \\
0\end{array}$ \\
\hline
\end{tabular}


(d)

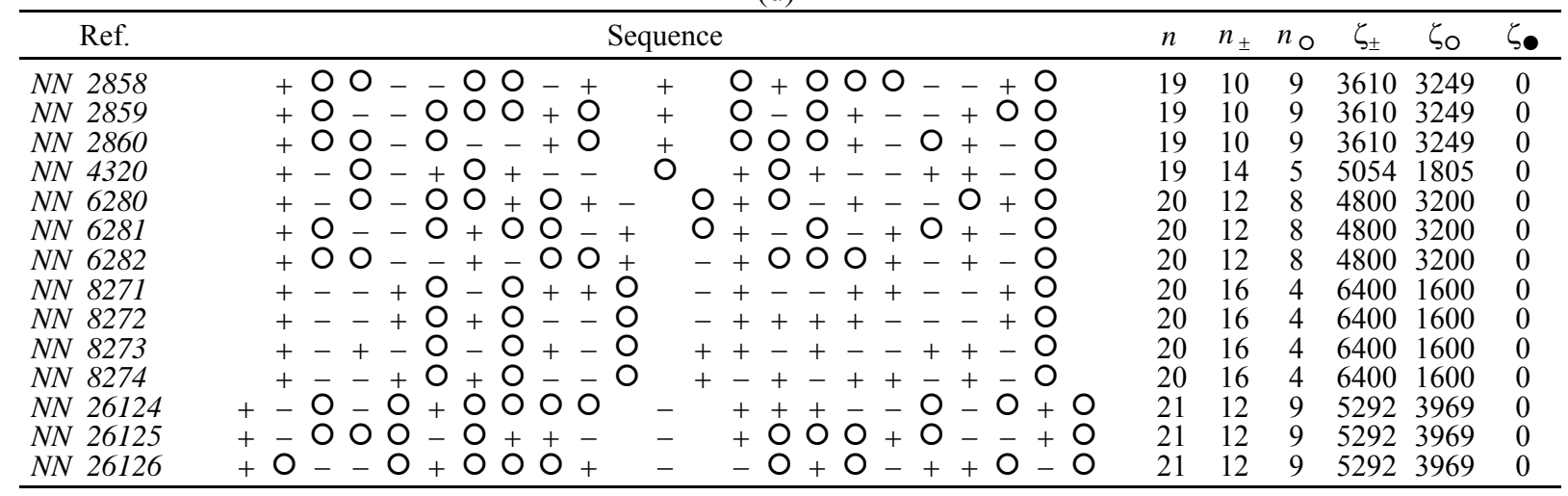

(e)

\begin{tabular}{llcccccccc}
\hline \multicolumn{1}{c}{ Ref. } & Sequence & $n$ & $n_{ \pm}$ & $n_{\circ}$ & $\zeta_{ \pm}$ & $\zeta_{\circ}$ & $\zeta_{\bullet}$ \\
\hline$N S 9$ & $+-O--+++$ & $O$ & $+--+O-+$ & 17 & 14 & 3 & 4046 & 867 & 0 \\
NS 10 & $+-O+---+$ & 0 & $+++--O-+$ & 17 & 14 & 3 & 4046 & 867 & 0 \\
\hline
\end{tabular}

(f)

\begin{tabular}{|c|c|c|c|c|c|c|c|c|c|}
\hline Ref. & & equer & & $n$ & $n_{ \pm}$ & $n_{\circ}$ & $\zeta_{ \pm}$ & $\zeta_{0}$ & $\zeta_{\bullet}$ \\
\hline $\begin{array}{l}\text { SS } 756 \\
\text { SS } 757\end{array}$ & $\begin{array}{l}+0 \mathrm{O}-\overline{0}-\mathrm{O}+\mathrm{O}+ \\
+-\mathrm{O} O \mathrm{O}-\mathrm{O}+-+\end{array}$ & $\begin{array}{l}0 \\
0\end{array}$ & $\begin{array}{l}+\mathrm{O}_{+}^{+} \mathrm{O}_{-}^{-}-\overline{\mathrm{O}} \mathrm{O}_{+}^{+} \\
+-+\mathrm{O}-\mathrm{O}\end{array}$ & $\begin{array}{l}21 \\
21\end{array}$ & $\begin{array}{l}12 \\
12\end{array}$ & $\begin{array}{l}9 \\
9\end{array}$ & $\begin{array}{l}5292 \\
5292\end{array}$ & $\begin{array}{l}3969 \\
3969\end{array}$ & $\begin{array}{l}0 \\
0\end{array}$ \\
\hline
\end{tabular}

